\title{
"Good Politicians": Experimental Evidence on Motivations for Political Candidacy and Government Performance*
}

\author{
Saad Gulzar ${ }^{\dagger}$ Muhammad Yasir Khan ${ }^{\ddagger}$
}

March 24, 2023

\begin{abstract}
How can we motivate good politicians - those that will carry out policy that is responsive to citizens' preferences - to enter politics? In a field experiment in Pakistan, we vary how political office is portrayed to ordinary citizens. We find that emphasizing prosocial motives for holding political office instead of personal returns - such as the ability to help others versus enhancing one's own respect and status - raises the likelihood that individuals run for office and that voters elect them. It also better aligns subsequent policies with citizens' preferences. We further find that social versus personal messaging only matters when randomly delivered in a public setting, suggesting that the extrinsic calculus is particularly important in candidacy decisions. Taken together, the results demonstrate that how politics is perceived in democracies shapes political entry as well as policy outcomes.
\end{abstract}

${ }^{*}$ We thank Graeme Blair, Robin Burgess, Leonardo Bursztyn, Michael Callen, Alex Coppock, Cesi Cruz, Ernesto Dal Bó, Livio Di Lonardo, Oeindrila Dube, James Fearon, Vicky Fouka, Guy Grossman, Miriam Golden, Michael Gilligan, Anna Grzymala-Busse, Rema Hanna, Maira Hayat, Saumitra Jha, Asim Khwaja, Horacio Larreguy, Sara Lowes, John Marshall, Sultan Mehmood, Umberto Mignozzetti, Laura Paler, Rohini Pande, Daniel Rubenson, Cyrus Samii, Raul Sanchez de la Sierra, Shanker Satyanath, Ken Scheve, Jacob Shapiro, Jeremy Springman, David Stasavage, Daniel Triesman, Pablo Querubin, Jeremy Weinstein, Lauren Young, Noam Yutchman, Austin Wright, and seminar participants at Berkeley, Brown, BREAD Stanford, Emory, Essex, ESOC, Georgetown, Harvard, Konstanz, LSE, MIT, MPSA, NEWEPS, NYU, Princeton, Stanford, UC Berkeley, UC Merced, UCLA, UCSD, UChicago Harris, Vanderbilt, World Bank, WESSI, and Yale for helpful comments and feedback. We also thank J-PAL Governance Initiative and the International Growth Center for research funding and support. Jawad Karim, Milad Khattak, and Mamoor Khan provided excellent research assistance. IRB approval was obtained at NYU and UC Berkeley.

${ }^{\dagger}$ Princeton University. Email: gulzar@princeton.edu

‡University of Pittsburgh. Email: yasir.khan@pitt.edu 


\section{Introduction}

While scholars have spent considerable effort in examining how democracies may be improved by tailoring the incentives of politicians who have already been elected, ${ }^{1}$ what is often missed, and no less important in improving democratic performance, is the supply of politicians. Who runs for political office affects policy, independent of, and prior to the rules under which politicians operate once elected.

Running for political office is typically associated with enhancing one's status and influence. In 2022, Gallup Pakistan conducted a nationally representative survey with 1,529 respondents. $81 \%$ of them agreed with the statement that "people enter politics to gain influence and status." ${ }^{2}$ Such perceptions can determine who self-selects into politics, perhaps leading to a preponderance of "bad" politicians across democracies. ${ }^{3}$

This paper asks if portraying political office as enabling prosocial behavior can, instead, encourage "good" politicians - those that will carry out policy that is responsive to citizens' preferences (Lipset 1959; Dahl 1973; Besley and Coate 1997; Caselli and Morelli 2004) - to emerge. What motivations might enable entry of such good politicians is a key puzzle in the literature (Dal Bó and Finan 2018; Bandiera et al. 2019). The answer to this question is theoretically unclear. While, highlighting prosocial motivations can encourage more prosocial people to seek office (Deci 1972; Besley and Ghatak 2005), they may also give public cover to selfish people to become politicians or crowd-out personally driven, but perhaps, more competent individuals from seeking office (Schlesinger 1966; Ferraz and Finan 2011b; Gagliarducci and Nannicini 2013).

We provide new evidence on these puzzles through a field experiment in Pakistan. We randomly sample 9,310 citizens across 192 villages and encourage them to consider running for new village councils in private meetings, in public village meetings, or in both. Encouragements vary across villages in how political office is portrayed to prospective candidates: in some villages status-quo motivations of personal returns from political office, such as en-

\footnotetext{
${ }^{1}$ See, for example, Ferraz and Finan (2011a); Pande (2011); Humphreys and Weinstein (2012); Gagliarducci and Nannicini (2013); Martinez-Bravo et al. (2017); Grossman and Michelitch (2018); Dunning et al. (2019); Arias et al. (2019).

${ }^{2}$ Gallup Pakistan provided us access to anonymized raw data for this analysis. In the data, only $28 \%$ of people agreed with the statement "people enter politics to serve their community." Besides Gallup, Pew Research Center (2020) finds that $64 \%$ of respondents across 34 countries do no believe that elected officials care about ordinary citizens.

${ }^{3}$ Scholars have shown that how people perceive occupations matters for who self-selects into a profession and how that profession is run (Ashraf et al. 2020; Linos 2017; Handy and Katz 1998). In the case of politics, previous work has shown, for example, that politicians are not representative (Cruz et al. 2017; Chattopadhyay and Duflo 2004; Querubin et al. 2016); are motivated by private rents (Fisman et al. 2014; Ferraz and Finan 2011b; Reinikka and Svensson 2004; Prakash et al. 2019; Eggers and Hainmueller 2009; Folke et al. 2017); and have criminal backgrounds (Vaishnav 2017; Blaydes 2010).
} 
hancing one's respect and status, are made salient (called personal villages, $\mathrm{n}=72$ ). In other villages, the ability to help the community through elected office is emphasized (called social villages, $\mathrm{n}=72) .{ }^{4}$ In addition to personal and social encouragements, in both arms citizens also receive basic information about contesting elections. A third arm of the experiment (called neutral villages, $\mathrm{n}=48$ ) carries out identical meetings that includes this basic information but does not include encouragements to run for office for social or personal gain. We study the impacts of social versus personal encouragements on who decides to run for office, who is voted into office, and, perhaps most importantly, whether policy outcomes align or diverge from the preferences of the electorate as a result. We also compare social and personal encouragements against the neutral condition to characterize the direction of effects.

The 2015 local government reform in Pakistan - the fifth most populous country - provides a good testing ground for this research. As opposed to state or national levels where other factors like parties and donors are perhaps more important, political entry decisions at the local level provide evidence on how one might broaden the composition and performance of the political class (Martinez-Bravo 2014; Martinez-Bravo et al. 2017), potentially nurturing leaders for higher level politics at the very first step of the political career ladder. ${ }^{5}$ Building a base of evidence on political entry at the local level is therefore an important precursor to understanding the political pipeline. ${ }^{6}$ In addition, local governments are also an important site of study because they are responsible for the implementation of government programs and the provision of public goods. ${ }^{7}$

We begin by analyzing the political entry decisions of citizens. We find that in villages where politics is portrayed as enabling community-minded policy, relative to villages where it is portrayed as yielding personal benefits, people in our experimental sample are 1.8 percentage points more likely to run for office (exact-p=0.007). Given that candidacy occurs

\footnotetext{
${ }^{4}$ Our formulation of treatments in the political sphere are inspired by Ashraf et al. (2020) who examine bureaucratic recruitment and demonstrate that career benefits versus status-quo prosocial recruitment attracts talented individuals to apply for a new health care position in Zambia.

${ }^{5}$ For instance, $22 \%$ of politicians elected in 2018 to the legislative assembly of the Punjab province had served previously in local governments.

${ }^{6}$ Indeed, Roger Myerson (2009), writing specifically about Pakistan, notes: "just as economic competition should motivate suppliers to offer better values in the market, so democratic competition in the political arena should motivate political leaders to promise better public services and more efficient government."

${ }^{7}$ Similar considerations are at play in many countries that have recently undertaken reforms to bring elected government closer to citizens, with the hopes that local policy can be made more responsive to citizen preferences. A recent example of this is the case of Nepal that, following a large civil war, established a republic and elected local governments across the country in 2017. Another example is Kenya which also passed a recent local government reform. In addition, the institutional details of the reform in Pakistan are similar to many other systems, including Gram Panchayats in India as well as non-party elections of school boards in the United States.
} 
with low frequency, this effect is about a 86 percent increase relative to the personal condition mean. Though we have limited statistical power, we also see that social and personal treatments move candidacy in opposite directions relative to the neutral condition: social treatment increases candidacy by 1 percentage points (exact-p $=0.07$ ) while personal treatment reduces candidacy by 0.9 percentage points (exact-p=0.107). Taken together, this first result shows that how politics is portrayed to ordinary citizens can be an important determinant of who becomes a political candidate.

Next, we ask if voters care to elect these new politicians to office? Improving policymaking requires both that the supply of politicians improve, but also that voters demand these politicians by voting them into office. It could be the case that deviations from status-quo candidacy do not matter as new politicians never stand a chance of getting elected by voters. To the contrary, we find that social versus personal treatments increase the probability that people from our experimental sample get elected by 1.2 percentage points higher (exact-p $=0.006)$, an effect of about 120 percent against the personal mean. As before, against the neutral condition, the probability of election increases with the social treatment (effect of 0.5 percentage point, exact-p $=0.113$ ), and decreases with the personal treatment (effect of 0.7 percentage point, exact-p $=0.057)$. This second set of results suggest that while the people mobilized into running for office by prosocial encouragements are electable, we may not be seeing them in office in the status quo because they do not put themselves forward as candidates.

Finally, while demonstrating the effectiveness of social versus personal encouragement in encouraging individuals to run and win office may be important, it alone is not sufficient to ensure good governance. We go a step further by examining if treatments improve the alignment of policy outcomes with citizens' preferences. To do so, we first measure citizen preferences for budgetary spending one year after their election through a survey. Preparing development budgets is the key decision made by these local politicians. We establish that there is considerable discrepancy in the decisions of the elected politicians and the preferences of the electorate in neutral villages. By benchmarking real policy decisions made by elected politicians against these preferences of the electorate, we ask if social versus personal messaging aligns or widens the gap between what policy is adopted and what citizens want? ${ }^{8}$

We find that in villages where people are encouraged to run to help their community instead of helping themselves, official budgetary spending is significantly more aligned with citizen preferences: the Euclidean distance between policy and citizen preferences decreases by 9.4 points (exact-p $=0.04$ ). This is a 13.4 percent decrease relative to the personal

\footnotetext{
${ }^{8}$ In this sense, our approach to studying policy outcomes is consistent with political agency models like Besley (2006).
} 
condition policy gap. In monetary terms, the gap closes by Rs. 380,415 or about USD 3,800 on average. As before, the social treatment reduces the policy gap by 7.039 points (exact-p $=0.08$ ) while personal treatment increases the gap by 2.361 points (exact-p $=0.322$ ) against the neutral condition. Together, these results on policy alignment provide direct evidence that social versus personal encouragements are yielding 'good' politicians to office. Indeed, citizens in these villages are more satisfied with politicians' policy choices and exhibit more positive affect towards politics and the state.

The paper proceeds to evaluate mechanisms on candidacy decisions and policy outcomes. We develop a stylized framework that examines intrinsic and extrinsic motivations (Bénabou and Tirole 2011) to run and their impact on policy in comparison to status-quo motivations: running for personal gain. The decision to enter politics involves a private intrinsic calculus, where prospective candidates evaluate returns from running. However, unlike other political actions, such as donating to campaigns that may primarily be informed by an intrinsic calculus, the candidacy decision is also likely shaped by an extrinsic calculus through at least two channels: it could be the case that community members encourage a person to run for office if they are seen as prosocial (Bursztyn and Jensen 2017) or if they can commit to doing good policy when elected (Fujiwara and Wantchekon 2013); and/or it may be the case that a person might run even absent encouragement by others because they derive utility from being seen as running for prosocial reasons (DellaVigna et al. 2016).

We examine how these motivations shape candidacy and policy outcomes by linking directly with the design of our experiment where each of the 72 social and 72 personal villages are randomized into three sub-treatments (see Figure 5 for details): (i) social or personal encouragement is delivered only in private one-on-one meetings to people in our experimental sample, (ii) only in public meetings in the village, (iii) or in both private and public meetings. As each of these comparisons comprise 48 villages, we interpret them as suggestive.

Our analysis shows that the extrinsic calculus is particularly important in driving the candidacy decision and that intrinsic motivations might play a role only when coupled with changes in the extrinsic calculus. Examining the first scenario of the framework, where social encouragements in private meetings can trigger intrinsic prosocial motivations for candidacy, the comparison of social versus personal messages when delivered only in private show that candidacy or election probabilities do not increase and policy outcomes do not improve. In the second scenario, social versus personal encouragements in public can encourage the prosocial people to run, but may also create space for non-prosocial people to enter as others in the community are more likely to ascribe prosocial motivations to their candidacy decision. Policy effects in the presence of public prosocial encouragements are therefore likely to 
be ambiguous. We observe increases in candidacy (effect of 2.2 percentage points, exact-p $=0.043$ ) and election (effect of 1.1 percentage points, exact-p $=0.096$ ) probabilities, and improvements in policy alignment (effect of -18.219 points, exact-p $=0.027$ ) when social versus personal treatments are delivered in public meetings alone. The final scenario combines the private and public calculi such that total effects on candidacy are likely larger as both the intrinsic and extrinsic motivations are triggered. However, as before, the effect on policy likely remain ambiguous. We find that effects on candidacy (effect of 3.8 percentage points, exact-p $=0.002$ ), election (effect of 2.3 percentage points, exact-p $=0.002$ ), and policy (effect of -18.763 points, exact-p $=0.024$ ) are largest when social versus personal encouragements are delivered in both private and public.

We further conduct exploratory analyses to unpack intrinsic and extrinsic motivations of candidacy. We show that social versus personal messaging increase the likelihood that prosocial people run for office, indicating that the extrinsic environment may shape which types of people decide to enter the race. Additionally, we find that candidates are more likely to report encouragements by others as a reason for their candidacy in social versus personal villages, suggesting that community coordination may also be at play in shaping entry.

We also study channels through which policy effects materialized. We explore if treatments improved the likelihood that a person from our experimental sample possessed the means to affect the policy making process. We find that social versus personal treatments increased the probability that someone from the experimental sample was elected as a leader of the village council by 0.7 percentage points (exact-p $=0.014$ ) or proposed a policy that was adopted by the council by 1.2 percentage points (exact-p=0.003). These results show that how political office is portrayed affects not just candidacy decisions but also who comprises positions of leadership and influence in the political class. Examining alternative explanations, we show that changes in citizen's preferences or behavior are less likely to explain the policy alignment results.

This paper makes several contributions. Social scientists have spent considerable energy to build a body of knowledge on how to move democracies to be more responsive to citizens. $^{9}$ While, prior work on aligning citizen preferences with policy tends to focus on the performance of politicians already in office, to our knowledge we report results from the first field experiment that mobilizes politicians and examines subsequent policy responsive-

\footnotetext{
${ }^{9}$ Both Dahl and Lipset famously recognized that an important element of a good democracy is the government's ability and willingness to carry out policies that are aligned with constituent preferences. Dahl (1973) described a democracy as a government that "continue[s] over a period of time to be responsive to the preferences of its citizens" (p. 2). Lipset (1959) wrote that "Democracy...[is] a political system which supplies regular constitutional opportunities for changing the governing officials, and a social mechanism which permits the largest possible part of the population to influence major decisions by choosing among contenders for political office" (p. 45).
} 
ness. In doing so our work compliments recent studies that examine the link between policy outcomes and the selection of government personnel, such as, judges (Mehmood 2022; Lim 2013), bureaucrats (Ashraf et al. 2020; Dal Bó et al. 2013; Colonnelli et al. 2020; Xu 2018), and politicians (Cirone et al. 2021; Casey et al. 2021; Karpowitz et al. 2017; Fujiwara 2015; Grossman 2014; Beath et al. 2016; Chattopadhyay and Duflo 2004).

The political economy literature has long examined which incentives are likely to yield politicians that are better at aligning policy with citizen preferences (Caselli and Morelli 2004; Besley 2005; Besley and Ghatak 2005). While previous work focuses on pecuniary and career incentives (Gagliarducci and Nannicini 2013; Fisman et al. 2015; Ferraz and Finan 2011b), our examination of prosocial motivation remains understudied. ${ }^{10}$ This is identified as an open question in a recent review of the political selection literature that says "while we have made progress in documenting some of the financial rewards of political office and how they affect political selection, we are still missing evidence on non-financial returns. Motives such as prestige or the desire to perform one's civic duty could play even larger roles in determining selection patterns" (Dal Bó and Finan 2018:p 566). As Bandiera et al. (2019) note, "finding (such) ways to leverage non-pecuniary incentives for politicians may be particularly important in poor countries," (p. 8) where budget constraints inhibit compensation as a primary recruitment strategy.

We also contribute to a field experimental literature on recruiting agents to public service jobs. Studies in this literature primarily examine recruitment to the bureaucracy. For instance, Dal Bó et al. (2013) randomize salary levels in Brazil and find that higher salaries recruit more competent bureaucrats. Ashraf et al. (2020) show that emphasizing career incentives without changing salary for public health jobs in Zambia similarly recruits agents who perform better at their job. While examining recruitment into a bureaucratic jobs is important because they implement policy, our contribution to this literature is to study recruitment into a political job which instead entails the formulation of policy. ${ }^{11}$ Improvements in policies in the political arena requires that they be benchmarked against citizen preferences (Dahl 1973). Our results suggest that recruitment for political job works in different ways than bureaucratic jobs: prosocial motivations and public signaling can play an important role in deciding who enters politics.

More broadly, contrary to the folk theory that people are primarily selfish, this paper also relates to a large body of literature spanning several disciplines that argues that intrinsic motivations such as prosociality and warm glow can shape civic and cooperative behavior

\footnotetext{
${ }^{10}$ An exception is Barfort et al. (2019) who carry out a survey experiment in Denmark to show that prosocial instead of pecuniary returns are more likely to motivate honest individuals to enter public service.

${ }^{11}$ Previous field experiments on politicians have focused on electoral rules (Beath et al. 2016) and organizations (Casey et al. 2021).
} 
(Andreoni 1990; Frey 1997; Andreoni 1995a; Broockman 2013; Bénabou and Tirole 2006). In this spirit, our research first extends prior work on how prosocial motivations can be mobilized (Blair et al. 2019) by extending analysis to the political class (Ravanilla 2016; Landmann and Vollan 2020), perhaps one of the most important agents of policy change. Second, our study brings field experimental evidence to demonstrate how messaging on prosocial features of political office can enhance coordination among voters around prosocial candidates, a question previously explored extensively in public goods games in lab studies (Andreoni 1995b; Ostrom 2000).

The rest of the paper proceeds as follows: Section 2 describes the context of the study; Section 3 provides details of the experiment; Section 4 presents the results; Section 5 discusses mechanisms; and Section 6 concludes the paper.

\section{Context}

This section briefly reviews the history of devolution in Pakistan to help place the new reform in context. Next, it provides specifics of how village councils are formed, as well as information on the candidacy process. Finally, it provides some information on the area where we conduct the experiment, and provides a brief description of status-quo politics.

\subsection{The Local Government Reform of 2015}

Local government reforms in Pakistan have been carried out by military regimes starting with dictator General Ayub Khan in 1962, usually with the aim of weakening the role of political parties over local politics. Consequently, existing party systems in Pakistan have become increasingly centralized, with the party leadership exercising strict control over party cadres (Cheema et al. 2010). While political parties do proclaim the principles of democracy within their parties, they seldom hold intra-party elections, preferring to assign party offices to loyalists as rewards (Salim 2005). Unsurprisingly, basic village and neighborhood levels are marked by the relative absence of formal party workers who can be called upon to run for offices of local government.

This paper focuses on Khyber Pakhtunkhwa, a province of thirty million people in Pakistan's northwest. Under the direction of the Supreme Court of Pakistan, the KP government promulgated "the Local Government Act (LGA) of 2013" under which Village Council elections were held on May 30th, 2015. These elections were held on non-party basis, that is, candidates could not use party symbols and affiliations. The absence of deep political networks in villages meant that parties did not play a very organized role in political selection 
or campaigns.

As shown in Figure 1, Village Councils (together with Neighborhood Councils for urban areas), constitute the lowest tier of local government. We conduct our experiment in Haripur and Abbottabad districts as shown in Figure 2. These districts have slightly better health, education, and public service outcomes compared to the provincial averages (MICS 2008). As we describe below, these districts were chosen once we identified a local partner.

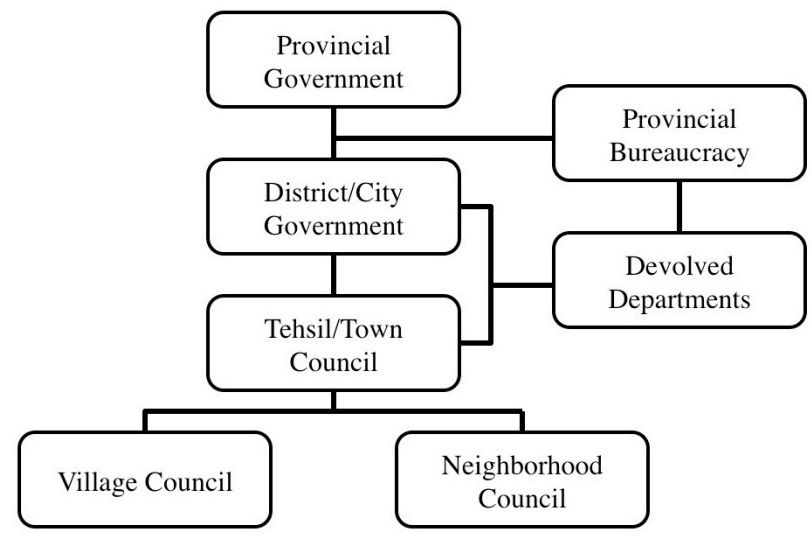

Figure 1: Village Councils in Political Hierarchy

\subsection{Village Councils}

The village councils established under the 2015 reform represent about 6,500 voters (see Table A2 for descriptives). Before this, the lowest tier of elections were at the union council level with latest elections at that level in 2007.

Responsibilities Much like the rest of the developing world, these local village governments in KP have two major sets of responsibilities. The first, more substantial, responsibility relates to the council's annual budget. Each year village councils are allocated money by the province, based on a formula codified in law. The median budget allocation per Village council in our sample is approximately $\$ 20,000$. The council has to decide how and where to spend the money. Each council draws up an annual budget, deciding which projects to undertake. Council members also oversee the implementation of these projects. Second, more informally, council members can also take up any issues that are of concern to their constituents. Related to this, council members look after the provision of public services in the village provided by the provincial government departments, such as health and educa- 

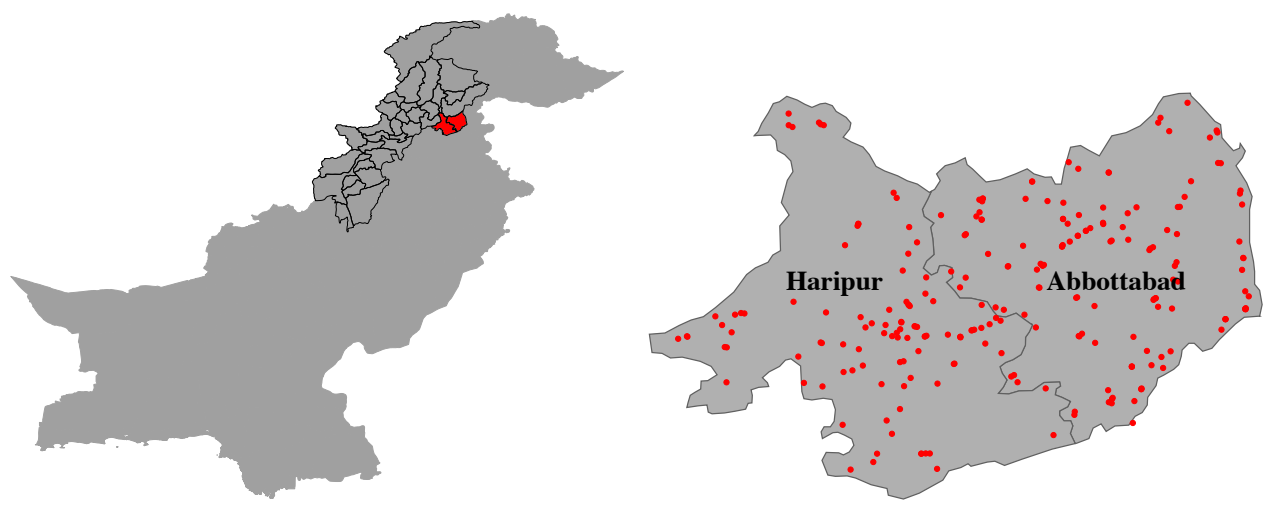

Figure 2: Villages in Haripur and Abbottabad Districts (right) in Khyber Pakhtunkwa Province (districts outlined in left panel)

tion. This role is limited as the law only empowers the council to informally report on the performance of service providers without giving them any sanctioning authority.

Composition The law follows the principle of equal representation, which translates into council sizes equal in proportion to the size of the villages. Each council has general (open) and reserved seats that are elected through a direct ballot for an at-large constituency comprising the village. Any eligible person can run for the election on a general seat, while the reserved seats require the candidate to meet specific criteria. The number of open seats varies between five and ten, depending on the population of the village. Each village also has two women, one youth (less than 30 years of age), one farmer/worker, and one minority seat that is reserved.

In line with the types of open and reserved seats in the village, voters cast five ballots: one for a general/open seat candidate, one for peasant/worker, one for youth, and two for women seats. The number of general/open seats in the village council are determined by how large the village is terms of population. If, for example, there are six open seats then the top six candidates that receive the most votes are elected to the open seats. The person receiving the highest number of votes on a general seat is elected as the Nazim (chairperson) of the village council, and the candidate securing the second highest number of votes is appointed as their deputy.

Candidacy All adults over the age of 21 that are eligible to vote can contest village elections. While there are no explicit restrictions, other than no criminal record and a clean financial history, the process of declaring candidacy requires an ability to navigate the bureaucratic apparatus. As described in detail in the Appendix A, citizens have to collect 
candidacy papers, prepare legal declarations, and deposit approximately USD 10 through bank draft to have their candidacy accepted. In this sense, candidacy outcomes are costly actions that citizens take after careful deliberation.

Role of Parties Elections for Village Councils were conducted on a non-party basis. This barred political party workers from using the party name and platform in campaigns. As discussed earlier, however, all political parties lack representation at the village level given the historical milieu in which they have developed. Thus, while unofficially, some candidates invoked party platforms, there was limited systematic involvement of political parties in village elections.

Overall, studying village council elections is important for at least two reasons. First, local elections introduce principles of democratic representation at the most local level, brining elected government closer to citizens. Previous work shows that this carries important consequences for what democracy delivers to citizens, particularly in South Asia (Chattopadhyay and Duflo 2004; Gulzar et al. 2020). Second, local elections provide opportunities for local prospective politicians to get hands-on training in politics, and to appear on party platforms for subsequent elections. In fact, during fieldwork party leaders stated that village elections enabled them to identify viable and high performing candidates for party nominations in subsequent elections. Thus, studying candidacy at the local level is the first step in understanding the broader pipeline of political candidates.

\section{Experiment}

We design an experiment in 192 randomly sampled villages of Haripur and Abbottabad districts. There are two key variations in the experiment: how political office is portrayed through whether invitations emphasize social or personal benefits or a neutral message, and whether the portrayal is varied in private or public. In this section we i) explain how field activities unfolded ii) describe the treatments, and iii) present details of the randomization. Appendix Section D presents a timeline of the project. Finally, in Appendix Section E, we discuss ethical considerations with respect to the experiment.

For the experiment we partnered with a local NGO headquartered in the city of Haripur called Sangum Development Organization. Sangum was chosen with the help of a network of community organizations who identified it as an able local NGO with a history of implementing community-level programs on the rule of law, access to justice, and community mobilization for village development. Working with a local community organization like Sangum is important because they have invested in trust-based relationships with commu- 
nities they serve. These relations are established because all personnel in the organization belong to local communities and have been working in these areas for a long period of time.

\subsection{Selection of the sample}

A pair of enumerators from our partner NGO Sangum canvass on average 48 households selected via random walk in every village for a total of 9,310 people across 192 villages in the experimental sample. In Appendix B, we provide further details regarding sampling, the challenges around working at the household level, and effectively yielding a male sample. Further, Section G shows that the sample is balanced across treatment arms on observable characteristics both at the individual and the village level.

\subsection{Public and Private Meetings}
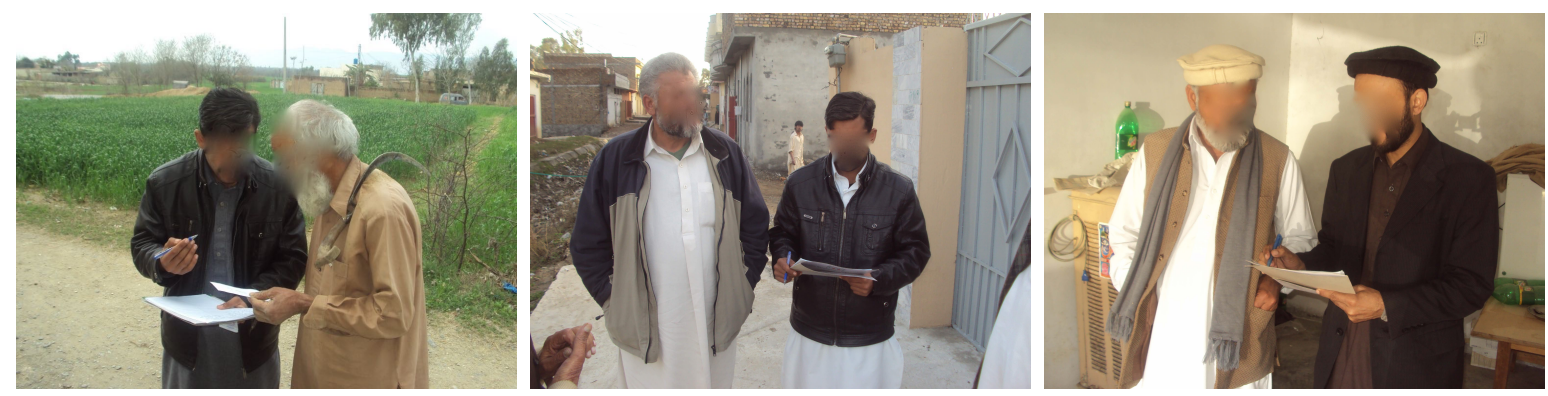

Figure 3: Private One-on-One Meetings

Next we describe meetings with the 9,310 selected individuals who comprise the experimental sample. First, enumerators have a private meeting with subjects. Once a household is approached, enumerators conduct a short survey with a male respondent. A detailed baseline survey was not possible because of the short election timeline. After the survey, enumerators deliver a social or personal encouragement, or a neutral message in this private one-on-one meeting with the subject (see Section 3.3 for details). Finally, subjects are invited to a public meeting in the village, and the time and location details for this meeting are shared. ${ }^{12}$ The private meetings are usually held at the respondent's dwelling and last

\footnotetext{
${ }^{12} \mathrm{It}$ is made clear that the public meeting is open to others who may be interested in finding out more about the upcoming elections. We decided to not make public meetings exclusive to those we invited for two reasons. First, since the treatments involve encouraging people to run for office, we wanted to ensure that at the village level, people had the opportunity to receive information on how to contest if they were interested. Second, logistically, it is difficult and unpleasant to deny permission to people who are interested in finding out more about the elections. Table A33 shows that there is no evidence for differential selection into the public meeting by social versus personal treatments.
} 
between 10-15 minutes. Figure 3 shows examples of these interactions between enumerators and citizens.
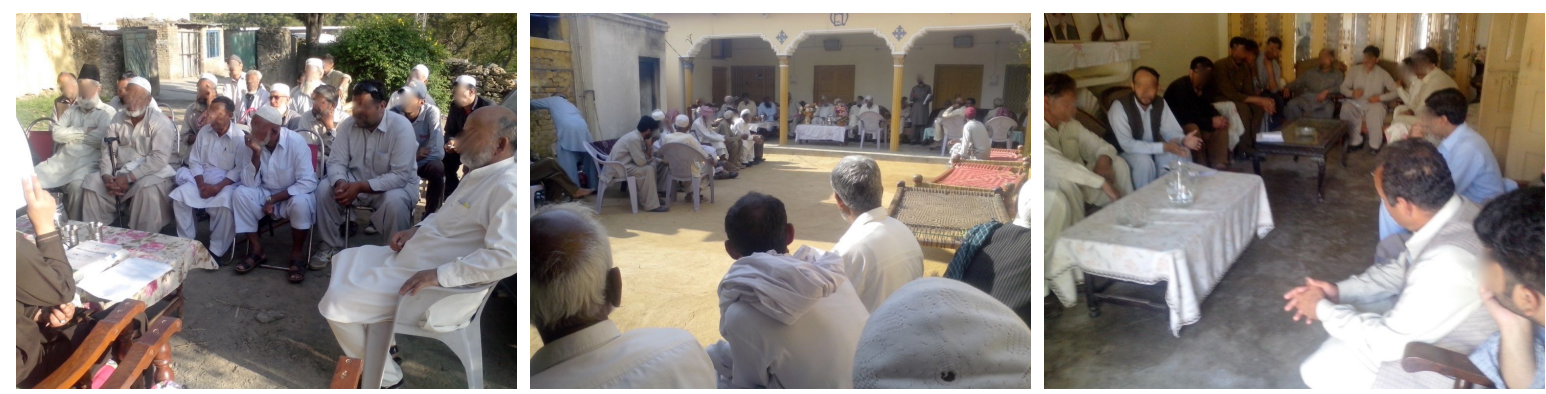

Figure 4: Public Meetings in Villages

Enumerators then proceed to prepare for the public meeting. All the public sessions are organized within the same village to make them accessible for citizens. As participants arrive, enumerators note their attendance. Then the public meetings begins and a social, personal, or neutral encouragement is offered to participants to run for office (more details in Section 3.3). Figure 4 shows examples of these sessions in three villages. On average, a public session lasts $30-40$ minutes in the village.

\subsection{Treatments on how Political Office is Portrayed}

During the private and public meetings we vary experimentally how political office is portrayed in conversation with citizens. These treatments were developed after detailed piloting with focus groups before fieldwork commenced. There are three types of conversations: neutral, social, and personal encouragement.

The encouragements carry language that comes from, and is directly relevant to, the population where we conduct the experiment. The treatments were delivered in a conversational manner by the enumerators to make the exercise natural - encouraging people to run for office while reading from a piece of paper is unlikely to work or be received well. Below we provide the scripts that were used to train the enumerators on the key talking points for each treatment. The enumerators had a copy of the training scripts in the field to refresh the key points they had to make in conversation with people.

Now, we describe the three ways in which encouragements to run for office were delivered. The first condition which we label neutral message, provides basic information about when elections are going to be held as well as the eligibility criteria for candidacy. The enumerators use the following script as a guide to deliver this treatment in private and public meetings. 
Neutral Script: "You may be aware that for the first time elections on May 30th will elect a 10-15 member council at the village level. People above the age of 21 can contest these elections. There isn't even an education requirement to contest. All you have to do is collect papers from the district office of the Election Commission, and submit them along with two references."

Importantly, all meetings across the 192 villages in our sample include this neutral message as a baseline from which further encouragements may be provided. In this sense, the neutral condition can be thought of as a premise for having a conversation with people.

On top of a neutral message, some conversations, labeled social messages, portray political office as a vehicle for improving the quality of government services in the village, as well as working for the welfare of the community more broadly. This is reflected in the following script.

Social Benefits Script: Neutral Script and "People who are elected to the village election will be given a excellent opportunity to do their part for the development of their area. Members of the village council will play an important role in improving the quality of government services in the village. They will work towards securing the welfare and rights of the poor. Working together with the district governments, they will improve village school and health facilities. An elected councillor will have a unique opportunity to address the problems of his neighborhood, and this will make him the standard-bearer of social development for the village."

Similarly, building on the neutral message, some conversations that we label personal messages highlight how political office can boost one's respect, status and influence.

Personal Benefits Script: Neutral Script and "People who are elected to the village election will be given a excellent opportunity to move forward in politics, and gain respect and influence in the area. Members of the village council will be able to build connections with tehsil and district level politicians, which will open avenues for advancing in politics. Besides this, council members will also be able to enhance their influence in the village. They will be known as leaders in their neighborhoods, and this get them more recognition. Their children will be able to build a network in the area, which will make their entry into politics easier."

\subsection{Randomization}

Figure 5 presents the overall design of the experiment across 192 villages. Villages are placed into 12 blocks by our field partner based on geographic proximity of and access constraints to villages. These blocks serve as randomization strata. All treatments are randomized at the 


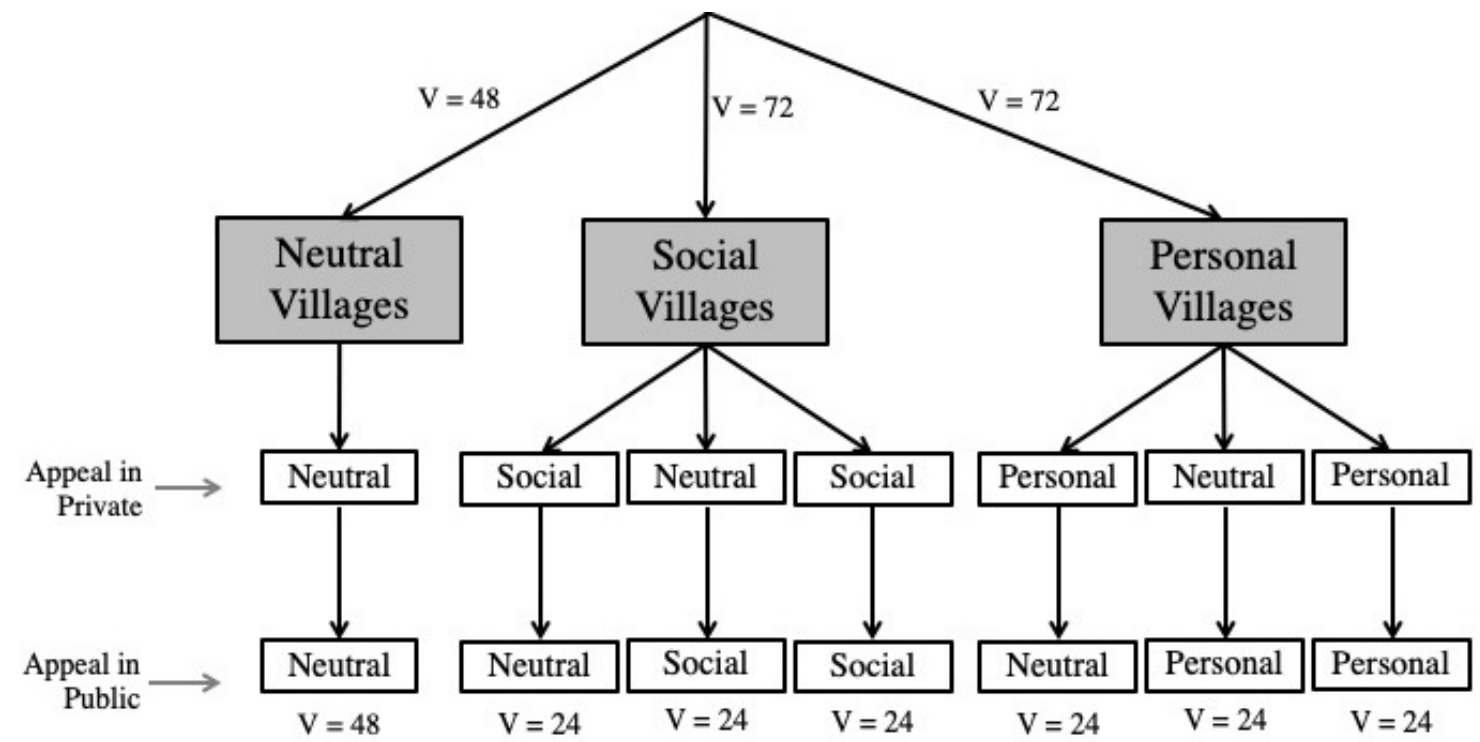

Figure 5: Design of Field Experiment

Notes: This figure shows the randomization scheme. All treatment randomizations are at the village level. $V$ refers to the number of villages in a treatment category. The bottom two layers of the figure show the type of appeal made to a person to run for office. See text for details.

village level within each block. We randomly divide villages into three types of treatments. In 48 "neutral villages" a neutral message is delivered both in private and public meetings. In 72 "social villages", a social message is added on top of a neutral message in private or public meetings or both. 72 "personal villages" are similarly selected. As a reminder, a neutral message is delivered in all treatment conditions as baseline private and public conversations. Finally, social and personal benefits treatments are not cross randomized: that is, a village can only receive one type of encouragement but not both.

\subsection{Balance}

Our field teams collected information on the population, number of settlements, distance to a main road and the local bureaucracy headquarters, and the size of the village council in a short village survey with key informants. Using these data, as well as the short survey with the experimental sample, we test for balance of our randomization at the village and individual level in Appendix Tables A4, A5, A6, and A7. Individually, we find only 7 instances of imbalance across 150 hypothesis tests, which is less than five percent of the total tests conducted. Only distance to district headquarter is significant in a joint orthogonality test. Below we show that our results are robust to controlling for imbalanced and all covariates. Appendix Table A2 presents the summary statistics for the subject pool. 


\subsection{Pre-Analysis Plan}

We pre-registered the main analysis of this paper with the American Economic Association RCT Registry (AEARCTR-0000685) and the Evidence in Governance and Politics registry (20151102AA). In Appendix F, we describe how the analysis in this paper relates to the PAP and list changes we made to the variables. There are two main points to note. First, the analysis on candidacy and election to the village council, the main outcomes in Sections 4.2 and 4.3, are registered as the primary outcomes of interest in the pre-analysis plan. Second, the performance outcomes reported in Section 4.4 are not pre-registered, though our main results in that section make use of official data on budgets.

Importantly, as the experiment contains many treatment arms there are many ways to cut the data. The main hypotheses we pre-registered relate to testing the overall effects of making social and personal benefits from office salient, as are presented in the results on candidacy, election, and performance in Sections 4.2, 4.3 and 4.4. As such, we treat these comparisons as the primary hypotheses of interest. We also decompose the main treatment effects in various ways to analyze how the main effects came to be. These are secondary, and exploratory, analyses.

\section{Results on Candidate Entry, Voter Selection, and Policy Outcomes}

\subsection{Estimation}

We focus on our subject pool of 9,310 individuals in the 192 treatment villages and run regressions of the following form:

$$
Y_{i v}=\beta_{1} \text { Social }_{v}+\beta_{2} \text { Personal }_{v}+\gamma_{b}+\varepsilon_{i v}
$$

where $Y_{i v}$ is an outcome, such as candidacy, for individual $i$ in village $v$. Social $v$ is an indicator variable for villages where a social message was delivered in either public or private; and Personal $_{v}$ is an indicator variable for villages where personal benefits were made salient in either public or private. $\beta_{1}$ and $\beta_{2}$ give the effect of treatments against neutral villages, which is the omitted category. $\gamma_{b}$ are block fixed effects that also hold fixed the effect of enumeration teams that vary only across blocks. Standard errors are clustered at the village level, the unit of treatment assignment. Guided by Young (2019), we also report Fisher exact p-values that do not require a limiting distribution for inference (Gerber and Green 
2012). This test assumes a null of no treatment effect for any unit. ${ }^{13}$

With this setup, we impose the linear restriction, $\beta_{1}-\beta_{2}=0$, to compute the effect of making social versus personal benefits of office salient and report the result at the end of each table.

\subsection{Results on the Decision to Run}

Table 1: Effects on Candidacy and Election

\begin{tabular}{|c|c|c|}
\hline & $\begin{array}{c}\text { Candidate }=1 \\
(1)\end{array}$ & $\begin{array}{c}\text { Elected }=1 \\
(2)\end{array}$ \\
\hline Social Treatment & $\begin{array}{c}0.010 \\
(0.008) \\
{[0.070]}\end{array}$ & $\begin{array}{l}0.005 \\
(0.005) \\
{[0.113]}\end{array}$ \\
\hline Personal Treatment & $\begin{array}{l}-0.009 \\
(0.006) \\
{[0.107]}\end{array}$ & $\begin{array}{l}-0.007 \\
(0.003) \\
{[0.057]}\end{array}$ \\
\hline $\begin{array}{l}\text { Neutral Mean } \\
\text { \# Villages } \\
\text { \# Observations }\end{array}$ & $\begin{array}{c}0.030 \\
192 \\
9310\end{array}$ & $\begin{array}{c}0.017 \\
192 \\
9310\end{array}$ \\
\hline \multicolumn{3}{|l|}{ Linear Restrictions } \\
\hline Social vs Personal & $\begin{array}{c}0.018 \\
(0.007) \\
{[0.007]}\end{array}$ & $\begin{array}{c}0.012 \\
(0.004) \\
{[0.006]}\end{array}$ \\
\hline
\end{tabular}

Notes: The table uses a dataset of randomly selected individuals. The dependent variable "Candidate" takes a value of one if the individual appears on the ballot and zero otherwise. "Elected" equals 1 if the individual won office and zero otherwise. Each regression uses block fixed effects. Standard errors are clustered at the village level and reported in parentheses. Exact p-values are in square brackets.

We first study whether the experiment had any effect on actual candidacy decision. To do this, we match each of 9,310 subjects from the sample to the official lists of candidates released by the Election Commission of Pakistan as well as those elected to village councils. ${ }^{14}$ Table 1 column 1 shows the results. ${ }^{15}$ Relative to personal benefits, social benefits increase the probability of candidacy by 1.8 percentage points (exact-p=0.007), an increase of 86

\footnotetext{
${ }^{13}$ We perform this test by creating a set of 5,000 artificial treatment assignments at the village level. The effect estimated using the actual treatment assignment is compared against the effects with these artificial treatments. The exact p-value is the share of artificial treatment effects that have a larger magnitude than the true treatment effect.

${ }^{14}$ We collected lists of candidates for each council from the Election Commission and matched people by name and father name to the experimental sample of 9,310. Rarely, if there was any confusion, our field partners called the village council secretary (a local bureaucrat) to confirm the match.

${ }^{15}$ The low baseline rate of candidacy in the general population means that smaller absolute movements on candidacy behavior translates into large relative effects.
} 
percent. Though we have limited statistical power, we also see that the effects are the result of social and personal benefits changing behavior in opposite directions: highlighting social benefits increases candidacy by 1 percentage point (exact- $\mathrm{p}=0.07$ ) while highlighting personal benefits reduces the probability of candidacy by 0.9 percentage points (exact- $\mathrm{p}=0.107$ ).

We probe the robustness of our results in four ways. First, to ensure that our effects are not driven by a few villages, we drop one village at a time from our sample (see Appendix Figure A2). Second, we progressively add pre-treatment controls to the regression, both balanced and imbalanced (see Table A19). Third, we add fixed effects for the order in which individuals were approached in a village (see Table A21). Fourth, we also add enumerator fixed effects to our analysis (see Table A22). In all cases we find that our results remain robust both statistically and substantively.

Beyond these main effects, we also examine how changes in the experimental sample affect candidacy at the village level (see Appendix Table A9). First, we find that the main effects carry through to the size of the candidate pool at the village level where we document that about 0.96 additional persons run in social versus personal villages, though this is not precisely estimated (exact-p=0.143). Second, we decompose this overall change in the candidate pool across open and reserved races and find that the effects are evenly split across the two types of races. Third, we also decompose the overall effect on the size of the candidate pool across three samples of interest: the experimental sample we randomly selected in villages; people not in the experimental sample who nevertheless attended the public meeting; and the rest of the village. Examining the first shows that the village level change primarily arises from changes in our experimental sample where social versus personal treatments increase candidacy by 0.861 individuals (exact- $\mathrm{p}=0.008$ ). On the second there is about a 0.3 person decrease for people who self-selected into the public meeting (exact- $\mathrm{p}=0.094$ ). In the rest of the village we do not detect changes in candidacy behavior, though, against the neutral condition, social treatment and personal treatments increases the candidate pool size a little. Finally, an examination of the candidate pool size in our experiment with other villages in our two districts where we did no field research (that is, pure control villages) shows that the neutral condition increases the candidate pool size by 0.409 (exact- $\mathrm{p}=0.52$ ) but that the main difference against pure controls emerges in the social treatment that adds about 1.3 people to the candidate pool (exact- $\mathrm{p}=0.102)$ (see Appendix Table A10). Conditioning on the neutral treatment therefore helps us partial out the effect of being approached and focus on the effect of how political office is portrayed. 


\subsection{Results on Voting}

Next, we analyze voters' decisions. Changes in candidacy, while important on their own, may not reflect changes in the elected political class if voters have a preference for status-quo politicians. In this sense, we might expect that the new candidates that have put themselves forward have a negligible chance of getting elected to office.

To test this empirically, we again make use of official electoral data to study the probability that a subject was elected to political office. We find in Column 2 of Table 1 that when social benefits are made salient versus personal benefits, the unconditional probability of people from our experimental sample getting elected to office is 1.2 percentage points higher $($ exact-p $=0.006)$. This can be decomposed into a 0.5 percentage point (exact-p $=0.113$ ) increase in the probability of getting elected when social benefits are made salient and a 0.7 percentage point (exact-p $=0.057$ ) decrease when personal benefits are highlighted.

As before, results remain robust to dropping one village at a time (Figure A2), adding controls (Table A19), and adding order of approach (Table A21) and enumerator fixed effects (Table A22).

We also check the electoral performance conditional on candidacy in Appendix Table A8. These analyses should be interpreted with caution for two reasons: first, they are no longer causally identified as we are conditioning on candidacy; and second, there is limited statistical power. We find that the probability of election among candidates in our experimental sample in social versus personal villages is 9.6 percentage points higher (exact-p $=0.103$ ). We also check the effect of social versus personal messaging on vote share and rank among candidates and find a decrease in the former by 3.6 percentage points (exact-p $=0.221$ ) and an increase in the later by 0.7 (exact-p $=0.113$ ). One interpretation of this suggestive analysis is that candidates in our sample, while having a higher likelihood of election, face races that are more competitive.

\subsection{Results on Policy Outcomes}

Next, we evaluate if these changes affect policy. Evaluating changes in policy outcomes, while important, is not straightforward. First, we cannot analyze individual level performance of our experimental sample as we can only observe the performance of elected individuals, and have no way of measuring how unelected politicians would have performed had they been elected. Our design, where we randomize treatments at the village level, helps with this

as we can study the performance of the entire elected council causally. Second, there are two dimensions on which policy can be affected. One is the extensive margin, where local political effort can generate more resources for the community (Burgess et al. 2015; Malik 
2019). The other is on the intensive margin, which refers to how a given amount of resources are distributed within the community.

\subsubsection{No policy change on the extensive margin}

In our context, the extensive margin is officially fixed as the amount of resources available to the Village Councils is determined by a legal fiscal formula. However, it is conceivable that varying the pool of politicians affects whether more resources from the provincial government arrive in the village even in the presence of such rules. ${ }^{16}$ To test this hypothesis, we return to villages one year after the elections between June and July of 2016. We collect information from the first budget documents prepared by each Village Council at the end of the fiscal year. These include information on the total amounts sanctioned by the provincial Finance Department, as well as information on how Village Councils actually decide to spend these allocations. $^{17}$

Examining the extensive margin, we confirm that our treatments do not explain any changes to the amount sanctioned to Village Councils (see Appendix Table A14). The data show that there is good adherence to rules on this margin.

\subsubsection{Policy aligns with citizen preferences on the intensive margin}

What remains is an examination of the intensive margin or how money is spent by the Village Councils. This decision is more under the control of elected Village Councilors. It may be the case, for example, that people motivated by social benefits are actually not better at their job than status quo politicians because they might have less human capital and would therefore deviate more from what citizens want. In contrast, it could be the case that these people are in fact better at their job because they are motivated to make government work for the community by ascertaining the needs of their constituents.

Our measure of policy efficacy on the intensive margin therefore compares the spending decisions of elected councils with how citizens would like the money to be spent. ${ }^{18}$ When we return to the field a year after elections we also survey a random sample of 1318 citizens in our sample villages to collect their spending preferences over budgets. ${ }^{19} \mathrm{We}$ ask citizens to

\footnotetext{
${ }^{16}$ Indeed previous research, for instance on politician salary caps, suggests there remains considerable variation around officially designated rules (Ferraz and Finan 2011b).

${ }^{17}$ This information is available with the village Secretary. We were able to collect it from all villages except three that were facing a gridlock over spending decisions. In Appendix I.2 we show that missing data is not correlated with treatments, and that our results are robust to extreme value (Manksi) bounds.

${ }^{18}$ This also links well with theoretic work on citizen candidates that measure the distance between the preferences of the citizenry with those who run for office (Besley and Coate 1997).

${ }^{19}$ One might be concerned that citizen preferences themselves could be affected by treatment. We discuss in Section 5.4.1 below that this is not the case. Additionally, the citizen preferences were collected before
} 


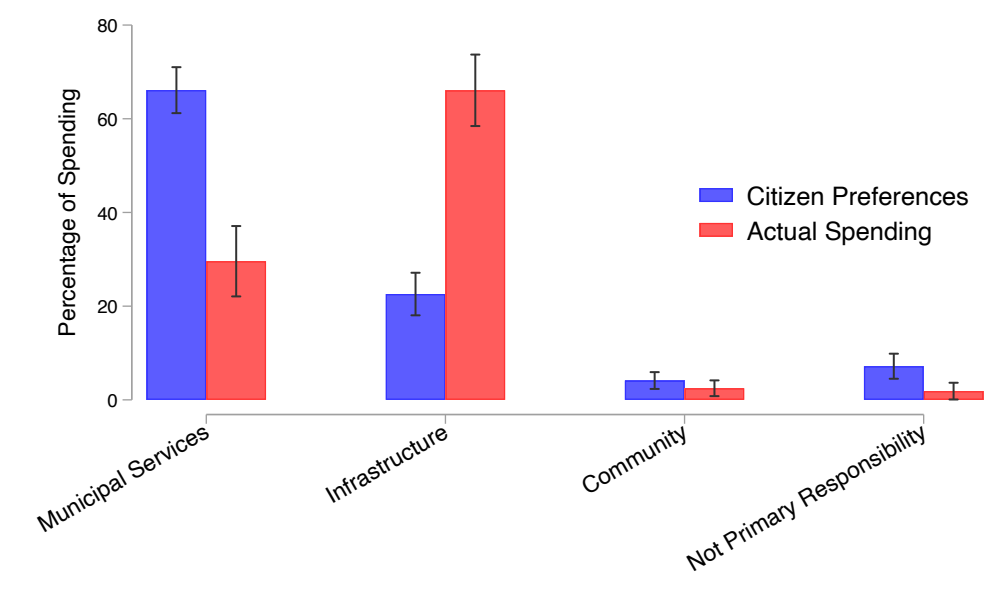

Figure 6: Citizen Preferences and Council Spending in Neutral Villages

Notes: This figure shows the proportion of budget allocated by citizens to different categories in a hypothetical exercise against the allocations by elected councils in the actual annual budget of 2016 in Neutral Villages. Error bars report the $95 \%$ confidence interval. Citizen preferences are statistically significantly different from budgetary spending for Municipal, Infrastructure, and Not Primary Responsibility with $p<0.01$. For Community the p-value of the difference is 0.2 .

divide a hypothetical Rs. 100 village development budget over a set of spending priorities. Citizen responses are collapsed into four broad categories based on the nature of the spending item. These categories are Municipal Services, Infrastructure, Community, and a residual category that stores preferences that are officially not the primary responsibility of the village council. ${ }^{20}$

Figure 6 plots the distribution of these citizen preferences against how councils actually chose to spend the money through their official budgets in Neutral message villages. While, it is evident that citizens prefer that a majority of the budget be spent on municipal services, councils actually spend mostly on infrastructure projects. Community projects are not preferred by either group. Similarly, both citizens and politicians are generally good at recognizing activities that are not the primary responsibility of the village councils.

The dichotomy in how councils are spending the money allocated to them versus constituent preferences motivate the investigation of whether treatments widened or closed this gap. To do this, we measure the Euclidean distance between spending and citizen preferences. We calculate the distance for each budget category $j \in J$ by using the formula the councils spent any money in the villages.

${ }^{20}$ Municipal Services include allocations to education, health, water, sewerage, and waste disposal. Infrastructure includes construction and rehabilitation of roads, streets, retainer walls, and street lights. Community includes spending money on sports, graveyard, mosque, and the community center. Not Primary Responsibility includes provision of electricity, transport service, security, skills development, and a residual other category. 
$\sqrt{\left(B_{j i}-\bar{C}_{j i}\right)^{2}}$, where $B_{j i}$ refers to the percentage of the budget spent on $j$ in village $i$ and $\bar{C}_{j i}$ is the average of citizen preferences for spending on that category in village $i$. We also calculate the overall difference in council spending and citizen preferences by summing over all four budget categories as follows: $\sqrt{\sum_{J}\left(B_{j i}-\bar{C}_{j i}\right)^{2}}$.

Table 2 shows the effects of treatment on the Euclidean distance between citizen preferences and council budgets as a sum in column (1) and decomposed across the four budget categories in columns (2) - (5). We find that elected councils in villages where public office was portrayed with a social message versus a personal benefits message spend their budgets in a manner that is more aligned with citizen preferences. The effect on the Euclidean distance between the two is 9.4 points (exact-p $=0.04$ ). Importantly, the primary contributors to this decrease in distance, as shown in columns (2) to (5), are spending on municipal and infrastructure categories which were the main non-aligned categories in Figure 6. As before, the effects move in opposite directions relative to the neutral condition though the statistical power here is limited: social treatments reduce the policy gap by 7.039 points (exact $\mathrm{p}$-value $=0.08)$ while personal treatments increase the gap by 2.361 (exact p-value=0.322). These results are robust to dropping one village at a time (Figure A2), adding controls (Table A20), and adding enumerator fixed effects (Table A22).

Table 2: Policy Effects: Distance between Citizen Preferences \& Council Budgets

\begin{tabular}{lccccc}
\hline & $\begin{array}{c}\text { Euclidean } \\
\text { Distance } \\
(1)\end{array}$ & $\begin{array}{c}\text { Municipal } \\
\text { Services } \\
(2)\end{array}$ & $\begin{array}{c}\text { Infrastructure } \\
(3)\end{array}$ & $\begin{array}{c}\text { Community } \\
(4)\end{array}$ & $\begin{array}{c}\text { Not Primary } \\
\text { Responsibility } \\
(5)\end{array}$ \\
\hline Social Treatment & -7.039 & -5.900 & -5.157 & 0.785 & 0.344 \\
& $(5.615)$ & $(4.318)$ & $(4.456)$ & $(1.328)$ & $(1.996)$ \\
& {$[0.080]$} & {$[0.063]$} & {$[0.104]$} & {$[0.261]$} & {$[0.427]$} \\
Personal Treatment & 2.361 & -0.175 & 1.948 & 0.259 & 3.231 \\
& $(5.212)$ & $(4.019)$ & $(4.192)$ & $(1.289)$ & $(2.103)$ \\
& {$[0.322]$} & {$[0.480]$} & {$[0.313]$} & {$[0.413]$} & {$[0.062]$} \\
Neutral Mean & 67.877 & 42.995 & 48.555 & 5.001 & 7.520 \\
\# Observations & 189 & 189 & 189 & 189 & 189 \\
\hline
\end{tabular}

\section{Linear Restrictions}

Social vs Personal

$\begin{array}{lllcl}-9.400 & -5.725 & -7.105 & 0.526 & -2.887 \\ (4.810) & (3.662) & (3.864) & (1.161) & (2.050) \\ {[0.040]} & {[0.083]} & {[0.049]} & {[0.338]} & {[0.097]}\end{array}$

Notes: This table uses a village level dataset that is constructed based on official budget data from the councils and the preferences of citizens regarding the budget. The dependent variable in each column is defined as the quadratic distance between citizen preferences and actual spending by the council. The distance for each category is calculated using the formula $\sqrt{\left(B_{j i}-\bar{C}_{j i}\right)^{2}}$, where $B_{j i}$ refers to the percentage of the budget spent on category $j$ in village $i$ and $\bar{C}_{j i}$ is the average of citizen preferences for spending on that category in village $i$. The overall difference in column (1) is calculated using the formula: $\sqrt{\sum_{J}\left(B_{j i}-\bar{C}_{j i}\right)^{2}}$. Each regression uses block fixed effects. Robust standard errors are reported in parentheses. Exact p-values are in square brackets. 
We also check effects on the linear difference in the rupee value of projects chosen as a part of the official budget and those that citizens wanted (see Appendix Table A15). The monetary value for official projects is available in official budget data. For citizens, we divide the total budget allocated to the village across policy domains in proportion to citizen preferences. We find that social versus personal messaging closes the policy gap by Rs. 380,415 (exact $\mathrm{p}=0.088$ ) - about USD 3,800 at the time - which, compared to the personal village gap of Rs. 2,603,333 is about a 14.6 percent effect.

For one of the two districts in our sample (Haripur), we were also able to retrieve budget data for an additional fiscal year (2017). Though the power is a little limited as the sample is cut in less than half, there is evidence that the effects persist for up to two years after the elections (see Appendix Table A16). We also check if these policy effects correlate with the degree to which citizen preferences align with each other in the village. We show in Appendix Table A17 that in villages where citizen preferences are less dispersed, policy effects are larger with social versus personal messaging. Whereas in places with more dispersed preferences this effect is relatively smaller. However, the difference between the two types of villages is not statistically significant.

\subsubsection{Effects on Citizen Satisfaction and Trust}

Next, we evaluate the impacts of treatments on citizen satisfaction with policy decision in terms of projects selected for implementation, as well as broader trust in state institutions. After the councils decide on projects, and during our citizen survey, we ask citizens to rate their approval of the projects selected by the council. We find that citizens are 17.3 percent point (exact $p=0.037$ ) more likely to say that they are satisfied with the specific projects chosen by their village council in social versus personal treatment villages (see Column 1 of Panel A, Appendix Table A18). Citizens are also 12.1 percent point (exact $p=0.094$ ) more likely to state that they trust the state in social versus personal treatment villages (Column 2). To code this index, we first ask citizens to tell us if they agree with the statement 'politics is a dirty word' to get their perception of overall politics. We convert the answers to a dichotomous variable that takes on a value of 1 to answers that did not agree with the statement and zero otherwise. We find the social versus personal villages increase disagreement with the statement by 12.2 percentage points (exact $p=0.075$ ). Second, we also ask citizens their perceived likelihood of their lost wallet being returned by a public servant (police or some other functionary) if they found it. The answers are dichotomized on the median of the responses with 1 indicating higher trust in public servants and zero otherwise. The results on this variable are less precisely estimated: we observe a 0.096 increase in trust (exact $p=0.130$ ). Panel B probes the robustness of this result with village 
averages instead of dichotomizing the outcomes. This reduces the statistical power for the analysis, but we find that the citizen satisfaction result remains robust. Taken together, these results suggest that the projects chosen by councils have aligned better in social versus personal villages, and that citizens are more satisfied with these choices and exhibit more positive affect towards politics and the state (Acemoglu et al. 2020).

\section{Mechanisms}

In this section, we conduct exploratory analyses of potential mechanisms for the main experimental effects on candidacy, election, and policy. We begin by discussing mechanisms related to the candidacy decisions where we first provide a simple framework of candidacy that explores the intrinsic and extrinsic calculus of citizens' decision to enter. Second, we link this calculus with our experimental conditions by examining how social versus personal effects emerge when encouragements are randomly given in public meetings, in private meetings, or in both. Third, we unpack the policy mechanisms by examining if access to positions of influence contributed to changes in policy outcomes. Finally, we evaluate alternative explanations of results. We caution that care be taken in interpreting these results as they rely on smaller samples than the main experimental results presented above.

\subsection{Framework}

We consider a citizens' decision to enter the race via two stages, the policy stage and the candidacy stage (see Appendix section K for details). In the policy stage, elected representatives decide on policy actions, where prosocial actions close the gap between policy and preferences of the community. In the candidacy stage, citizens decide whether to enter the political race or not.

Beginning with the candidacy stage, we conceive of citizens' decisions as being influenced first by their intrinsic utility to run (see, for example, Dal Bó et al. (2017)). This intrinsic utility can include non-pecuniary benefits from political office including the ones that comprise our focus: personal benefits, such as ego rents, and social benefits, such as the ability to help others in their community. People have preferences over prosocial and personal actions in office, and private beliefs about the extent to which these benefits will accrue to them when elected. As political actions are publicly observed, and not private, the calculus of running will also include extrinsic motivations. ${ }^{21}$ This extrinsic utility of a person can come

\footnotetext{
${ }^{21}$ Indeed, research has shown evidence for a large suite of mechanisms through which public interactions operate in shaping political behavior (Caselli and Morelli 2004; Bénabou and Tirole 2006; Gerber et al. 2008; Bond et al. 2012; DellaVigna et al. 2016; Harmon et al. 2019)
} 
from multiple sources, for example, community members could encourage the person to run for office if they are seen as prosocial (Bursztyn and Jensen 2017) or if they can commit to doing good policy when elected (Fujiwara and Wantchekon 2013). A person might run even absent encouragement by others because they derive utility from being seen as running for prosocial reasons (DellaVigna et al. 2016).

These intrinsic and extrinsic motivations are shaped by the way in which politics is seen in the status quo: a domain of the elite, where the selfish primarily run, carrying out policy actions that leads to personal enrichment over the benefit of society as a whole. Indeed, as noted in the introduction, Gallup Pakistan conducted a nationally representative survey with 1,529 respondents in 2022 where $81 \%$ of respondents agreed that "People enter politics to gain influence and status", while only $28 \%$ agreed with the statement that "People enter politics to serve their community". Similarly, Pew Research Center (2020) finds that $64 \%$ of respondents across 34 countries do no believe that elected officials care about ordinary citizens. Finally, according to the World Values survey, 69.1 percent and 66.4 percent of respondents in Pakistan report little to no confidence in the parliament and political parties respectively (Inglehart et al. 2014).

In the status-quo, therefore citizens form beliefs through a framing of political job as a means of personal enrichment and growth in status. We take this to be the baseline scenario in our framework. This corresponds with villages where personal benefits are highlighted in the experiment. We further assume that people prefer to be seen as prosocial in their actions. This creates opportunities for the treatments to move policy outcomes and candidacy behavior by shifting citizens' beliefs on returns from office as well as what motivations others in their community ascribe to their political actions of candidacy and policy choice.

Relative to the status-quo, we explore three scenarios. First, prosocial encouragements in private updates subjects' beliefs about the intrinsic social returns from office, while leaving their extrinsic calculus unaffected. Relative to the status-quo, the change in beliefs under the social treatment in private increases the likelihood that those people enter for whom prosocial intrinsic returns from policy outweigh personal intrinsic returns that they can get in the status-quo. This therefore can also make policy outcomes more socially aligned.

Second, publicly highlighting the social benefits from office influences citizens' extrinsic calculus while leaving their private beliefs unchanged. ${ }^{22}$ Relative to status-quo decisions, the updated public perception that candidacy is for prosocial reasons can influence individuals' extrinsic calculus in third ways. First, being seen as prosocial will improve the extrinsic

\footnotetext{
${ }^{22}$ Publicly highlighting benefits of office can influence citizens' private beliefs as well. For now, we make the assumption that they do not but relaxing this assumption will be similar to the third scenario we discuss below.
} 
utility that people with prosocial preferences derive from running thereby increasing the likelihood that they enter the race. Second, and importantly, the public signal also creates incentives for non-prosocial types to enter by altering the beliefs of others that those running for office are doing so for prosocial reasons even through the candidates do not have prosocial preferences themselves. Third, the public signal can also spur coordination among the community to encourage people to run for office who may or may not be prosocially motivated but may nevertheless deliver a prosocial policy once elected because of a commitment to their community. The prediction here is that candidacy will increase relative to status-quo and but because of these competing channels the policy effects are ambiguous.

The third case is one where we highlight social benefits both in private and public, meaning that both the intrinsic and extrinsic calculus shifts at the same time. Combining insights from the two cases above, under this scenario three types of people can enter the race. First are those who may derive a greater utility from office due to the prosocial component of their intrinsic utility and because of the higher extrinsic payoff from being seen as running for prosocial reasons. The candidacy effects are likely to be larger than when social benefits were highlighted only in private or only in public because both intrinsic and extrinsic utility can increase at the same time. The second are those kinds of people who do not carry prosocial preferences but are able to run because of opportunities created by the social signal that candidates are likely to be prosocially motivated. Third, like before, are those people who enter the race as a result of community coordination with a commitment to act in prosocial manner once elected, irrespective of their prosocial preferences. Therefore the policy effects under this condition are likely ambiguous as well.

\subsection{Results on Intrinsic and Extrinsic Calculus of Candidacy}

To bring the intuitions regarding the intrinsic and extrinsic calculus to the data, we use a feature of the experiment that randomizes whether social versus personal encouragements are randomly delivered in public meetings, in private one-on-one meetings, or in both.

As before we focus on our subject pool of 9,310 individuals in 192 treatment villages. As a reminder, meetings always occurred but when they did not include a social or personal message they were delivered with a neutral message. We run the following regressions:

$$
\begin{gathered}
Y_{i v}=\beta_{1} \text { Social Private }_{v}+\beta_{2} \text { Social Public }_{v}+\beta_{3} \text { Social Private \& Public }_{v} \\
+\beta_{4} \text { Personal Private }_{v}+\beta_{5} \text { Personal Public }_{v}+\beta_{6} \text { Personal Private \& Public }_{v}+\gamma_{b}+\varepsilon_{i v}
\end{gathered}
$$

The omitted category corresponds to villages that receive a neutral message in the private as well as the public meeting. We can impose linear restrictions to calculate further effects 
of interest as before. For example, $\beta_{2}-\beta_{5}$ gives the effect of social vs personal messages in public only, while $\beta_{1}-\beta_{4}$ gives the effect in private only. Finally, $\beta_{3}-\beta_{6}$ gives the effect of a social versus a personal message in both the public meeting as well as the private meeting. ${ }^{23}$

Table 3 presents the results on candidacy, election, and overall policy alignment. The first part of the table reports results from the regression above, while the bottom part shows results from linear restrictions on this regression. We find three results. First, we do not see any effects of highlighting social versus personal benefits from office in private meetings only. Second, highlighting social versus personal benefits of office in public meetings alone increases candidacy (effect of 2.2 percentage points, exact $\mathrm{p}=0.043$ ), election (effect of 1.1 percentage points, exact $\mathrm{p}=0.096$ ), and improves policy alignment (effect of 18.219 points, exact $\mathrm{p}=0.027)$. Finally, when social versus personal benefits are highlighted in both private and public meetings we observe the largest treatment effects on candidacy (effect of 3.8 percentage points, exact $\mathrm{p}=0.002$ ), election (effect of 2.3 percentage points, exact $\mathrm{p}=0.002$ ), as well as policy alignment (effect of 18.763 points, exact $\mathrm{p}=0.024$ )

Taken together, these results shed light on the mechanisms for the main treatment effects. First, we observe that private treatments on their own produced no changes to candidacy decisions, suggesting that mechanisms, such as, individual encouragements, nudges, and information alone minimally impact the intrinsic calculus of candidacy. Second, we observe effects on candidacy and election in the presence of public treatments either by themselves or combined with private treatments, suggesting that extrinsic calculus may be particularly important in shaping the candidacy decisions. Third, the largest treatment effects effects in private and public shows that private encouragements can have a role to play but they must be accompanied by changes to the extrinsic calculus of the candidacy decision. For example, telling people that they could run to help their community may come in conflict with their priors that they would be seen to be running to help themselves and a change to the extrinsic calculus can possibly ameliorate this barrier.

Of course, there can be several channels through which the extrinsic calculus on candidacy may be affected: prosocial people might put themselves forward because others now are more likely to expect that they are running for prosocial reasons; non-prosocial people might put themselves forward for the same reason; and community members might be more likely to coordinate around candidates who commit to helping the community. We assemble evidence on these channels by studying heterogeneity of treatment effects by prosociality and whether candidates report running because they were asked by their community to enter the race. We treat these as exploratory analyses.

\footnotetext{
${ }^{23} \mathrm{~A}$ concern here is that there might be differential selection into attending the public meetings by what treatments were delivered in private. We find no evidence for this in the data (see Appendix Section L.8).
} 


\section{Table 3: Candidacy, Election, and Policy Effects of Public and Private Treatments}

\begin{tabular}{|c|c|c|c|}
\hline & $\begin{array}{c}\text { Candidate } \\
(1)\end{array}$ & $\begin{array}{c}\text { Elected } \\
\text { to Council } \\
(2) \\
\end{array}$ & $\begin{array}{c}\text { Policy } \\
\text { Euclidean } \\
\text { Distance } \\
(3) \\
\end{array}$ \\
\hline Social Treatment, Private & $\begin{array}{l}-0.009 \\
(0.009) \\
{[0.195]}\end{array}$ & $\begin{array}{l}-0.002 \\
(0.006) \\
{[0.419]}\end{array}$ & $\begin{array}{c}0.097 \\
(8.279) \\
{[0.496]}\end{array}$ \\
\hline Social Treatment, Public & $\begin{array}{l}0.013 \\
(0.012) \\
{[0.100]}\end{array}$ & $\begin{array}{l}0.004 \\
(0.006) \\
{[0.252]}\end{array}$ & $\begin{array}{c}-10.520 \\
(6.966) \\
{[0.073]}\end{array}$ \\
\hline Personal Treatment, Private & $\begin{array}{l}-0.005 \\
(0.007) \\
{[0.331]}\end{array}$ & $\begin{array}{l}-0.004 \\
(0.005) \\
{[0.271]}\end{array}$ & $\begin{array}{l}-9.349 \\
(7.203) \\
{[0.102]}\end{array}$ \\
\hline Personal Treatment, Public & $\begin{array}{l}-0.009 \\
(0.006) \\
{[0.205]}\end{array}$ & $\begin{array}{l}-0.007 \\
(0.003) \\
{[0.162]}\end{array}$ & $\begin{array}{l}7.700 \\
(6.106) \\
{[0.164]}\end{array}$ \\
\hline Social Treatment, Private \& Public & $\begin{array}{c}0.026 \\
(0.013) \\
{[0.008]}\end{array}$ & $\begin{array}{c}0.013 \\
(0.009) \\
{[0.024]}\end{array}$ & $\begin{array}{c}-10.586 \\
(7.741) \\
{[0.077]}\end{array}$ \\
\hline Personal Treatment, Private \& Public & $\begin{array}{l}-0.012 \\
(0.008) \\
{[0.121]}\end{array}$ & $\begin{array}{l}-0.010 \\
(0.004) \\
{[0.055]}\end{array}$ & $\begin{array}{c}8.177 \\
(6.528) \\
{[0.136]}\end{array}$ \\
\hline $\begin{array}{l}\text { Neutral Mean } \\
\text { \# Villages } \\
\text { \# Observations }\end{array}$ & $\begin{array}{c}0.030 \\
192 \\
9310\end{array}$ & $\begin{array}{c}0.017 \\
192 \\
9310\end{array}$ & $\begin{array}{c}67.877 \\
189 \\
189\end{array}$ \\
\hline \multicolumn{4}{|l|}{ Linear Restrictions } \\
\hline Social Private Vs Personal Private & $\begin{array}{l}-0.004 \\
(0.009) \\
{[0.392]}\end{array}$ & $\begin{array}{c}0.003 \\
(0.007) \\
{[0.378]}\end{array}$ & $\begin{array}{c}9.446 \\
(9.176) \\
{[0.160]}\end{array}$ \\
\hline Social Public Vs Personal Public & $\begin{array}{c}0.022 \\
(0.011) \\
{[0.043]}\end{array}$ & $\begin{array}{c}0.011 \\
(0.006) \\
{[0.096]}\end{array}$ & $\begin{array}{c}-18.219 \\
(6.989) \\
{[0.027]}\end{array}$ \\
\hline Social Public \& Private Vs Personal Public \& Private & $\begin{array}{c}0.038 \\
(0.013) \\
{[0.002]}\end{array}$ & $\begin{array}{c}0.023 \\
(0.009) \\
{[0.002]}\end{array}$ & $\begin{array}{c}-18.763 \\
(8.125) \\
{[0.024]}\end{array}$ \\
\hline
\end{tabular}

Notes: Columns 1 and 2 use a dataset of randomly selected individuals (the experimental sample) to report the effect of treatments based on whether the treatment was delivered in private only, in public only, or in both. "Candidate" takes a value of one if the individual appears on the ballot and zero otherwise. "Elected to Council" takes a value one if the individual wins the election and zero otherwise. Column 3 use a village level dataset. "Policy Euclidean Distance" uses the euclidean distance between budget spending and citizens preferences as described in Section 4.4. Each regression uses block fixed effects. Standard errors are clustered at the village level and reported in parentheses. Exact p-values are in square brackets. 
First, we examine heterogeneity of treatment effects by an ex-ante measure of prosociality. Before treatments were delivered, we conducted a short survey with subjects where we measured the degree to which a person associates political office with prosocial goals. We use responses to these questions as our measure of the prosocial motivations of potential candidates. ${ }^{24}$ We take the average of responses across four questions and code greater than median responses as high prosocial types. ${ }^{25}$ We find that social versus personal messaging increases the likelihood that a prosocial person from our sample becomes a candidate by 2.6 percentage points (exact-p =0.035) (see Appendix Table A23), and is elected to the village council by 1.6 percentage points (exact $\mathrm{p}=0.0578$ ). We also decompose this analysis by sub-treatments using equation 2 (see Appendix Table A24) and find that these differences in selection of prosocial type are driven by the villages where social versus personal treatments are delivered in both private and public settings. In Appendix Section L.2, we show that these results are robust to controlling for the proportion of prosocial types in a village and other covariates at the individual and village level.

Second, we provide suggestive evidence that, in addition to changing the types of people who put themselves forward as candidates, social versus personal treatments can also encourage community members to informally coordinate on certain people, nominating them to run for office. The community can coordinate on people who can commit to act in a prosocial manner once in office, irrespective of their type. This commitment can come from a number of channels, such as, having a higher reputation cost or by identifying people who are likely to reciprocate the trust of the community by acting in a prosocial manner, for instance. We do not have data to parse through these specific channels within the coordination story but we explore if social versus personal treatments affect coordination overall in candidacy decisions. After the candidates filed papers, we interviewed them and asked if they were nominated by their clan or neighborhood to run for office. Using the responses of people from our experimental sample, we code a variable that equals one if they ran for office and were asked to run. The variable equals to zero if they were not asked to run or if they did not run. ${ }^{26}$ We find that social versus personal increases the likelihood that candidates

\footnotetext{
${ }^{24}$ Specifically, we asked how much respondents agreed with four statements on a scale of one to five: 'Elected representatives serve people by solving their problems'; 'Helping others brings internal peace'; 'Publicly provided services are very important for ordinary people'; 'Improving village schools is directly linked to the performance of public representatives'.

${ }^{25}$ The benefit of this strategy is that it maximizes our statistical power by splitting respondents equally across high and low types on prosociality. The drawback which makes this variable imperfect is that it uses a stated instead of behavioral measure of prosociality. The concern here is that instead of treatments motivating the most prosocial types to enter politics, they motivate those with the strongest social desirability concerns. It is unclear, however, why those with greater social desirability get elected by voters or implement better policy outcomes as we observe with our treatments.

${ }^{26}$ Note that these data are self-reported and are only collected directly from the candidates.
} 
report that they were nominated by 1.8 percentage points (exact $\mathrm{p}=0.007$, see Appendix Table A27). We also find that this treatment effect primarily emerges when social versus personal message is given in public, and private and public conditions, but not in private alone (see Appendix Table A28).

In summary, we take these results as providing suggestive evidence in support of selection by individuals themselves or by their communitiese. In Section 5.3.2, we report the impact of selection on policy outcomes through an instrumental variables analysis.

\subsection{Unpacking Policy Mechanisms}

How did treatments affect the policy making process? In this section, we show that people elected from the experimental sample had the means to affect policy change and did so during policy deliberations.

\subsubsection{Effects on Leadership Positions and Project Proposals}

We study if people from our experimental sample gained influence over the budget-making process. The budget is a document prepared by committees that cannot be approved if the Chairperson (or Deputy Chairperson in lieu of the Chairperson) of the village council does not give their final sign-off. Therefore, while the budget-making process itself is collaborative, it gives village council members who are assigned to specific committees as well as those who are elected to leadership positions more influence in the final policy decisions. In addition to holding positions of influence, we also study if people elected from the experimental sample contributed to policy deliberations by proposing projects.

To study this, we first code a variable as one if, when elected to the council, a person from our experimental sample was the chairperson, the vice chairperson, or a member of a village council committee. Next, we create a variable that equals one when someone from our experimental sample is elected to the village council and proposed a project that was adopted by the council. This variable proxies for agenda setting on the village council. Both variables equal zero when the person did not fulfill the criteria or if they were not elected.

Table 4 presents the results. We find that social versus personal messaging increases the likelihood that a person from our sample: is a leader or committee member by 0.7 percentage points in column 1 (exact $\mathrm{p}=0.014$ ); and is someone who proposed a project that was adopted by the village council by 1.2 percentage points in column 2 (exact $\mathrm{p}=0.003$ ). In Appendix Table A29, we decompose these results for private, public, and private and public sub-treatments and show that leadership and proposer effects are largest when social versus personal messaging is done in both private and public as before. 


\section{Table 4: Effects on Leadership Positions and Project Proposals}

\begin{tabular}{lcc}
\hline & $\begin{array}{c}\text { Elected as Leader } \\
\text { or Committee } \\
\text { Member } \\
(1)\end{array}$ & $\begin{array}{c}\text { Elected and } \\
\text { Project } \\
\text { Proposer } \\
(2)\end{array}$ \\
\hline Social Treatment & 0.001 & 0.010 \\
& $(0.004)$ & $(0.004)$ \\
Personal Treatment & {$[0.309]$} & {$[0.010]$} \\
& -0.006 & -0.002 \\
Neutral Mean & $(0.003)$ & $(0.003)$ \\
\# Villages & {$[0.026]$} & {$[0.297]$} \\
\# Observations & 0.012 & 0.009 \\
\hline Linear Restrictions & 192 & 192 \\
Social vs Personal & 9310 & 9310 \\
\hline & & \\
& 0.007 & 0.012 \\
& $(0.003)$ & $(0.004)$ \\
& {$[0.014]$} & {$[0.003]$}
\end{tabular}

Notes: The table uses a dataset of randomly selected individuals. The dependent variable in column 1 , is equal to 1 if the person held the chair or vice chair position on the village council, or was a member of a working committee on the council. The dependent variable in column 2 equals 1 if the person proposed a project that was selected in the final budget for the village council after the first year. Each regression uses block fixed effects. Standard errors are clustered at the village level and reported in parentheses. Exact p-values are in square brackets. 


\subsubsection{Instrumental Variables Results}

We also conduct an exploratory analysis where we examine if the number of people elected to the village council from our experimental sample contributes to reducing the Euclidean distance between citizen preferences and budgetary decisions. We use treatment indicators as the instruments for the number of people elected to the council (see Appendix L.5 for details) and use Anderson-Rubin confidence intervals for inference (Andrews et al. 2019; Lal et al. 2021). Focusing on the social versus personal villages, we find that policy outcomes improve as the total number of people elected from the experimental sample increases. We can further decompose this along two dimensions. Exploring selection, we show that policy outcomes improve when the number of prosocial types or the number of those who are encouraged by the community to run increase in the council. Examining policy influence, we find that policy improves when the number of those elected to leadership positions from this sample increase, as well as if the number of project proposers elected from this sample increase.

The benefit of this approach is that it helps identify the effect of both the election of individuals from our experimental sample to the village council as well as a withdrawal of some of these individuals as a result of treatments. The drawback is that the key assumption of this instrumental variables analysis is that of exclusion restriction, which in this context, means that treatments affect policy outcomes only through the channel of people getting elected (or not) to the village council. It is, of course, conceivable that treatments can influence policy outcomes via other channels, such as, changing the beliefs or actions of citizens at large. While the evidence in section 5.4.1 suggest that this may not be the case, we nevertheless recommend that the IV results should be interpreted with caution.

\subsection{Alternative Explanations}

\subsubsection{Changes in citizen preferences.}

Since there are two components of the Euclidean distance that measures policy alignment, citizen preferences and official budgetary spending decided by elected politicians, the changes we observe in policy alignment could arise because of movement in either component. For example, if treatments influence how elected politicians behave while making budgets, this should be reflected in how they spend the money. Alternatively, the treatments could have directly affected citizens' preferences which change the incentives environment under which politicians operate. We distinguish between these two explanations by decomposing the euclidean distance effects into its component parts in budgetary spending and citizen preferences (see Appendix Table A31). We find that the reduction in the euclidean distance 
between politician behavior and citizen preferences arises primarily from changes in the former term. That is, politicians' budgetary spending changes along infrastructure and municipal services dimensions. In contrast, citizen preferences do not change substantively or statistically. This finding is significant because it shows that the likely main driver of change in policy alignment is shifts in politician behavior instead of citizen policy preferences.

\subsubsection{Citizen behavior after elections.}

In addition to direct changes in citizens' policy preferences, it could also be the case that treatments affect how citizens hold politicians to account. There are at least two aspects of this: first it could be the case that citizens increase the rate at which they hold politicians to account by meeting them more regularly and expressing their demands. Second, it is possible that citizens meet politicians at the same rate, but that they increase the intensity of demands in those meetings or make the criteria of evaluating the performance of politicians more stringent.

During the citizen survey that was conducted a year after councils were elected, we asked citizens if they had met with anyone from the village council in the previous month. We sum the total number of meetings reported in the village in our sample and show in Appendix Table A32 that while the baseline rate of political engagement is fairly high at over 80 meetings per neutral village, there is no difference in meetings held in social versus personal villages. ${ }^{27}$ This provides evidence that at least the first channel of citizen behavior is not affected by treatments. Unfortunately, in the absence of data on the contents of citizen meetings with politicians, we are unable to directly test for the second channel whose existence we cannot rule out.

\subsubsection{Enumerator Effort}

It is possible that the social versus personal treatment effects are explained by differential effort by the enumeration team of the NGO. While this is not explicitly testable, a few pieces of evidence allay this concern: First, we find that social vs personal messaging in private had no effect on the probability that individuals attended the public meetings, an immediate outcome to measure differences in enumerator effort (see Appendix Section L.8). Second, we find that there are no effects of social versus personal messaging in private on candidacy for office (see Table 3). Third, our balance analysis shows that there is also no evidence that enumerator effort in recruiting individuals in social versus personal villages yields citizens

\footnotetext{
${ }^{27}$ If anything, both social and personal villages exhibit slightly fewer meetings with councilors compared to neutral villages.
} 
that differed on observables (see Appendix Table A7). Finally, we find that our results are also robust to the inclusion of enumerate fixed effects which block concerns that the results are driven by differences in effort by some enumerators (see Appendix Table A22).

\section{Conclusion}

This paper presents new evidence on an important channel of improving representative democracy: the supply of politicians. It shows that the way in which politics is portrayed to ordinary citizens affects who decides to enter politics, who gets elected, as well as what policy outcomes the political class delivers.

We study candidate entry in the shadow of a large policy reform in democratization in Pakistan, where the number of directly elected representatives in the province we study rise from 125 in 2013 to more than 48,000 in 2017. Locally elected government holds the promise of feeding a stream of talent that can eventually rise up the political ranks. Understanding how the decisions to run for these offices are shaped and how the local talent pool can be improved is therefore important not just in Pakistan, but in a variety of contexts where local governments are the grassroots of democracy.

Our experiment reveals that non-pecuniary prosocial incentives can be particularly powerful in mobilizing a political class that delivers responsive policy to the electorate. When political office is presented in terms of its prosocial versus personal benefits, particularly in public settings, people who would not have otherwise run for office become political candidates. Presenting themselves as candidates has the knock on effect of them getting elected because they are now presented to voters on the ballot. Finally, the prosocial encouragements at the candidacy stage also align downstream policy outcomes in the village more closely with preferences of citizens, suggesting that who runs for office has a direct bearing on the policy outcomes we observe.

As politics continues to be viewed with greater skepticism in many developing countries, ${ }^{28}$ our results outline that it is perhaps possible to improve the supply of politicians in developing countries if we focus on the determinants of their initial decision to run. There exist people who are responsive to citizen preferences but are not contesting elections and, therefore, giving citizens a chance to elect them.

\footnotetext{
${ }^{28}$ According to the World Values survey, 69.1 percent and 66.4 percent of respondents in Pakistan report little to no confidence in the parliament and political parties respectively (Inglehart et al. 2014).
} 


\section{References}

Acemoglu, Daron, Ali Cheema, Asim I Khwaja, and James A Robinson, "Trust in state and nonstate actors: Evidence from dispute resolution in Pakistan," Journal of Political Economy, 2020, 128 (8), 3090-3147.

Andreoni, James, "Impure Altruism and Donations to Public Goods: A Theory of WarmGlow Giving," The Economic Journal, 1990, 100 (401), 464-477.

_ , "Cooperation in Public-Goods Experiments: Kindness or Confusion?," The American Economic Review, 1995, 85 (4), 891-904.

- , "Warm-Glow versus Cold-Prickle: The Effects of Positive and Negative Framing on Cooperation in Experiments*," The Quarterly Journal of Economics, 02 1995, 110 (1), $1-21$.

Andrews, Isaiah, James H Stock, and Liyang Sun, "Weak instruments in instrumental variables regression: Theory and practice," Annual Review of Economics, 2019, 11, 727753.

Arias, Eric, Pablo Balán, Horacio Larreguy, John Marshall, and Pablo Querubín, "Information provision, voter coordination, and electoral accountability: Evidence from Mexican social networks," American Political Science Review, 2019, 113 (2), 475-498.

Ashraf, Nava, Oriana Bandiera, Edward Davenport, and Scott S Lee, "Losing Prosociality in the Quest for Talent? Sorting, Selection, and Productivity in the Delivery of Public Services," American Economic Review, 2020.

Bandiera, Oriana, Michael Callen, Katherine Casey, Eliana La, Camille Landais Ferrara, and Matthieu Teachout, "State effectiveness," IGC Working Paper, 2019.

Barfort, Sebastian, Nikolaj A Harmon, Frederik Hjorth, and Asmus Leth Olsen, "Sustaining Honesty in Public Service: The Role of Selection," American Economic Journal: Economic Policy, November 2019, 11 (4), 96-123.

Beath, Andrew, Fotini Christia, Georgy Egorov, and Ruben Enikolopov, "Electoral Rules and Political Selection: Theory and Evidence from a Field Experiment in Afghanistan," Review of Economic Studies, 2016, (July).

Bénabou, Roland and Jean Tirole, "Incentives and prosocial behavior," American economic review, 2006, 96 (5), 1652-1678.

_ and _ , "Identity, morals, and taboos: Beliefs as assets," The Quarterly Journal of Economics, 2011, 126 (2), 805-855.

Besley, Timothy, "Political selection," Journal of Economic perspectives, 2005, 19 (3), 43-60.

_, Principled agents?: The political economy of good government, Oxford University Press on Demand, 2006. 
_ and Maitreesh Ghatak, "Competition and incentives with motivated agents," American Economic Review, 2005, 95 (3), 616-636.

- and Stephen Coate, "An economic model of representative democracy," The Quarterly Journal of Economics, 1997, (February).

Blair, Graeme, Rebecca Littman, and Elizabeth Levy Paluck, "Motivating the adoption of new community-minded behaviors: An empirical test in Nigeria," Science advances, 2019, 5 (3), eaau5175.

Blaydes, Lisa, Elections and distributive politics in Mubaraks Egypt, Cambridge University Press, 2010.

Bó, Ernesto Dal, Frederico Finan, Olle Folke, Torsten Persson, and Johanna Rickne, "Who Becomes a Politician?," The Quarterly Journal of Economics, 2017, 132 (4), 1877-1914.

Bond, Robert M, Christopher J Fariss, Jason J Jones, Adam D I Kramer, Cameron Marlow, Jaime E Settle, and James H Fowler, "A 61-million-person experiment in social influence and political mobilization," Nature, sep 2012, 489 (7415), 295-298.

Broockman, David E, "Black politicians are more intrinsically motivated to advance blacks? interests: A field experiment manipulating political incentives," American Journal of Political Science, 2013, 57 (3), 521-536.

Burgess, Robin, Remi Jedwab, Edward Miguel, Ameet Morjaria, and Gerard Padró i Miquel, "The value of democracy: evidence from road building in Kenya," American Economic Review, 2015, 105 (6), 1817-51.

Bursztyn, Leonardo and Robert Jensen, "Social image and economic behavior in the field: Identifying, understanding, and shaping social pressure," Annual Review of Economics, 2017, 9, 131-153.

Caselli, Francesco and Massimo Morelli, "Bad politicians," Journal of Public Economics, 2004, 88 (3-4), 759-782.

Casey, Katherine, Abou Bakarr Kamara, and Niccoló Meriggi, "An experiment in candidate selection," American Economic Review, 2021.

Chattopadhyay, $\mathbf{R}$ and E Duflo, "Women as policy makers: Evidence from a randomized policy experiment in India," Econometrica, 2004, 72 (5), 1409-1443.

Cheema, Ali, Adnan Khan, and Roger Myerson, "Breaking the Counter-cyclical Pattern of Local Democracy in Pakistan," 2010, (May).

Cirone, Alexandra, Gary W Cox, and Jon H Fiva, "Seniority-based nominations and political careers," American Political Science Review, 2021, 115 (1), 234-251. 
Colonnelli, Emanuele, Mounu Prem, and Edoardo Teso, "Patronage and selection in public sector organizations," American Economic Review, 2020, 110 (10), 3071-99.

Cruz, Cesi, Julien Labonne, and Pablo Querubin, "Politician Family Networks and Electoral Outcomes: Evidence from the Philippines," American Economic Review, 2017.

Dahl, Robert Alan, Polyarchy: Participation and opposition, Yale University Press, 1973.

Dal Bó, Ernesto and Frederico Finan, "Progress and perspectives in the study of political selection," Annual Review of Economics, 2018, 10, 541-575.

Dal Bó, Ernesto, Frederico Finan, and Martín a Rossi, "Srengthening State Capabilities: The Role of Financial Incentives in the Call to Public Service," Quarterly Journal of Economics, 2013.

Deci, Edward L, "Intrinsic motivation, extrinsic reinforcement, and inequity." Journal of personality and social psychology, 1972, 22 (1), 113.

DellaVigna, Stefano, John A List, Ulrike Malmendier, and Gautam Rao, "Voting to tell others," The Review of Economic Studies, 2016, 84 (1), 143-181.

Dunning, Thad, Guy Grossman, Macartan Humphreys, Susan D Hyde, Craig McIntosh, and Gareth Nellis, Information, Accountability, and Cumulative Learning: Lessons from Metaketa I, Cambridge University Press, 2019.

Eggers, Andrew $\mathbf{C}$ and Jens Hainmueller, "MPs for sale? Returns to office in postwar British politics," American Political Science Review, 2009, 103 (4), 513-533.

Ferraz, Claudio and Frederico Finan, "Electoral accountability and corruption: Evidence from the audits of local governments," American Economic Review, 2011, 101 (June), 1274-1311.

_ and _, "Motivating politicians: The impacts of monetary incentives on quality and performance," Working Paper, 2011.

Fisman, Raymond, Florian Schulz, and Vikrant Vig, "The private returns to public office," Journal of Political Economy, 2014, 122 (4), 806-862.

_, Nikolaj A Harmon, Emir Kamenica, and Inger Munk, "Labor supply of politicians," Journal of the European Economic Association, 2015, 13 (5), 871-905.

Folke, Olle, Torsten Persson, and Johanna Rickne, "Dynastic political rents? Economic benefits to relatives of top politicians," Economic Journal, 2017.

Frey, Bruno S, "Not just for the money," 1997.

Fujiwara, Thomas, "Voting Technology, Political Responsiveness, and Infant Health: Evidence from Brazil," Econometrica, 2015. 
- and Leonard Wantchekon, "Can informed public deliberation overcome clientelism? Experimental evidence from Benin," American Economic Journal: Applied Economics, 2013, 5 (4), 241-55.

Gagliarducci, Stefano and Tommaso Nannicini, "Do better paid politicians perform better? Disentangling incentives from selection," Journal of the European Economic Association, 2013, 11 (2), 369-398.

Gerber, Alan S and Donald P Green, Field experiments: Design, analysis, and interpretation, WW Norton, 2012.

Gerber, Alan S., Donald P. Green, and Christopher W. Larimer, "Social Pressure and Voter Turnout: Evidence from a Large-Scale Field Experiment," American Political Science Review, 2008, 102 (01), 33-48.

Grossman, Guy, "Do Selection Rules Affect Leader Responsiveness? Evidence from Rural Uganda," Quarterly Journal of Political Science, mar 2014, 9 (1), 1-44.

- and Kristin Michelitch, "Information dissemination, competitive pressure, and politician performance between elections: A field experiment in Uganda," American Political Science Review, 2018, 112 (2), 280-301.

Gulzar, Saad, Nicholas Haas, and Benjamin Pasquale, "Does Political Affirmative Action Work, and For Whom? Theory and Evidence on India's Scheduled Areas," American Political Science Review, 2020.

Handy, Femida and Eliakim Katz, "The Wage Differential between Nonprofit Institutions and Corporations: Getting More by Paying Less?," Journal of Comparative Economics, 1998, 26 (2), 246-252.

Harmon, Nikolaj, Raymond Fisman, and Emir Kamenica, "Peer effects in legislative voting," American Economic Journal: Applied Economics, 2019, 11 (4), 156-80.

Humphreys, Macartan and Jeremy Weinstein, "Policing politicians: Citizen empowerment and political accountability in Uganda," Unpublished manuscript, 2012.

Inglehart, R., C. Haerpfer, A. Moreno, C. Welzel, K. Kizilova, J. Diez-Medrano, M. Lagos, P. Norris, E. Ponarin, and B. Puranen, "World Values Survey: Round Six - Country-Pooled Datafile," Technical Report 2014.

Joseph, A Schlesinger, "Ambition and politics: political careers in the United States," Chicago: Rand NcNally, 1966.

Karpowitz, Christopher F, J Quin Monson, and Jessica Robinson Preece, "How to elect more women: Gender and candidate success in a field experiment," American Journal of Political Science, 2017, 61 (4), 927-943.

Lal, Apoorva, Mackenzie William Lockhart, Yiqing Xu, and Ziwen Zu, "How much should we trust instrumental variable estimates in political science? Practical advice based on over 60 replicated studies," Working Paper, 2021. 
Landmann, Andreas and Bjorn Vollan, "Pro-sociality of democratic leaders: Evidence from village elections in the Philippines," Working Paper, 2020.

Lim, Claire SH, "Preferences and incentives of appointed and elected public officials: Evidence from state trial court judges," American Economic Review, 2013, 103 (4), 136097.

Linos, Elizabeth, "More Than Public Service: A Field Experiment on Job Advertisements and Diversity in the Police," Journal of Public Administration Research and Theory, 11 2017, 28 (1), 67-85.

Lipset, Seymour Martin, "Political man: The social bases of politics," 1959.

Malik, Rabia, “(A) Political Constituency Development Funds: Evidence from Pakistan," British Journal of Political Science, 2019, pp. 1-18.

Martinez-Bravo, Monica, "The Role of Local Officials in New Democracies: Evidence From Indonesia," American Economic Review, 2014, pp. 1-49.

_, Priya Mukherjee, and Andreas Stegmann, "The Non-Democratic Roots of Elite Capture: Evidence From Soeharto Mayors in Indonesia," Econometrica, 2017, 85 (6), 1991-2010.

Mehmood, Sultan, "The impact of Presidential appointment of judges: Montesquieu or the Federalists?," American Economic Journal: Applied Economics, 2022, 14 (4), 411-45.

MICS, "Report on Multiple Indicator Cluster Survey," 2008.

Myerson, Roger, "Local foundations for strong democracy in Pakistan," Working Paper, 2009.

Ostrom, Elinor, "Collective action and the evolution of social norms," Journal of economic perspectives, 2000, 14 (3), 137-158.

Pande, Rohini, "Can informed voters enforce better governance? Experiments in lowincome democracies," Annual Review of Economics, 2011.

Pew Research Center, "Democratic Rights Popular Globally but Commitment to Them Not Always There," 2020.

Prakash, Nishith, Marc Rockmore, and Yogesh Uppal, "Do criminally accused politicians affect economic outcomes? Evidence from India," Journal of Development Economics, 2019, 141, 102370.

Querubin, Pablo et al., "Family and politics: Dynastic persistence in the Philippines," Quarterly Journal of Political Science, 2016, 11 (2), 151-181.

Ravanilla, Nico, "Attracting Good People into Public Service: Evidence from a Field Experiment in the Philippines," Working Paper, 2016. 
Reinikka, Ritva and Jakob Svensson, "Local capture: evidence from a central government transfer program in Uganda," The quarterly journal of economics, 2004, 119 (2), 679-705.

Salim, Ahmed, "Political Parties in Pakistan," 2005, 12 (1).

Vaishnav, Milan, When crime pays: Money and muscle in Indian politics, Yale University Press, 2017.

$\mathrm{Xu}, \mathbf{G u o}$, "The costs of patronage: Evidence from the british empire," American Economic Review, 2018, 108 (11), 3170-98.

Young, Alwyn, "Channelling Fisher: Randomization Tests and the Statistical Insignificance of Seemingly Significant Experimental Results," The Quarterly Journal of Economics, 2019. 


\section{ONLINE APPENDIX}

\section{A Details of How Candidacy is Declared}

To be eligible to run for election, prospective politicians must fill out a candidacy form, as well as declare income sources and wealth. Defaulters of bank loans and public servants are not eligible to contest the elections. The process is summarized as follows:

1. Collect and fill the candidacy declaration form, which includes details of at least two people who endorse the candidacy of the interested person

2. Prepare an affidavit, endorsed by a Public Notary, declaring that the candidate has not been a defaulter

3. Prepare an income and wealth declaration

4. Deposit a fee of Rs. 1000 (USD \$10) through a bank draft

5. Attach certified copies of educational certificates and the national identity card

\section{B Sampling procedure}

Random Walk As no household rosters or maps of villages exist, field teams are instructed to begin at the center of the village. The center is identified as a key landmark at the geographic center of the village, by the survey team supervisors. The teams start the activity by talking to every 5 th household in the direction of North and repeat this process in different directions interviewing about 10 households in one direction on average. An advantage of drawing a random sample is that we capture the effect of treatments for the average household office-eligible male member. As with most research in this context, contact was made with more than 95 percent of households approached. Appendix G shows that this sampling procedure yields similar samples across treatment arms. In addition, Table A21 shows that the results are robust to fixed effects for the order in which individuals were approached in the field.

Sample Selection Sampling at the household level effectively translates into male respondents in our context. First, field research with women in most areas of Pakistan requires women enumerators. Due to funding constraints, we were unable to double team sizes to canvass women respondents. Second, discussions in the pilots suggested that women's political participation through candidacy was expected to be low, mostly restricted to the two reserved seats for women. In fact, 45 of the 384 reserved women's seats in our sample remained uncontested, and General (open) seats did not have a single woman contestant across 48 villages where we carry out no treatment fieldwork whatsoever. Finally, research has shown that the expression of womens' political preferences in Pakistan tend to align with male members of the household (Bari 2005). However, Khan (2017) shows that even when actual preferences are different across men and women within a household, expressed preferences might be the same. In this sense, boosting women's political participation directly might require a deeper transformation of norms that we are now examining in current work in Pakistan.

Sampling Procedure for the Citizen Survey We followed a random walk procedure for the citizen survey as well. The enumerators were instructed to start at the center of the 
village and interview every 20th household in the direction of north till they reached the end of the village. They were to return the procedure in all four directions.

\section{Outline of Public Meetings}

1. Welcome and Introductions

2. Overview of Local Elections, including information on Village Councils

3. Provide details of:

- Composition of councils (Chairpersons, General Seats, Reserved Seats)

- Pre-requisites for Filing Papers (age, nationality, etc)

4. Detail Process of Declaring Candidacy (neutral message)

5. Discussion on Personal or Social Benefits to councilors

6. Questions and Discussion

7. End

\section{Timeline}

Below, we provide a condensed timeline for the project.

1. March 3-14, 2015: Pilot for treatment design in Haripur District, KP

2. Last week of March - April 13, 2015: Administering Treatments

3. April 13-17, 2015: Candidates file their papers

4. May 3-28, 2015: Survey of all candidates

5. May 30, 2015: Election Day

6. June 25, 2015: Initial notification of results

7. August 30, 2015: Oaths of office begin

8. June 23 - July 31, 2016: Performance surveys of council members and citizens

\section{E Ethical considerations}

This experiment is focused on improving the supply of politicians in an actual election. This merits a discussion of ethical considerations. The project has received approval from Institutional Review Boards (IRB) of our universities. Nonetheless, there are additional concerns that go beyond the scope of IRB which we want to address in this note. We take guidance from the framework of ethical concerns presented in Asiedu et al. (2021)

Policy Equipoise: Theoretically it is unclear whether people attracted with prosocial messaging will become better politicians or those driven by the possibility of ego-rents. As explained in the paper, while prosocial messaging may attract more community minded persons it is unclear if such people are good at delivering public goods. Similarly, ego-rents may attract higher ability people who have the potential to be good policy makers/politicians. Due to these competing predictions, we believe the treatments in this paper are in policy equipoise. 
Role of researchers with respect to implementation: The researchers actively participated in the project. This fact was conveyed to the subjects through verbal consent approved by NYU IRB via protocol number 15-10593. However, there may be a concern that western researchers may ask the subjects to undertake activities that are detrimental to them or the Pakistani state. We believe this concern is ameliorated by the fact that both researchers on this project are from Pakistan and one of us is a native of the province where this project was implemented and the other one has spent significant time in that province. In fact, at the time of implementation of this project, one member of the research team was not even based at a western institution and worked locally in Pakistan.

Potential harms to participants or nonparticipants from the interventions or policies: Ex-ante there was no potential of harm to participants. The decision to run for office or not is a right of every citizen above the age of 21 years. One additional concern may be that the project provided valuable information to a select few citizens in the village and hence gave them an undue advantage in terms of candidacy. However, this concern is ameliorated because of two reasons. One, the people selected to be a part of our experimental sample were drawn at random from the village and every potential male citizen had an equal chance of being selected. Second, our treatments always included community meetings that were open to everyone in the village. This was intentionally designed as such to give an additional opportunity to people not selected for the in-person arm to receive the same information in the public meeting. There is, however, a concern left about women being excluded from the process. Our team comprised male enumerators who could not reach women citizens while respecting local norms. Due to the limitation of our resources, we could not hire women enumerators and bus them to locations to approach women citizens. We are circumventing some of these limitations in our subsequent work as enabling women's political participation is an important question in Pakistan.

Potential harms to research participants or research staff from data collection: We did not find any potential of harm to research participants or staff during the implementation of the study. One concern that might be important here relates to the results on policy outcomes where we see that in some villages the gap between budgetary spending and citizen preferences increases, that is policy outcomes become worse. Ex-ante, as we discuss at length in the paper, and in the policy equipoise discussion above, it was unclear if 1) our relatively light touch treatments would impact at all people's decisions to run for office, 2) if voters would even elect the people who decided to run because of the treatments, and 3) if the politicians would behave differently once elected. There are compelling theoretical reasons to believe that policy outcomes would not change even if who was running and who got elected changed. We see our paper as a first data point in connecting these motivations for candidacy with policy outcomes, and because of the importance of these questions, hope that we have more research on this question so that we can have a better evidence base for what motivations yield a political class that performs well in office, and how we might mobilize such politicians.

Financial and reputational conflicts of interest: The researcher had no conflict of interest.

Intellectual freedom: The researchers have complete intellectual freedom to report the results of this study. 
Feedback to participants or communities: We did not have resources to provide feedback to each of the 9,310 participants after the project.

Foreseeable misuse of research results: We do not foresee any potential of misuse of the research results.

Other Ethics Issues to Discuss: None to our knowledge.

\section{F Linkages and Deviations from Pre-Analysis Plan}

In this report, we summarize how our analysis relates to the Pre-Analysis Plan (PAP) that was specified before candidacy data was delivered to the authors. The PAP is registered at AEA RCT Registry (0000685) and at EGAP (20151102AA). Below, we report on linkages and deviations from the PAP by using the same section headings used in the PAP.

Experiment The registered PAP is a comprehensive document for three separate experiments that were built into the design of the overall study. The focus of this paper is only on one of the experiments titled "Experiment 1" on page 12 in the PAP that relates to the one-on-one and public meetings in villages. The other experiments are smaller in scope.

Data collection All data on candidacy and election are available to the authors after the PAP is registered. The analysis on candidacy and election is pre-registered, while the analysis on policy effects is not pre-registered. However, the policy results makes use of administrative data and a citizen survey on budgets and the collection of those data commenced before authors had the final administrative data on elections in hand. That is, we were not aware of the effects on candidacy and election by the time we started collecting data on performance. Variables Guided by Olken (2015), we consider effects on 'primary outcomes' of interest. In Table A1 we report a mapping of main variables used in the paper with the relevant section of the PAP. As noted in the PAP, we also collect a host of outcomes for the candidate pool. However, various seminar comments recommended that we drop analysis on those outcomes as they were collected post-treatment. Consequently, in the present paper, we focus only on the main (primary) outcomes that were pre-registered: candidacy and election to council as measured through administrative data. Specifically, we measure candidacy and election with variable 4 and 5 (page 16 of PAP), which is not self-reported and is retrieved directly from the election commission. Using the administrative measure of candidacy and election removes the possibility of survey response bias and allows comparisons with election to the council, which is only measured in administrative data. In addition, we have made changes to the labels of some variables. The Personal Benefits treatment was labeled as Career Benefits, while prosocial type (used for heterogeneous effects in the paper) was labeled as "prior on prosociality" in the PAP. We consider the new labels are better reflections of what the variables measure.

Analysis Table A1 shows the mapping of our outcomes to pre-registration status. Overall, the results reported in Section 4 are pre-registered and correspond to Analysis 2.1 in the PAP. This analysis focuses on the relevant sample for this experiment, that is, 9310 people approached in 192 villages. The village level policy outcomes in Section 4.4 are not preregistered but correspond to Analysis 2.5 in the PAP, that relates to calculating village level effects. As noted in the main draft, we treat the mechanisms analysis as suggestive. 
Table A1: Mapping of Variables from main tables with Pre-Analysis Plan

\begin{tabular}{|c|c|c|c|c|}
\hline Variable & Var Type & $\begin{array}{l}\text { Tables in } \\
\text { Paper }\end{array}$ & $\begin{array}{l}\text { Registered } \\
\text { in PAP? }\end{array}$ & $\begin{array}{l}\text { PAP Section } 5 \\
\text { variable \# }\end{array}$ \\
\hline \multicolumn{5}{|l|}{ Primary Outcomes: } \\
\hline Filed papers & Outcome & Table 1 & Yes & 4 \\
\hline Elected to council & Outcome & Table 1 & Yes & 5 \\
\hline Budget and Preferences & Outcome & Table 2 & No & \\
\hline
\end{tabular}

\section{G Summary Statistics and Balance Tables}

\begin{tabular}{lccccc}
\multicolumn{1}{c}{ Table A2: Summary Statistics of Candidacy Stage Variables } \\
\hline \hline \multicolumn{1}{c}{ Variable } & Mean & Std. Dev. & Min. & Max. & N \\
\hline Main Outcomes & & & & & \\
Filed Papers & 0.031 & 0.174 & 0 & 1 & 9310 \\
Elected to Council & 0.017 & 0.129 & 0 & 1 & 9310 \\
Prosocial Low Type & 0.614 & 0.487 & 0 & 1 & 9310 \\
Prosocial High Typ & 0.386 & 0.487 & 0 & 1 & 9310 \\
Village Characteristics & & & & & \\
Village Population (1998) & 4366.505 & 1875.097 & 1831 & 12489 & 192 \\
Number of Settlements & 2.224 & 1.574 & 1 & 11 & 192 \\
Distance to main road & 8.105 & 16.944 & 0.5 & 100 & 192 \\
Distance to District HQ & 26.654 & 19.516 & 2 & 165 & 192 \\
Distance to County HQ & 22.872 & 17.575 & 1 & 110 & 192 \\
Longitude & 34.053 & 0.126 & 33.776 & 34.356 & 192 \\
Latitude & 73.120 & 0.222 & 72.593 & 73.489 & 192 \\
Number of General Seats & 6.073 & 0.957 & 5 & 10 & 192
\end{tabular}

Notes: This table reports summary statistics of data used in Section 4.

Table A3: Summary Statistics for Budget and Citizen Preferences

\begin{tabular}{lccccc}
\hline \hline \multicolumn{1}{c}{ Variable } & Mean & Std. Dev. & Min. & Max. & N \\
\hline Average Citizens' Preferences & & & & & \\
Municipal & 66.256 & 16.735 & 16 & 100 & 192 \\
Infrastructure & 20.639 & 13.554 & 0 & 84 & 192 \\
Community & 4.623 & 6.909 & 0 & 38.571 & 192 \\
Not Primary Responsibility & 8.481 & 10.771 & 0 & 48.75 & 192 \\
Budget Spending & & & & & \\
Municipal & 30.692 & 25.019 & 0 & 100 & 189 \\
Infrastructure & 64.846 & 25.268 & 0 & 100 & 189 \\
Community & 2.234 & 5.459 & 0 & 30.769 & 189 \\
Not Primary Responsibility & 2.228 & 9.012 & 0 & 80 & 189 \\
\hline
\end{tabular}

Notes: This table reports summary statistics of data used in Section 4.4. Three Village Councils did not prepare a budget due to gridlock. Table A12 provides evidence that treatments do not predict missing data. 
Table A4: Village Characteristics Balance for Sub-Treatments

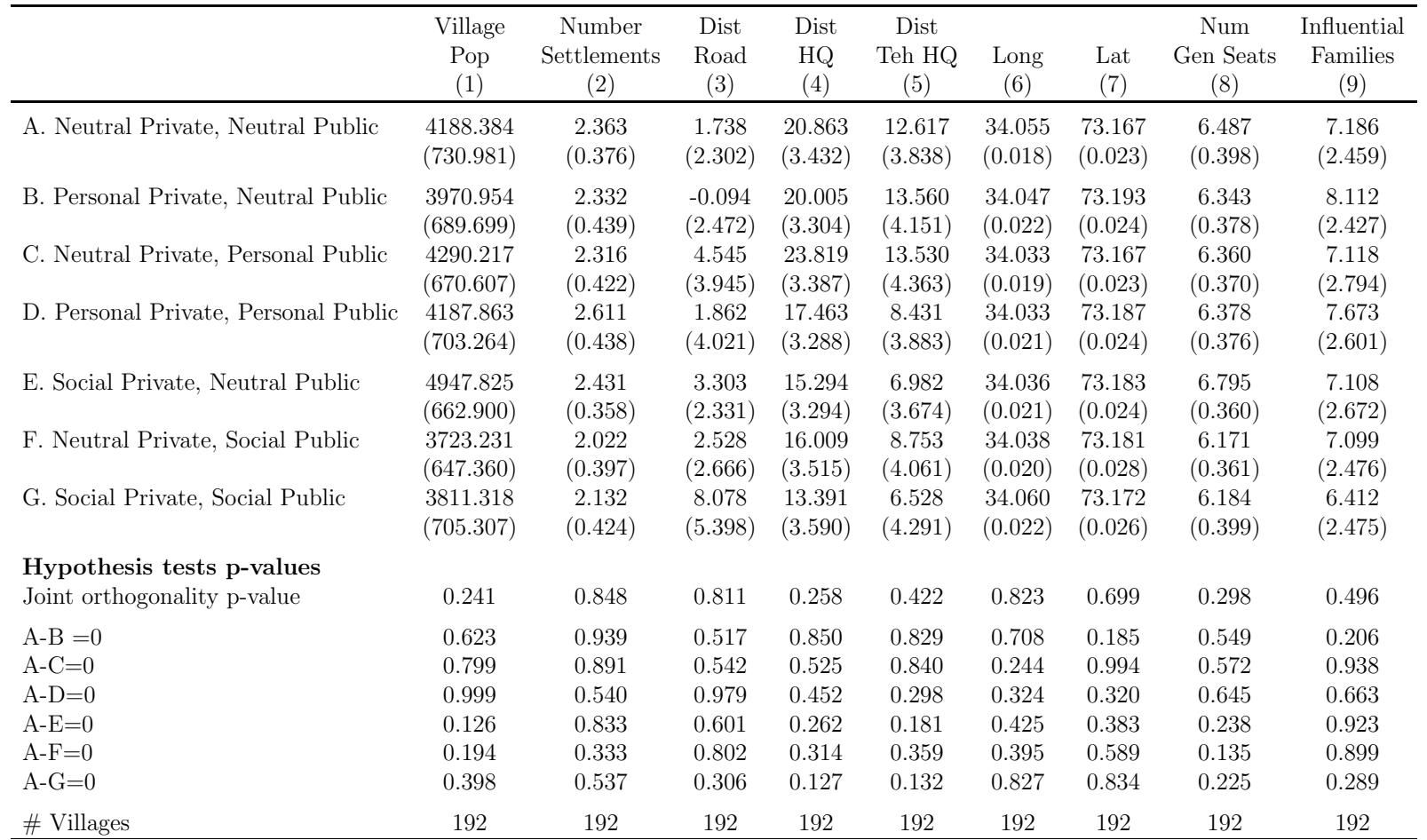

Notes: This table shows randomization balance by sub-treatment arms. The bottom part reports p-values comparing indicated coefficients. The joint orthogonality test checks if all coefficients are equal. All regressions include block fixed effects. Robust standard errors are reported in parentheses.

Table A5: Village Characteristics Balance for Main Treatments

\begin{tabular}{|c|c|c|c|c|c|c|c|c|c|}
\hline & $\begin{array}{l}\text { Village } \\
\text { Pop } \\
(1)\end{array}$ & $\begin{array}{c}\text { Number } \\
\text { Settlements } \\
(2)\end{array}$ & $\begin{array}{l}\text { Dist } \\
\text { Road } \\
(3)\end{array}$ & $\begin{array}{l}\text { Dist } \\
\text { HQ } \\
(4)\end{array}$ & $\begin{array}{c}\text { Dist } \\
\text { Teh HQ } \\
(5)\end{array}$ & $\begin{array}{l}\text { Long } \\
(6)\end{array}$ & $\begin{array}{l}\text { Lat } \\
(7)\end{array}$ & $\begin{array}{c}\text { Num } \\
\text { Gen Seats } \\
(8)\end{array}$ & $\begin{array}{l}\text { Influential } \\
\text { Families } \\
(9)\end{array}$ \\
\hline Social & $\begin{array}{l}3396.552 \\
(420.112)\end{array}$ & $\begin{array}{l}1.635 \\
(0.283)\end{array}$ & $\begin{array}{c}7.037 \\
(1.932)\end{array}$ & $\begin{array}{l}21.135 \\
(3.564)\end{array}$ & $\begin{array}{l}16.307 \\
(3.639)\end{array}$ & $\begin{array}{l}34.180 \\
(0.013)\end{array}$ & $\begin{array}{l}73.300 \\
(0.020)\end{array}$ & $\begin{array}{c}5.714 \\
(0.237)\end{array}$ & $\begin{array}{c}3.008 \\
(0.481)\end{array}$ \\
\hline Personal & $\begin{array}{l}3388.282 \\
(461.083)\end{array}$ & $\begin{array}{l}1.861 \\
(0.318)\end{array}$ & $\begin{array}{l}4.504 \\
(2.385)\end{array}$ & $\begin{array}{l}26.665 \\
(3.779)\end{array}$ & $\begin{array}{l}20.720 \\
(3.877)\end{array}$ & $\begin{array}{r}34.173 \\
(0.016)\end{array}$ & $\begin{array}{l}73.304 \\
(0.019)\end{array}$ & $\begin{array}{c}5.692 \\
(0.255)\end{array}$ & $\begin{array}{l}3.769 \\
(0.603)\end{array}$ \\
\hline Neutral & $\begin{array}{l}3426.920 \\
(499.068)\end{array}$ & $\begin{array}{l}1.804 \\
(0.347)\end{array}$ & $\begin{array}{l}4.134 \\
(2.600)\end{array}$ & $\begin{array}{l}27.098 \\
(4.665)\end{array}$ & $\begin{array}{l}21.498 \\
(4.574)\end{array}$ & $\begin{array}{l}34.190 \\
(0.017)\end{array}$ & $\begin{array}{l}73.289 \\
(0.022)\end{array}$ & $\begin{array}{l}5.819 \\
(0.272)\end{array}$ & $\begin{array}{c}3.322 \\
(0.646)\end{array}$ \\
\hline $\begin{array}{l}\text { Hypothesis tests p-values } \\
\text { Joint orthogonality p-value }\end{array}$ & 0.993 & 0.613 & 0.586 & 0.078 & 0.129 & 0.564 & 0.633 & 0.768 & 0.376 \\
\hline $\begin{array}{l}\text { Social }- \text { Personal }=0 \\
\text { Social }- \text { Neutral }=0 \\
\text { Personal }- \text { Neutral }=0\end{array}$ & $\begin{array}{l}0.977 \\
0.928 \\
0.905\end{array}$ & $\begin{array}{l}0.342 \\
0.540 \\
0.842\end{array}$ & $\begin{array}{l}0.397 \\
0.341 \\
0.899\end{array}$ & $\begin{array}{l}0.032 \\
0.141 \\
0.911\end{array}$ & $\begin{array}{l}0.076 \\
0.125 \\
0.820\end{array}$ & $\begin{array}{l}0.592 \\
0.541 \\
0.290\end{array}$ & $\begin{array}{l}0.741 \\
0.494 \\
0.339\end{array}$ & $\begin{array}{l}0.890 \\
0.573 \\
0.478\end{array}$ & $\begin{array}{l}0.165 \\
0.589 \\
0.504\end{array}$ \\
\hline \# Villages & 192 & 192 & 192 & 192 & 192 & 192 & 192 & 192 & 192 \\
\hline
\end{tabular}

Notes: This table shows randomization balance by main treatments. The bottom part reports p-values comparing indicated coefficients. The joint orthogonality test checks if all coefficients are equal. All regressions include block fixed effects. Robust standard errors are reported in parentheses. 
Table A6: Individual Characteristics Balance for Sub Treatments

\begin{tabular}{lccccc}
\hline & $\begin{array}{c}\text { Prosocial Type } \\
\text { High }\end{array}$ & $\begin{array}{c}\text { Perceived } \\
\text { Electability } \\
(1)\end{array}$ & $\begin{array}{c}\text { Perceived } \\
\text { Affordability } \\
\end{array}$ & $\begin{array}{c}\text { Leadership } \\
\text { Experience } \\
(3)\end{array}$ & $\begin{array}{c}\text { Main } \\
\text { Castes } \\
(5)\end{array}$ \\
\hline A. Neutral Private, Neutral Public & 0.543 & 0.299 & 0.342 & 0.006 & 0.772 \\
& $(0.062)$ & $(0.023)$ & $(0.061)$ & $(0.005)$ & $(0.082)$ \\
B. Personal Private, Neutral Public & 0.497 & 0.275 & 0.347 & 0.005 & 0.810 \\
& $(0.066)$ & $(0.023)$ & $(0.061)$ & $(0.005)$ & $(0.086)$ \\
C. Neutral Private, Personal Public & 0.518 & 0.301 & 0.386 & 0.008 & 0.795 \\
& $(0.060)$ & $(0.027)$ & $(0.066)$ & $(0.005)$ & $(0.085)$ \\
D. Personal Private, Personal Public & 0.487 & 0.295 & 0.400 & 0.016 & 0.760 \\
& $(0.068)$ & $(0.024)$ & $(0.063)$ & $(0.006)$ & $(0.086)$ \\
E. Social Private, Neutral Public & 0.422 & 0.290 & 0.386 & 0.012 & 0.764 \\
& $(0.063)$ & $(0.024)$ & $(0.064)$ & $(0.006)$ & $(0.083)$ \\
F. Neutral Private, Social Public & 0.559 & 0.285 & 0.392 & 0.009 & 0.644 \\
& $(0.069)$ & $(0.026)$ & $(0.063)$ & $(0.005)$ & $(0.098)$ \\
G. Social Private, Social Public & 0.537 & 0.294 & 0.398 & 0.008 & 0.793 \\
& $(0.071)$ & $(0.024)$ & $(0.069)$ & $(0.005)$ & $(0.088)$ \\
Hypothesis tests p-values & & & & & \\
Joint orthogonality p-value & 0.104 & 0.399 & 0.736 & 0.266 & 0.208 \\
A-B =0 & 0.350 & 0.026 & 0.905 & 0.943 & 0.486 \\
A-C=0 & 0.560 & 0.846 & 0.387 & 0.465 & 0.653 \\
A-D=0 & 0.262 & 0.781 & 0.169 & 0.036 & 0.818 \\
A-E=0 & 0.005 & 0.474 & 0.359 & 0.155 & 0.879 \\
A-F=0 & 0.778 & 0.379 & 0.271 & 0.227 & 0.025 \\
A-G=0 & 0.921 & 0.711 & 0.243 & 0.431 & 0.719 \\
\# Observations & 9310 & 9310 & 9310 & 9303 & 9310 \\
\hline
\end{tabular}

Notes: This table shows randomization balance by sub treatment arms. The bottom part reports p-values comparing indicated coefficients. The joint orthogonality test checks if all coefficients are equal. All regressions include block fixed effects. Robust standard errors are reported in parentheses.

\section{Table A7: Individual Characteristics Balance for Main Treatments}

\begin{tabular}{lccccc}
\hline & $\begin{array}{c}\text { Prosocial Type } \\
\text { High } \\
(1)\end{array}$ & $\begin{array}{c}\text { Perceived } \\
\text { Electability } \\
(2)\end{array}$ & $\begin{array}{c}\text { Perceived } \\
\text { Affordability } \\
(3)\end{array}$ & $\begin{array}{c}\text { Leadership } \\
\text { Experience } \\
(4)\end{array}$ & $\begin{array}{c}\text { Main } \\
\text { Castes } \\
(5)\end{array}$ \\
\hline Social & 0.338 & 0.240 & 0.391 & 0.010 & 0.676 \\
& $(0.076)$ & $(0.025)$ & $(0.061)$ & $(0.005)$ & $(0.076)$ \\
Personal & 0.334 & 0.241 & 0.377 & 0.010 & 0.730 \\
& $(0.073)$ & $(0.023)$ & $(0.062)$ & $(0.005)$ & $(0.073)$ \\
Neutral & 0.376 & 0.249 & 0.342 & 0.006 & 0.713 \\
& $(0.074)$ & $(0.023)$ & $(0.066)$ & $(0.006)$ & $(0.076)$ \\
Hypothesis tests p-values & & & & & \\
Joint orthogonality p-value & 0.469 & 0.532 & 0.380 & 0.206 & 0.322 \\
Social - Personal =0 & 0.896 & 0.920 & 0.626 & 0.996 & 0.137 \\
Social - Neutral =0 & 0.337 & 0.327 & 0.167 & 0.114 & 0.367 \\
Personal - Neutral =0 & 0.237 & 0.339 & 0.308 & 0.130 & 0.686 \\
\# Observations & 9310 & 9310 & 9310 & 9303 & 9310 \\
\hline
\end{tabular}

Notes: This table shows randomization balance by main treatments. The bottom part reports p-values comparing indicated coefficients. The joint orthogonality test checks if all coefficients are equal. All regressions include block fixed effects. Robust standard errors are reported in parentheses. 


\section{H Additional Results on Candidacy}

\section{H.1 Effects on Conditional Electoral Performance}

Table A8: Effects on Electoral Performance among Candidates

\begin{tabular}{lccc}
\hline & $\begin{array}{c}\text { Elect= } 1 \\
(1)\end{array}$ & $\begin{array}{c}\text { Vote Share } \\
(2)\end{array}$ & $\begin{array}{c}\text { Vote Rank } \\
(3)\end{array}$ \\
\hline Social Treatment & 0.011 & 0.004 & 0.594 \\
& $(0.064)$ & $(0.031)$ & $(0.572)$ \\
& {$[0.442]$} & {$[0.446]$} & {$[0.140]$} \\
Personal Treatment & -0.084 & 0.040 & -0.106 \\
& $(0.070)$ & $(0.053)$ & $(0.575)$ \\
& {$[0.108]$} & {$[0.167]$} & {$[0.431]$} \\
Neutral Mean & 0.571 & 0.220 & 3.443 \\
\# Villages & 102 & 102 & 102 \\
\# Observations & 290 & 290 & 290 \\
\hline Linear Restrictions & & & \\
Social vs Personal & 0.096 & -0.036 & 0.700 \\
& $(0.066)$ & $(0.046)$ & $(0.487)$ \\
& {$[0.103]$} & {$[0.221]$} & {$[0.113]$}
\end{tabular}

Notes: The table uses administrative data from Election Commission of Pakistan. The dependent variable in column 1 measures election to the village council conditional on candidacy. The dependent variable in column 2 is the vote share for a candidate from the experimental sample. For the ten out of 290 candidates in this sample who got elected unopposed, this variable is coded as 1. The dependent variable in column 3 conditions on candidacy in the experimental sample and codes the rank of the person in terms of vote share, where a lower value reflects a higher rank. Each regression uses block fixed effects. Robust Standard errors clustered at the village level are reported in parentheses. Exact p-values are reported in square brackets.

\section{H.2 Village level Effects on Candidate Pool Size}

Table A9: Effects on Number of Candidates at Village Level

\begin{tabular}{|c|c|c|c|c|c|c|}
\hline & $\begin{array}{c}\text { \# Total } \\
\text { Candidates } \\
(1) \\
\end{array}$ & $\begin{array}{c}\text { \# Candidates } \\
\text { Open Seats } \\
(2)\end{array}$ & $\begin{array}{c}\text { \# Candidates } \\
\text { Reserved Seats } \\
(3)\end{array}$ & $\begin{array}{l}\text { \# Candidates } \\
\text { Experimental } \\
\text { Sample Only } \\
(4) \\
\end{array}$ & $\begin{array}{c}\text { \# Candidates } \\
\text { Additional Public } \\
\text { Meeting Attendees } \\
(5)\end{array}$ & $\begin{array}{l}\text { \# Candidates } \\
\text { Rest of the } \\
\text { Village } \\
(6)\end{array}$ \\
\hline Social Treatment & $\begin{array}{c}0.920 \\
(0.981) \\
{[0.136]}\end{array}$ & $\begin{array}{c}0.416 \\
(0.462) \\
{[0.156]}\end{array}$ & $\begin{array}{c}0.504 \\
(0.671) \\
{[0.198]}\end{array}$ & $\begin{array}{c}0.451 \\
(0.385) \\
{[0.080]}\end{array}$ & $\begin{array}{l}-0.398 \\
(0.241) \\
{[0.034]}\end{array}$ & $\begin{array}{c}0.867 \\
(1.005) \\
{[0.163]}\end{array}$ \\
\hline Personal Treatment & $\begin{array}{l}-0.041 \\
(0.849) \\
{[0.478]}\end{array}$ & $\begin{array}{l}-0.068 \\
(0.411) \\
{[0.426]}\end{array}$ & $\begin{array}{c}0.027 \\
(0.592) \\
{[0.491]}\end{array}$ & $\begin{array}{l}-0.410 \\
(0.294) \\
{[0.113]}\end{array}$ & $\begin{array}{l}-0.098 \\
(0.259) \\
{[0.335]}\end{array}$ & $\begin{array}{c}0.468 \\
(0.841) \\
{[0.306]}\end{array}$ \\
\hline $\begin{array}{l}\text { Neutral Mean } \\
\text { \# Observations }\end{array}$ & $\begin{array}{c}19.083 \\
192\end{array}$ & $\begin{array}{c}8.917 \\
192\end{array}$ & $\begin{array}{c}10.167 \\
192\end{array}$ & $\begin{array}{c}1.458 \\
192\end{array}$ & $\begin{array}{c}1.000 \\
192\end{array}$ & $\begin{array}{c}16.625 \\
192\end{array}$ \\
\hline \multicolumn{7}{|l|}{ Linear Restrictions } \\
\hline Social vs Personal & $\begin{array}{l}0.961 \\
(0.824) \\
{[0.143]}\end{array}$ & $\begin{array}{l}0.483 \\
(0.407) \\
{[0.133]}\end{array}$ & $\begin{array}{c}0.477 \\
(0.571) \\
{[0.227]}\end{array}$ & $\begin{array}{c}0.861 \\
(0.326) \\
{[0.008]}\end{array}$ & $\begin{array}{l}-0.300 \\
(0.200) \\
{[0.094]}\end{array}$ & $\begin{array}{c}0.399 \\
(0.884) \\
{[0.338]}\end{array}$ \\
\hline
\end{tabular}

Notes: The table uses administrative data from Election Commission of Pakistan and matches the candidates across various samples. The dependent variable in column 1 is total number of candidates that appeared on ballot. Column 2 uses the total number of candidates who ran on open seats and column 3 uses number of candidates that ran on reserved seats as dependent variables. Column 4 shows effects on the total number of candidates who ran from the experimental sample. Column 5 does this for those outside the experimental sample who attended the public meeting. Column 6 reports the results for the rest of the village, those not part of the experimental sample and did not attend the public meeting. Each regression uses block fixed effects. Robust Standard errors are reported in parentheses. Exact p-values are reported in square brackets. 


\section{Table A10: Effects on Number of Candidates against Pure Control Villages}

\begin{tabular}{lc}
\hline & $\begin{array}{c}\text { \# Total } \\
\text { Candidates } \\
(1)\end{array}$ \\
\hline Social Treatment & 1.303 \\
& $(1.073)$ \\
& {$[0.102]$} \\
Personal Treatment & 0.360 \\
& $(0.969)$ \\
Neutral Treatment & $0.539]$ \\
& 0.409 \\
& {$[1.117)$} \\
Pure Control Mean & 18.479 \\
\# Villages & 240
\end{tabular}

Notes: The table uses administrative data from Election Commission of Pakistan and matches the candidates across various samples. The outcome is the number of candidates in that village. Each regression uses block fixed effects. Robust Standard errors are reported in parentheses. Exact p-values are reported in square brackets.

\section{Additional Results on Performance of Councils}

\section{I.1 Summary Statistics on Preferences and Budgets}

\section{Table A11: Citizen Preferences and Actual Spending in Neutral Villages}

\begin{tabular}{lccccc}
\hline \multicolumn{1}{c}{ Variable } & Mean (Percentage) & Std. Dev. & Min. & Max. & N \\
\hline Panel A: Avg. Preferences of Citizens in Neutral Villages & & \\
Municipal Services & 66.105 & 17.342 & 16 & 92 & 48 \\
Infrastructure & 22.588 & 16.054 & 0 & 84 & 48 \\
Community & 4.127 & 6.344 & 0 & 36.429 & 48 \\
Not Primary Responsibility & 7.18 & 9.449 & 0 & 40 & 48 \\
\hline Panel B: Actual Spending in Neutral Villages & & & & \\
Municipal Services & 29.59 & 25.982 & 0 & 100 & 46 \\
Infrastructure & 66.069 & 26.398 & 0 & 100 & 46 \\
Community & 2.476 & 5.821 & 0 & 30.769 & 46 \\
Not Primary Responsibility & 1.865 & 6.178 & 0 & 35 & 46
\end{tabular}

Notes: This table presents summary statistics in neutral villages of citizen preferences for village budget spending, as well as the actual spending by the village councils. Municipal Services include allocation to education, health, water, sewerage and waste disposal. Infrastructure includes construction and rehabilitation of roads, streets, and street lights. Community includes spending money on sports, graveyard, mosque, and the community center. Not Primary Responsibility includes provision of electricity, transport service, security, skills development, and a residual other category. Panel A reports the percentage of the village budget that citizens want to be spent on each category in pure control. Panel B is calculated from a village dataset that comprises actual budget allocations to each category, converted to percentages.

\section{I.2 Missing Data Analysis}




\section{Table A12: Budget Data Missingness Balance}

\begin{tabular}{lc}
\hline & $\begin{array}{c}\text { Budget Missing } \\
(1)\end{array}$ \\
\hline A. Neutral Canvass, Neutral Train & 0.092 \\
& $(0.082)$ \\
B. Personal Canvass, Neutral Train & 0.090 \\
& $(0.071)$ \\
C. Neutral Canvass, Personal Train & 0.050 \\
& $(0.061)$ \\
D. Personal Canvass, Personal Train & 0.048 \\
& $(0.061)$ \\
E. Social Canvass, Neutral Train & 0.053 \\
& $(0.064)$ \\
F. Neutral Canvass, Social Train & 0.050 \\
& $(0.061)$ \\
G. Social Canvass, Social Train & 0.050 \\
& $(0.061)$ \\
Hypothesis tests p-values & \\
Joint orthogonality p-value & 0.803 \\
A-B $=0$ & 0.961 \\
A-C $=0$ & 0.151 \\
A-D $=0$ & 0.150 \\
A-E $=0$ & 0.150 \\
A-F $=0$ & 0.149 \\
A-G $=0$ & 0.149 \\
\# Villages & 192 \\
m
\end{tabular}

Notes: This table checks for balance in missingness of data used in Table 2. The dependent variable takes a value of 1 if data is missing and zero otherwise. We are missing budget data from three villages out of a sample of 192. The regression uses robust standard errors reported in parentheses. All regressions include block fixed effects.

\section{Table A13: Policy Effects - Manski Bounds}

\begin{tabular}{lccc}
\hline & $\begin{array}{c}\text { Effects on Euclidean } \\
\text { Dist in Table 2 } \\
(1)\end{array}$ & $\begin{array}{c}\text { Best Case } \\
\text { Scenario } \\
(2)\end{array}$ & $\begin{array}{c}\text { Worst Case } \\
\text { Scenario } \\
(3)\end{array}$ \\
\hline Social Treatment & -7.039 & -7.570 & -7.356 \\
& $(5.615)$ & $(5.489)$ & $(5.496)$ \\
Personal Treatment & {$[0.080]$} & {$[0.070]$} & {$[0.072]$} \\
& 2.361 & 2.858 & 1.121 \\
Neutral Mean & $(5.212)$ & $(5.120)$ & $(5.104)$ \\
\# Villages & {$[0.322]$} & {$[0.298]$} & {$[0.412]$} \\
\hline \multirow{2}{*}{ Linear Restrictions } & 68 & 68 & 68 \\
Social Vs Personal & 189 & 192 & 192 \\
& & & \\
& -9.400 & -10.428 & -8.477 \\
& $(4.810)$ & $(4.877)$ & $(4.841)$ \\
& {$[0.040]$} & {$[0.026]$} & {$[0.057]$}
\end{tabular}

Notes: This table uses Manski bounds to assess the best and worst case scenarios for missing budget data. The table uses a village level dataset that is constructed based on official budget data from the councils and the preferences of citizens regarding the budget. Each column is a dependent variable that is defined as quadratic distance between the preferences of citizens regarding the category of budget mentioned in the column header and the actual spending by the council. The distance is calculated using the formula $j \in J$ by $\sqrt{\left(B_{j}-\bar{C}_{j}\right)^{2}}$, where $B_{j}$ refers to the percentage of the budget spent on $j$ and $\bar{C}_{j}$ is the average of citizen preferences for spending on that category. The overall difference in column (1) is calculated using the formula: $\sqrt{\sum_{J}\left(B_{j}-\bar{C}_{j}\right)^{2}}$. In columns 2 and 3, we replace the missing budget observations in the Neutral villages with the mean of the neutral group and define the best and worst case scenario for comparisons between Social and Personal villages. For the calculation of the best-case scenario in column 2, we replace the overall distance for any social villages that are missing the budget information with the minimum observed value of the overall distance. For personal villages, we replace missing information with the maximum value. For the worst-case scenario reported in column 3, we replace the former with the maximum and the latter with the minimum value. Each regression uses block fixed effects. Robust standard errors are reported in parentheses and exact p-values are reported in square brackets. 


\section{I.3 Policy Effects on Extensive Margin}

Table A14: Extensive Margin of Performance - Total Resources

\begin{tabular}{lcc}
\hline & $\begin{array}{c}\text { Total Resources (in Rs.) } \\
(1)\end{array}$ & $\begin{array}{c}\log (\text { Total Resources) } \\
(2)\end{array}$ \\
\hline Social Treatment & 99383.769 & 0.050 \\
& $(1.72 \mathrm{e}+05)$ & $(0.078)$ \\
Personal Treatment & {$[0.260]$} & {$[0.231]$} \\
& $1.09 \mathrm{e}+05$ & 0.044 \\
Neutral Mean & $(1.60 \mathrm{e}+05)$ & $(0.073)$ \\
\# Observations & {$[0.238]$} & {$[0.267]$} \\
\hline \multirow{2}{*}{ Linear Restrictions } & $2.28 \mathrm{e}+06$ & 14.535 \\
Social vs Personal & 189 & 189 \\
& & \\
& -9762.895 & 0.007 \\
& $(1.45 \mathrm{e}+05)$ & $(0.065)$ \\
& {$[0.483]$} & {$[0.452]$}
\end{tabular}

Notes: This table presents the effect of treatments on extensive margin of total resources available to Village Councils. Dependent variable in column 1 is total amount of budget allocated to the village council in Pakistani Rupees, and the dependent variable in column 2 is $\log$ of Pakistani rupees column 2. Each regression uses block fixed effects, robust standard errors reported in parentheses and the exact p-value are reported in brackets.

\section{Table A15: Effect on Linear Distance between Budgetary Spending and Citizen Preferences (in 1,000 Rupees)}

\begin{tabular}{|c|c|c|c|c|c|}
\hline & $\begin{array}{c}\text { Total } \\
\text { Distance } \\
(1)\end{array}$ & $\begin{array}{c}\text { Municipal } \\
(2)\end{array}$ & $\begin{array}{c}\text { Infrastructure } \\
(3) \\
\end{array}$ & $\begin{array}{c}\text { Community } \\
(4)\end{array}$ & $\begin{array}{c}\text { Not Primary } \\
\text { Responsibility } \\
(5)\end{array}$ \\
\hline Social Treatment & $\begin{array}{c}-116.363 \\
(289.839) \\
{[0.319]}\end{array}$ & $\begin{array}{c}-125.297 \\
(127.615) \\
{[0.134]}\end{array}$ & $\begin{array}{c}-44.483 \\
(145.047) \\
{[0.360]}\end{array}$ & $\begin{array}{c}20.324 \\
(29.880) \\
{[0.250]}\end{array}$ & $\begin{array}{c}33.093 \\
(49.516) \\
{[0.301]}\end{array}$ \\
\hline Personal Treatment & $\begin{array}{c}264.052 \\
(286.301) \\
{[0.158]}\end{array}$ & $\begin{array}{c}22.479 \\
(124.285) \\
{[0.421]}\end{array}$ & $\begin{array}{c}117.710 \\
(142.012) \\
{[0.191]}\end{array}$ & $\begin{array}{c}15.229 \\
(29.935) \\
{[0.296]}\end{array}$ & $\begin{array}{c}108.633 \\
(58.032) \\
{[0.040]}\end{array}$ \\
\hline $\begin{array}{l}\text { Neutral Mean } \\
\text { \# Observations }\end{array}$ & $\begin{array}{c}2339.281 \\
189\end{array}$ & $\begin{array}{c}985.441 \\
189 \\
\end{array}$ & $\begin{array}{c}1083.658 \\
189 \\
\end{array}$ & $\begin{array}{c}106.427 \\
189 \\
\end{array}$ & $\begin{array}{c}163.755 \\
189 \\
\end{array}$ \\
\hline \multicolumn{6}{|l|}{$\underline{\text { Linear Restrictions }}$} \\
\hline Social vs Personal & $\begin{array}{c}-380.415 \\
(237.021) \\
{[0.088]}\end{array}$ & $\begin{array}{c}-147.776 \\
(104.330) \\
{[0.108]}\end{array}$ & $\begin{array}{c}-162.193 \\
(120.046) \\
{[0.120]}\end{array}$ & $\begin{array}{c}5.095 \\
(28.083) \\
{[0.434]}\end{array}$ & $\begin{array}{c}-75.540 \\
(61.118) \\
{[0.134]}\end{array}$ \\
\hline
\end{tabular}

Notes: This table uses a village level dataset. The dependent variable in each column is defined as the linear absolute distance between citizen preferences and actual spending by the council in thousands of rupees. Each regression uses block fixed effects. Robust standard errors are reported in parentheses and exact p-values are reported in square brackets. 


\section{Table A16: Overtime Policy Alignment in District Haripur}

\begin{tabular}{|c|c|c|c|c|c|}
\hline & $\begin{array}{c}\text { Total } \\
\text { Distance } \\
(1)\end{array}$ & $\begin{array}{c}\text { Municipal } \\
(2)\end{array}$ & $\begin{array}{c}\text { Infrastructure } \\
(3)\end{array}$ & $\begin{array}{l}\text { Community } \\
(4)\end{array}$ & $\begin{array}{c}\text { Not Primary } \\
\text { Responsibility } \\
(5)\end{array}$ \\
\hline \multicolumn{6}{|c|}{ Panel A: 2016 Budget for Haripur District } \\
\hline Social Treatment & $\begin{array}{c}-12.521 \\
(8.720) \\
{[0.052]}\end{array}$ & $\begin{array}{c}-10.572 \\
(6.578) \\
{[0.035]}\end{array}$ & $\begin{array}{l}-9.725 \\
(6.781) \\
{[0.050]}\end{array}$ & $\begin{array}{c}2.151 \\
(1.733) \\
{[0.100]}\end{array}$ & $\begin{array}{c}1.421 \\
(2.255) \\
{[0.345]}\end{array}$ \\
\hline Personal Treatment & $\begin{array}{l}-2.432 \\
(8.522) \\
{[0.376]}\end{array}$ & $\begin{array}{l}-6.309 \\
(6.485) \\
{[0.136]}\end{array}$ & $\begin{array}{l}-2.238 \\
(6.591) \\
{[0.345]}\end{array}$ & $\begin{array}{c}0.382 \\
(1.360) \\
{[0.393]}\end{array}$ & $\begin{array}{c}8.473 \\
(3.122) \\
{[0.003]}\end{array}$ \\
\hline $\begin{array}{l}\text { Neutral Mean } \\
\text { \# Observations }\end{array}$ & $\begin{array}{c}67.791 \\
82 \\
\end{array}$ & $\begin{array}{c}44.710 \\
82 \\
\end{array}$ & $\begin{array}{c}48.247 \\
82 \\
\end{array}$ & $\begin{array}{c}4.287 \\
82 \\
\end{array}$ & $\begin{array}{c}6.677 \\
82 \\
\end{array}$ \\
\hline Social vs Personal & $\begin{array}{c}-10.089 \\
(7.064) \\
{[0.110]}\end{array}$ & $\begin{array}{l}-4.264 \\
(5.522) \\
{[0.249]}\end{array}$ & $\begin{array}{l}-7.487 \\
(5.660) \\
{[0.128]}\end{array}$ & $\begin{array}{c}1.770 \\
(1.621) \\
{[0.163]}\end{array}$ & $\begin{array}{l}-7.052 \\
(3.154) \\
{[0.021]}\end{array}$ \\
\hline \multicolumn{6}{|c|}{ Panel B: 2017 Budget for Haripur District } \\
\hline Social Treatment & $\begin{array}{c}-13.154 \\
(8.732) \\
{[0.048]}\end{array}$ & $\begin{array}{l}-7.521 \\
(6.757) \\
{[0.117]}\end{array}$ & $\begin{array}{l}-13.367 \\
(6.888) \\
{[0.016]}\end{array}$ & $\begin{array}{c}0.938 \\
(2.379) \\
{[0.314]}\end{array}$ & $\begin{array}{c}1.834 \\
(2.829) \\
{[0.314]}\end{array}$ \\
\hline Personal Treatment & $\begin{array}{l}-0.138 \\
(8.619) \\
{[0.489]}\end{array}$ & $\begin{array}{l}-0.567 \\
(6.794) \\
{[0.464]}\end{array}$ & $\begin{array}{l}-3.707 \\
(6.785) \\
{[0.282]}\end{array}$ & $\begin{array}{l}-1.669 \\
(2.115) \\
{[0.203]}\end{array}$ & $\begin{array}{l}10.086 \\
(3.556) \\
{[0.002]}\end{array}$ \\
\hline $\begin{array}{l}\text { Neutral Mean } \\
\text { \# Observations }\end{array}$ & $\begin{array}{c}63.075 \\
79 \\
\end{array}$ & $\begin{array}{c}38.656 \\
79 \\
\end{array}$ & $\begin{array}{c}44.769 \\
79 \\
\end{array}$ & $\begin{array}{c}5.850 \\
79 \\
\end{array}$ & $\begin{array}{c}7.811 \\
79 \\
\end{array}$ \\
\hline \multicolumn{6}{|l|}{$\underline{\text { Linear Restrictions }}$} \\
\hline Social vs Personal & $\begin{array}{l}-13.016 \\
(7.104) \\
{[0.061]}\end{array}$ & $\begin{array}{l}-6.954 \\
(5.868) \\
{[0.148]}\end{array}$ & $\begin{array}{l}-9.660 \\
(5.855) \\
{[0.077]}\end{array}$ & $\begin{array}{c}2.606 \\
(1.902) \\
{[0.104]}\end{array}$ & $\begin{array}{l}-8.251 \\
(3.569) \\
{[0.014]}\end{array}$ \\
\hline
\end{tabular}

Notes: This table uses a village level dataset that is constructed based on official budget data of 2016 and 2017 from the councils and the preferences of citizens regarding the budget in the Haripur district. The dependent variable in each column is defined as the quadratic distance between citizen preferences and actual spending by the council. The distance for each category is calculated using the formula $\sqrt{\left(B_{j i}-\bar{C}_{j i}\right)^{2}}$, where $B_{j i}$ refers to the percentage of the budget spent on category $j$ in village $i$ and $\bar{C}_{j i}$ is the average of citizen preferences for spending on that category in village $i$. The overall difference in column (1) is calculated using the formula: $\sqrt{\sum_{J}\left(B_{j i}-\bar{C}_{j i}\right)^{2}}$. Each regression uses block fixed effects. Robust standard errors are reported in parentheses and exact p-values are reported in square brackets. 


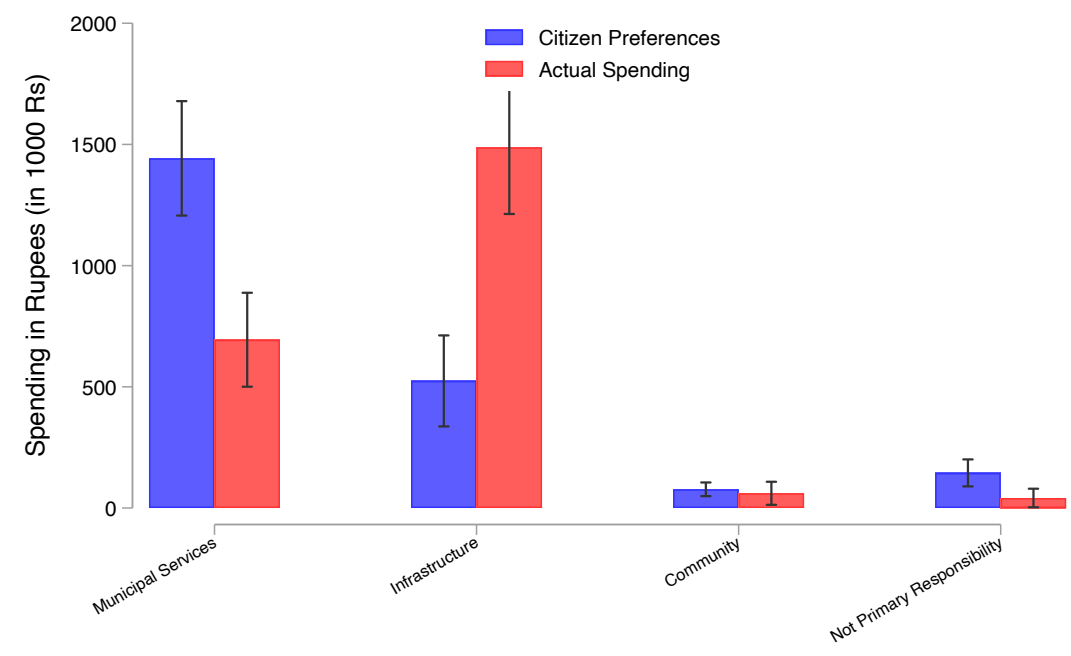

Figure A1: Citizen Preferences and Council Spending in Neutral Villages in Rupees

Notes: This figure shows the budget allocated by citizens to different categories in a hypothetical exercise against the allocations by elected councils in the actual annual budget of 2016 in Neutral Villages. Error bars report the $95 \%$ confidence interval.

\section{Table A17: Policy Effects by tightness of Citizen Preferences}

\begin{tabular}{lccc}
\hline & $\begin{array}{c}\text { Low Dispersion } \\
(1)\end{array}$ & $\begin{array}{c}\text { High Dispersion } \\
(2)\end{array}$ & $\begin{array}{c}\text { High vs Low } \\
(3)\end{array}$ \\
\hline Social Treatment & -9.804 & -3.757 & 5.502 \\
& $(8.467)$ & $(6.792)$ & $(10.812)$ \\
& {$[0.122]$} & {$[0.279]$} & {$[0.303]$} \\
Personal Treatment & 4.107 & 4.709 & 1.051 \\
& $(9.183)$ & $(6.023)$ & $(10.626)$ \\
& {$[0.322]$} & {$[0.231]$} & {$[0.447]$} \\
Neutral Mean & 68.911 & 66.532 & \\
\# Observations & 95 & 94 & 189 \\
\hline \multirow{2}{*}{ Linear Restrictions } & & & \\
Social vs Personal & -13.911 & -8.465 & 4.451 \\
& $(8.225)$ & $(6.206)$ & $(9.836)$ \\
& {$[0.064]$} & {$[0.114]$} & {$[0.377]$}
\end{tabular}

Notes: This table uses a village level dataset. The dependent variable in each column is the Euclidean distance between official budgets and citizen preferences. The first column restricts the data to villages where the sum of standard deviation of citizen preferences for the village across the four policy domains (municipal, infrastructure, community, and not primary responsibility) is lower than or equal to the median, that is the distribution of citizen policy preference is tighter in these villages. Column 2 restricts the data to villages where the dispersion is greater than the median. Column 3 reports the difference between the two from one regression. 


\section{I.4 Treatments improve citizens satisfaction with chosen policy}

Table A18: Citizen Satisfaction and Trust

\begin{tabular}{|c|c|c|c|c|}
\hline & $\begin{array}{l}\text { Satisfaction with } \\
\text { Projects Chosen } \\
\text { by Politicians } \\
(1)\end{array}$ & $\begin{array}{l}\text { Trust } \\
\text { in State } \\
\text { Index } \\
(2)\end{array}$ & $\begin{array}{c}\text { Doesn't Hold } \\
\text { Negative View } \\
\text { of Politics } \\
(3)\end{array}$ & $\begin{array}{c}\text { Trusts } \\
\text { Public Servants } \\
(4)\end{array}$ \\
\hline \multicolumn{5}{|c|}{ Panel A: Outcome Dichotomized (=1> median) } \\
\hline Social Treatment & $\begin{array}{c}0.070 \\
(0.094) \\
{[0.207]}\end{array}$ & $\begin{array}{c}0.105 \\
(0.098) \\
{[0.114]}\end{array}$ & $\begin{array}{c}0.074 \\
(0.092) \\
{[0.197]}\end{array}$ & $\begin{array}{c}0.070 \\
(0.085) \\
{[0.203]}\end{array}$ \\
\hline Personal Treatment & $\begin{array}{l}-0.103 \\
(0.093) \\
{[0.127]}\end{array}$ & $\begin{array}{l}-0.016 \\
(0.091) \\
{[0.420]}\end{array}$ & $\begin{array}{l}-0.048 \\
(0.088) \\
{[0.293]}\end{array}$ & $\begin{array}{l}-0.026 \\
(0.087) \\
{[0.384]}\end{array}$ \\
\hline $\begin{array}{l}\text { Neutral Mean } \\
\text { \# Observations }\end{array}$ & $\begin{array}{c}0.500 \\
192\end{array}$ & $\begin{array}{c}1.652 \\
192\end{array}$ & $\begin{array}{c}0.354 \\
192\end{array}$ & $\begin{array}{c}0.604 \\
192\end{array}$ \\
\hline \multicolumn{5}{|l|}{$\underline{\text { Linear Restrictions }}$} \\
\hline Social vs Personal & $\begin{array}{c}0.173 \\
(0.083) \\
{[0.037]}\end{array}$ & $\begin{array}{c}0.121 \\
(0.082) \\
{[0.094]}\end{array}$ & $\begin{array}{c}0.122 \\
(0.082) \\
{[0.075]}\end{array}$ & $\begin{array}{c}0.096 \\
(0.078) \\
{[0.130]}\end{array}$ \\
\hline \multicolumn{5}{|c|}{ Panel B: Outcome in Likert Scale (1-5) } \\
\hline Social Treatment & $\begin{array}{l}-0.007 \\
(0.085) \\
{[0.467]}\end{array}$ & $\begin{array}{c}0.082 \\
(0.105) \\
{[0.196]}\end{array}$ & $\begin{array}{l}-0.255 \\
(0.248) \\
{[0.128]}\end{array}$ & $\begin{array}{c}0.023 \\
(0.127) \\
{[0.441]}\end{array}$ \\
\hline Personal Treatment & $\begin{array}{l}-0.129 \\
(0.089) \\
{[0.064]}\end{array}$ & $\begin{array}{l}-0.036 \\
(0.099) \\
{[0.355]}\end{array}$ & $\begin{array}{l}-0.384 \\
(0.246) \\
{[0.042]}\end{array}$ & $\begin{array}{l}-0.067 \\
(0.134) \\
{[0.302]}\end{array}$ \\
\hline $\begin{array}{l}\text { Neutral Mean } \\
\text { \# Observations }\end{array}$ & $\begin{array}{c}4.102 \\
188\end{array}$ & $\begin{array}{c}2.569 \\
192\end{array}$ & $\begin{array}{c}2.875 \\
192\end{array}$ & $\begin{array}{c}2.438 \\
192\end{array}$ \\
\hline \multicolumn{5}{|l|}{$\underline{\text { Linear Restrictions }}$} \\
\hline Social vs Personal & $\begin{array}{c}0.122 \\
(0.076) \\
{[0.077]}\end{array}$ & $\begin{array}{l}0.118 \\
(0.093) \\
{[0.126]}\end{array}$ & $\begin{array}{c}0.129 \\
(0.212) \\
{[0.295]}\end{array}$ & $\begin{array}{c}0.089 \\
(0.122) \\
{[0.262]}\end{array}$ \\
\hline
\end{tabular}

Notes: Each regression uses block fixed effects. This table uses data from citizen surveys collated at the village council level. Dependent variable in column 1 is above the median citizen approval of development projects. Citizens were asked to rank each project on a five point Likert scale. This information was used to first calculate village level approval ratings then create a dichotomized variable by using the median approval rating across village councils. Column 2 uses a mean index of columns 3 and 4 as a dependent variable. Column 3 uses disagreement of citizens with a negative statement about politics, as a dependent variable. Citizen respond on five points Likert scale to the statement 'Politics is a dirty word'. The responses are first averaged at the village level. A dichotomous variable is constructed that takes a value of one if citizens disagree with the statement and zero otherwise. Column 4 uses responses of citizens to an imaginary scenario about losing their wallet. They are asked separately to rank on a five point Likert scale a policeman and a government servant's likelihood to return the wallet. These responses are averaged at the village level, then dichotomized on median. A dichotomous variable of trust variable is created if the average response is above median on either of the two statements. Robust standard errors are reported in parentheses. Exact p-values are in square brackets. 


\section{J Robustness of Main Effects}

\section{J.1 Dropping one village at a time}
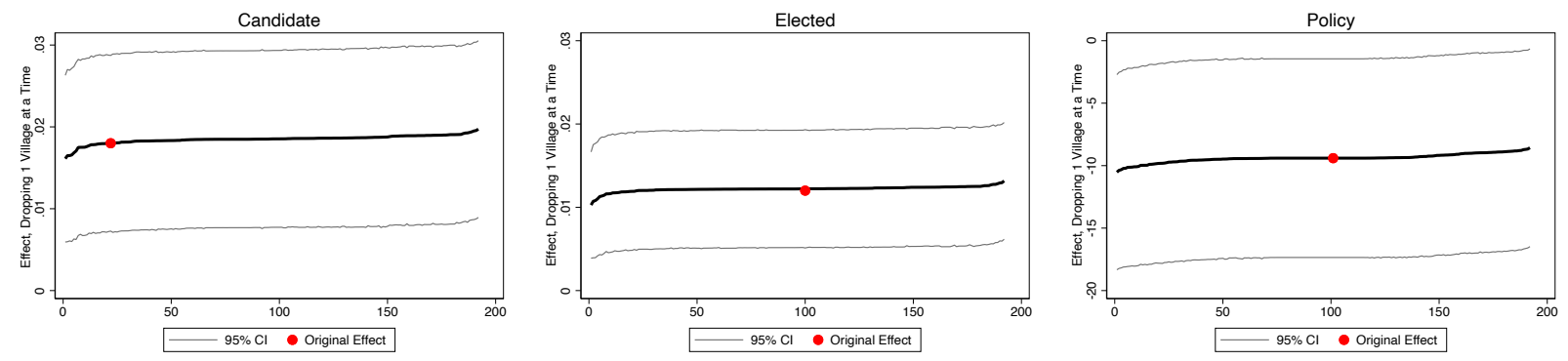

Figure A2: Effects after dropping one village at a time

Notes: This figure shows the sensitivity of treatment effects to dropping one village at a time. The x-axis indexes each regression in an ascending order of the overall treatment effect after a village is dropped. Since we have 192 villages in the sample, we run 192 simulations.

\section{J.2 Adding controls}

Table A19: Candidacy and Election Effects with Controls

\begin{tabular}{lcccc}
\hline & $\begin{array}{c}\text { Filed } \\
\text { Papers } \\
(1)\end{array}$ & $\begin{array}{c}\text { Elected } \\
\text { to Council } \\
(2)\end{array}$ & $\begin{array}{c}\text { Filed } \\
\text { Papers } \\
(3)\end{array}$ & $\begin{array}{c}\text { Elected } \\
\text { to Council } \\
(4)\end{array}$ \\
\hline Social Treatment & 0.009 & 0.004 & 0.009 & 0.004 \\
& $(0.007)$ & $(0.005)$ & $(0.007)$ & $(0.004)$ \\
& {$[0.089]$} & {$[0.150]$} & {$[0.087]$} & {$[0.192]$} \\
Personal Treatment & -0.008 & -0.006 & -0.008 & -0.007 \\
& $(0.006)$ & $(0.003)$ & $(0.006)$ & $(0.004)$ \\
& {$[0.132]$} & {$[0.066]$} & {$[0.134]$} & {$[0.053]$} \\
Neutral Mean & 0.030 & 0.017 & 0.030 & 0.017 \\
\# Villages & 192 & 192 & 192 & 192 \\
\# Observations & 9303 & 9303 & 9303 & 9303 \\
Imbalanced Controls & $\checkmark$ & $\checkmark$ & - & - \\
All Controls & - & - & $\checkmark$ & $\checkmark$ \\
\hline Linear Restrictions & & & & \\
Social vs Personal & 0.017 & 0.011 & 0.017 & 0.011 \\
& $(0.006)$ & $(0.004)$ & $(0.006)$ & $(0.004)$ \\
& {$[0.011]$} & {$[0.009]$} & {$[0.011]$} & {$[0.010]$}
\end{tabular}

Notes: This table reports the robustness of the main results to the inclusion of controls. Columns 1 and 2 include controls for distance to headquarters, distance to tehsil headquarters, high prosocial types, perceived electability, perceived affordability, leadership experience and main castes. Columns 3 and 4 include controls for village populations, number of settlements, distance to road, distance to headquarters, distance to tehsil headquarters, longitude, latitude, number of general seats, number of influential families, high prosocial type, perceived electability, perceived affordability, leadership experience, and main caste. Each regression also uses block fixed effects. Standard errors are clustered at the village level and reported in parentheses. Exact p-values are in square brackets. 


\section{Table A20: Policy Effects with Controls}

\begin{tabular}{|c|c|c|}
\hline & $\begin{array}{l}\text { Policy } \\
\text { Euclidean } \\
\text { Distance } \\
(1) \\
\end{array}$ & $\begin{array}{c}\text { Policy } \\
\text { Euclidean } \\
\text { Distance } \\
(2) \\
\end{array}$ \\
\hline Social Treatment & $\begin{array}{l}-7.036 \\
(5.599) \\
{[0.079]}\end{array}$ & $\begin{array}{l}-5.937 \\
(5.627) \\
{[0.122]}\end{array}$ \\
\hline Personal Treatment & $\begin{array}{c}2.275 \\
(5.193) \\
{[0.327]}\end{array}$ & $\begin{array}{c}2.212 \\
(5.191) \\
{[0.331]}\end{array}$ \\
\hline $\begin{array}{l}\text { Neutral Mean } \\
\text { \# Villages } \\
\text { \# Observations } \\
\text { Imbalanced Controls } \\
\text { All Controls }\end{array}$ & $\begin{array}{c}67.877 \\
189 \\
\checkmark \\
-\end{array}$ & $\begin{array}{c}67.877 \\
189 \\
- \\
\checkmark\end{array}$ \\
\hline \multicolumn{3}{|l|}{ Linear Restrictions } \\
\hline Social vs Personal & $\begin{array}{l}-9.312 \\
(4.737) \\
{[0.041]}\end{array}$ & $\begin{array}{l}-8.149 \\
(4.811) \\
{[0.069]}\end{array}$ \\
\hline
\end{tabular}

Notes: This table reports the robustness of the main results to the inclusion of controls. Columns 1 includes controls for distance to headquarters and distance to tehsil headquarters. Columns 2 includes controls for village population, number of settlements, distance to road, distance to headquarters, distance to tehsil headquarters, longitude, latitude, number of general seats, number of influential families. Each regression also uses block fixed effects. Standard errors are clustered at the village level and reported in parentheses. Exact p-values are in square brackets.

\section{Table A21: Effects on Candidacy and Election with Order of Approach FEs}

\begin{tabular}{lcc}
\hline & & \\
& $\begin{array}{c}\text { Candidate } \\
(1)\end{array}$ & $\begin{array}{c}\text { Elected } \\
\text { to Council } \\
(3)\end{array}$ \\
\hline Social Treatment & 0.009 & 0.005 \\
& $(0.008)$ & $(0.005)$ \\
Personal Treatment & {$[0.093]$} & {$[0.122]$} \\
& -0.010 & -0.007 \\
Neutral Mean & $(0.006)$ & $(0.003)$ \\
\# Villages & {$[0.071]$} & {$[0.048]$} \\
\# Observations & 0.030 & 0.017 \\
\hline Linear Restrictions & 192 & 192 \\
Social vs Personal & 9310 & 9310 \\
& & \\
& 0.019 & 0.013 \\
& $(0.007)$ & $(0.004)$ \\
& {$[0.006]$} & {$[0.005]$}
\end{tabular}

Notes: This table shows the robustness of main result to the inclusion of fixed effects for the order in which a given subject in the experimental sample was approached by an enumerator. Each regression also uses block fixed effects. Standard errors are clustered at the village level and reported in parentheses. Exact p-values are in square brackets. 


\section{J.3 Adding enumerator fixed effects}

Table A22: Candidacy, Election, and Policy Effects with Enumerator Fixed Effects

\begin{tabular}{lccc}
\hline & $\begin{array}{c}\text { Filed } \\
\text { Papers } \\
(1)\end{array}$ & $\begin{array}{c}\text { Elected } \\
\text { to Council } \\
(2)\end{array}$ & $\begin{array}{c}\text { Policy } \\
\text { Euclidean } \\
\text { Distance } \\
(3)\end{array}$ \\
\hline Social Treatment & 0.005 & 0.002 & -6.930 \\
& $(0.008)$ & $(0.005)$ & $(6.425)$ \\
Personal Treatment & {$[0.251]$} & {$[0.338]$} & {$[0.120]$} \\
& -0.010 & -0.009 & 4.653 \\
Neutral Mean & $(0.007)$ & $(0.004)$ & $(5.765)$ \\
\# Village & $0.104]$ & {$[0.029]$} & {$[0.209]$} \\
\# Observations & 192 & 0.017 & 67.877 \\
\hline \multirow{2}{*}{ Linear Restrictions } & & 192 & 189 \\
Social vs Personal & 0.015 & 9310 & 189 \\
& $0.007)$ & 0.011 & \\
& {$[0.038]$} & {$[0.005)$} & -11.584 \\
\end{tabular}

Notes: This table reports the robustness of the main results to the inclusion of enumerator fixed effects. Each regression also uses block fixed effects. Standard errors are clustered at the village level and reported in parentheses. Exact p-values are in square brackets.

\section{K Stylized Framework}

Citizens decide to become politicians for primarily two non-pecuniary reasons - they either want to derive personal benefits, such as ego rents via prestige and status from political office or they may want to help others, that is, social benefits. We assume that agents have prosocial preferences, $v_{s}$, and non-prosocial preferences, $v_{y}$ (Bénabou and Tirole 2006). Further, they have private beliefs over what kind of benefits the political office can provide, $\hat{b} \in 0,1$, where 0 stands for personal benefits and 1 denotes prosocial benefits. Once elected, agents can take policy decisions, $a \in 0,1$, where 1 reflects a prosocial policy (for example, budget spending aligned with the citizen preferences) and 0 denotes non-prosocial policy decision. The agents' intrinsic utility from political office is $\hat{b}\left(v_{s}\right) a+(1-\hat{b}) v_{y}(1-a)$.

In addition to the intrinsic utility, people may also draw extrinsic utility $\left(U_{\bar{b}, a}\right)$. This extrinsic utility of a person can come from multiple sources, for example, community members could encourage the person to run for office if they are seen as prosocial (Bursztyn and Jensen 2017) or if they can commit to doing good policy when elected (Fujiwara and Wantchekon 2013). A person might run even absent encouragement by others because they derive utility from being seen as running for prosocial reasons (DellaVigna et al. 2016). In both cases, the beliefs of the community matter. We proxy these beliefs by $\bar{b}$ which equals zero if the community believes that people run for selfish reasons. $\bar{b}=1$ if the community believes that people run to help others. We assume that prospective candidates derive greater extrinsic utility from being seen as prosocial, such that, $U_{b=1, a}>U_{b=0, a}$. 
People's extrinsic utility also depends on their policy actions $(a)$ which the community observes to update their beliefs about the person. People get positive extrinsic utility if they carry out policy that benefits the wider community (if $a=1$ ) as opposed to benefiting themselves personally (if $a=0$ ), such that $U_{\bar{b}, a=1}>U_{\bar{b}, a=0}$.

Based on these formulations of intrinsic and extrinsic utilities, the citizens' expected utility, $U_{p}$, from the political office can be written as:

$$
U_{p}=\hat{b} v_{s} a+(1-\hat{b}) v_{y}(1-a)+U_{\bar{b}, a}
$$

Timing. We consider a citizen's decision to enter the race via two stages, the policy stage and the candidacy stage. Using backward induction, the citizen decides on an action in the policy stage and infers the payoff based on equation 2. Comparing the expected pay off to the outside option, net of cost, they decide whether it is worth declaring candidacy, $c \in 0,1$. We have normalized the outside option, net of cost, to zero.

We similarly use backward induction to infer how our treatments may influence candidacy and policy decisions under different conditions. The candidacy calculus is described as below. If the expected utility at the policy stage is greater than zero the person will decide to become a candidate, and if the expected utility is less than or equal to zero they will not enter the race.

$$
c= \begin{cases}1, & \text { if }(1-a) U_{p, a=0}+a U_{p, a=1}>0 \\ 0, & \text { if }(1-a) U_{p, a=0}+a U_{p, a=1} \leq 0\end{cases}
$$

We now describe four scenarios that correspond to the treatment conditions of the experiment.

Status-quo: As discussed in the introduction of the paper, we assume in the status-quo that people privately believe that political office is primarily a vehicle for private gain, that is, $\hat{b}=0$. In addition the community also believe that those who run for office do so primarily for private gain, that is, $\bar{b}=0$. This corresponds to the baseline condition in the experiment of highlighting personal benefits from office.

If a citizen is elected to office and decides to carry out a non-prosocial (personally beneficial) policy, $a=0$, they will yield a positive intrinsic utility of $v_{y}$ and the extrinsic utility is $E\left(U_{\bar{b}=0, a=0}\right)$. The total expected utility is $v_{y}+E\left(U_{\bar{b}=0, a=0}\right)$ from the policy stage. In this case, the citizen will only declare candidacy if $v_{y}+U_{\bar{b}=0, a=0}>0$. Assuming that the extrinsic utility is negative from carrying out personally motivated policy, the person will run only when the personal payoff from office is large enough to compensate for the negative utility of being seen as personally benefiting from office.

If the citizen instead adopts a prosocial policy once elected $a=1$, they will not get any intrinsic utility. This is because the first term of the intrinsic utility is zero as $\hat{b}=$ 0 and the second part of the intrinsic utility is also zero because the action is prosocial $(a=1)$. Further, the prosocial action may improve the person's extrinsic utility because $E\left(U_{\bar{b}=0, a=1}\right)>E\left(U_{\bar{b}=0}, a=0\right)$, that is good actions in office can improve one's social image. There are two possibilities for how this improves the extrinsic calculation: first, it could be the case that the improvement in social image is not enough to make the extrinsic utility 
positive, such that, $U_{\bar{b}=0, a=0}<U_{\bar{b}=0, a=1}<0$. Second, the improvement could indeed be large enough to make the extrinsic utility positive, such that, $U_{\bar{b}=0, a=0}<0<U_{\bar{b}=0, a=1}$. In the candidacy stage this citizen will run for office only when the expected improvement in social image from social action is large enough to convert the baseline negative social image of politicians into a positive social image for this person, that is, the second case, as this will make the returns from office bigger than the outside options which is scaled to 0 .

Overall, under what conditions would a citizen consider running for office in the statusquo scenario? First, if the personal benefits from office under a non-prosocial policy action are big enough. Second, if they believe that their good policy actions will convert others' beliefs about their motivation sufficiently, improving their extrinsic utility. That is they will enter the race if the expected utility is $(1-a)\left(v_{y}+U_{\bar{b}=0, a=0}\right)+a U_{\bar{b}=0, a=1}>0$. This can be simplified to:

$$
(1-a) v_{y}+U_{\bar{b}=0, a=0}+a\left(U_{\bar{b}=0, a=1}-U_{\bar{b}=0, a=0}\right)>0
$$

The first term $(1-a) v_{y}$ is the intrinsic utility and is only activated when personally motivated action is chosen in office. The second term is the baseline extrinsic utility from carrying out personally motivated policy which is negative by assumption. The third term is the improvement in this extrinsic payoff when the person chooses a good policy in office.

Given this setup, a person will run under two scenarios. First, if the person runs and carries out a non-prosocial policy then the intrinsic return has to be bigger than the negative extrinsic utility of carrying out that policy. Second, if the person runs and carries out prosocial policy then the extrinsic utility gains of that policy has to be greater than zero.

Social messaging in private: In this condition our treatment changes the private beliefs about returns of office to $\hat{b}=1$, while keeping the perception $\bar{b}$ the same as the status-quo. When a citizen is elected to office, and they take a prosocial policy decision, that is, $a=1$, they will receive some intrinsic utility from this action, $v_{s}$. In this case, even though the overall perception, $\bar{b}$, remains the same, their extrinsic utility from social image may still improve as they take a prosocial policy action, $U_{\bar{b}=0, a=1}$. As before, this improvement may be sufficient to turn the overall extrinsic utility from the social image positive or not. In the scenario where they chose a non-prosocial policy, $a=0$, they will not get any intrinsic utility and their social image utility will also remain negative at the policy stage. Overall in this condition, a citizen's expected utility from office is:

$$
a\left(v_{s}+U_{\bar{b}=0, a=1}\right)+(1-a) U_{\bar{b}=0, a=0}
$$

Differencing equation 4 from equation 5 shows that people who satisfy the following condition are the marginal candidates in the presence of this treatment condition: $a v_{s}>(1-a) v_{y}$. These marginal people are the ones for whom the intrinsic return from carrying out prosocial policy under this condition outweigh the returns from carrying out a personally beneficial policy under the status-quo condition. Therefore, the policy effects of this condition are likely to be prosocial relative to the status-quo. 
Social messaging in public: This treatment changes $\bar{b}=1$ from $\bar{b}=0$ but does not affect the private beliefs, $\hat{b}$ about the office. If a citizen elected to office in this condition makes a prosocial policy, $a=1$, they will not receive any intrinsic utility but their extrinsic utility may improve. We assume that the extrinsic utility from a prosocial policy action in office under this condition is larger than the utility one may get from taking a prosocial policy action under the status-quo condition, that is, $U_{\bar{b}=0, a=1}<U_{\bar{b}=1, a=1}$.

However, if the citizen decides to take a policy decision that provides personal benefits, they can get $v_{y}$ intrinsic utility and still get an improvement in their extrinsic utility, such that $U_{\bar{b}=0, a=0}<U_{\bar{b}=1, a=0}$. In this condition, a citizen's expected utility from office is:

$$
a U_{\bar{b}=1, a=1}+(1-a)\left(v_{y}+U_{\bar{b}=1, a=0}\right)
$$

Differencing equation 4 from equation 6 gives $a\left(U_{\bar{b}=1, a=1}-U_{\bar{b}=0, a=1}\right)+(1-a)\left(U_{\bar{b}=1, a=0}-\right.$ $\left.U_{\bar{b}=0, a=0}\right)>0$. The first term is positive and refers to reputation gains that people who carryout prosocial policy will expect to receive under the social public treatment. The second term is also positive and accrues to those who will carry out personally beneficial policy once in office. These are the people who enter politics now that others are more likely to believe that they are running for prosocial reasons due the public social message. The overall policy effects of this condition are therefore ambiguous and will depend on community involvement in the candidacy decision, or on the types of people who enter the race as a result of the treatment.

Social in messaging private and public: This treatment changes the perception of citizens to $\bar{b}=1$ from $\bar{b}=0$ and the private beliefs to $\hat{b}=1$ from $\hat{b}=0$. The intrinsic utility calculus in this treatment is the same when $\hat{b}=1$ (social in private treatment) and the extrinsic calculus is the same when $\bar{b}=1$ (social in public treatment). In this condition, a citizen's expected utility is:

$$
a\left(v_{s}+U_{\bar{b}=1, a=1}\right)+(1-a) U_{\bar{b}=1, a=0}
$$

As before, to retrieve the marginal candidate under this condition we difference equation 4 from equation 7 which yields $\left[a v_{s}-(1-a) v_{y}\right]+\left[a\left(U_{\bar{b}=1, a=1}-U_{\bar{b}=0, a=1}\right)+(1-a)\left(U_{\bar{b}=1, a=0}-\right.\right.$ $\left.\left.U_{\bar{b}=0, a=0}\right)\right]>0$. People who run under this condition relative to the status-quo are the ones for whom the returns given by the left hand side of the equation are larger than zero. The marginal calculus of candidacy in this scenario is combination of the forces we highlighted in the private and public treatment above. The intrinsic calculus, shown by the first part of the equation, suggests that the marginal candidates under this scenario are likely persuaded by the prosocial intrinsic returns relative to private intrinsic returns, as was discussed in the social messages in private treatment above. Similarly, the extrinsic calculus, highlights that there exists positive extrinsic returns from being known as prosocial candidate that accrue to both those that carry out policy as well as those that do not, the later of which creates public cover for non-prosocial types to enter the race. To summarize, the total movement on candidacy is likely largest under this scenario because people who will carry out good policy are motivated by intrinsic and extrinsic returns while people who will carryout non-prosocial policy may run because of the public cover. As before, the extrinsic calculus makes policy 
effects ambiguous.

Summary: We present a stylized framework where citizens decide to run for office based on their intrinsic and extrinsic calculus which they compare against status-quo beliefs that political office is consistent with personal gains from office. When prosocial benefits are highlighted in private, more people might run for office and carry out prosocial policy because of higher potential intrinsic results. When social benefits are highlighted in public more prosocial people might run for office and carry our prosocial policy because of increased extrinsic returns. However, non prosocial people may also run because of the cover afforded by the public prosocial message. Finally, the effects of highlighting social benefits in both public and private should be a combination of the two effects. In the presence of public prosocial message policy effects are ambiguous in the presence of competing incentives selecting different types of individuals.

\section{Additional Results on Mechanisms}

\section{L.1 Effects by Prosocial Type}

Table A23: Heterogeneous Effects by Prosocial Type

\begin{tabular}{lcc}
\hline & Candidate $=1$ & Elected $=1$ \\
& $(1)$ & $(2)$ \\
\hline Social Treatment & 0.006 & 0.002 \\
& $(0.007)$ & $(0.005)$ \\
Personal Treatment & {$[0.170]$} & {$[0.330]$} \\
& -0.002 & -0.004 \\
& $(0.005)$ & $(0.004)$ \\
Prosocial Type & {$[0.421]$} & {$[0.197]$} \\
& 0.022 & 0.011 \\
Social Treatment $\times$ Prosocial Type & $(0.010)$ & $(0.008)$ \\
& {$[0.416]$} & {$[0.586]$} \\
Personal Treatment $\times$ Prosocial Type & 0.012 & 0.011 \\
& $(0.016)$ & $(0.012)$ \\
Neutral Mean & {$[0.211]$} & {$[0.166]$} \\
\# Villages & -0.014 & -0.006 \\
Observations & $(0.011)$ & $(0.009)$ \\
Linear Restrictions & {$[0.129]$} & {$[0.246]$} \\
Social Treatment $\times$ Prosocial Type vs Personal Treatment $\times$ Prosocial Type & 0.026 & 0.017 \\
& 0.030 & 192 \\
\end{tabular}

Notes: The table uses a dataset of randomly selected individuals. The dependent variable in column 1 and 2 is equal to 1 if the person from the experimental sample became a filer and was elected to the village council respectively. Each regression uses block fixed effects. Standard errors are clustered at the village level and reported in parentheses. Exact p-values are in square brackets. 
Table A24: Heterogeneous Effects by Prosocial Type: Public and Private Treatments

\begin{tabular}{|c|c|c|}
\hline & $\begin{array}{c}\text { Candidate }=1 \\
\text { (1) }\end{array}$ & $\begin{array}{c}\text { Elected }=1 \\
(2)\end{array}$ \\
\hline Social Treatment, Private & $\begin{array}{l}-0.008 \\
(0.007) \\
{[0.237]}\end{array}$ & $\begin{array}{l}-0.004 \\
(0.005) \\
{[0.269]}\end{array}$ \\
\hline Social Treatment, Public & $\begin{array}{c}0.015 \\
(0.014) \\
{[0.065]}\end{array}$ & $\begin{array}{c}0.005 \\
(0.008) \\
{[0.170]}\end{array}$ \\
\hline Personal Treatment, Private & $\begin{array}{c}0.002 \\
(0.007) \\
{[0.374]}\end{array}$ & $\begin{array}{l}-0.005 \\
(0.005) \\
{[0.280]}\end{array}$ \\
\hline Personal Treatment, Public & $\begin{array}{l}-0.004 \\
(0.005) \\
{[0.409]}\end{array}$ & $\begin{array}{l}-0.001 \\
(0.004) \\
{[0.539]}\end{array}$ \\
\hline Social Treatment, Private \& Public & $\begin{array}{c}0.014 \\
(0.012) \\
{[0.080]}\end{array}$ & $\begin{array}{c}0.005 \\
(0.007) \\
{[0.213]}\end{array}$ \\
\hline Personal Treatment, Private \& Public & $\begin{array}{l}-0.005 \\
(0.009) \\
{[0.359]}\end{array}$ & $\begin{array}{l}-0.008 \\
(0.005) \\
{[0.126]}\end{array}$ \\
\hline Prosocial Type & $\begin{array}{c}0.022 \\
(0.010) \\
{[0.417]}\end{array}$ & $\begin{array}{c}0.011 \\
(0.008) \\
{[0.585]}\end{array}$ \\
\hline Social Treatment, Private $\times$ Prosocial Type & $\begin{array}{c}0.005 \\
(0.020) \\
{[0.407]}\end{array}$ & $\begin{array}{c}0.014 \\
(0.017) \\
{[0.198]}\end{array}$ \\
\hline Social Treatment, Public $\times$ Prosocial Type & $\begin{array}{l}-0.005 \\
(0.024) \\
{[0.400]}\end{array}$ & $\begin{array}{l}-0.004 \\
(0.015) \\
{[0.397]}\end{array}$ \\
\hline Personal Treatment, Private $\times$ Prosocial Type & $\begin{array}{l}-0.015 \\
(0.015) \\
{[0.206]}\end{array}$ & $\begin{array}{c}0.003 \\
(0.012) \\
{[0.447]}\end{array}$ \\
\hline Personal Treatment, Public $\times$ Prosocial Type & $\begin{array}{l}-0.012 \\
(0.013) \\
{[0.252]}\end{array}$ & $\begin{array}{c}-0.015 \\
(0.009) \\
{[0.131]}\end{array}$ \\
\hline Social Treatment, Private $\&$ Public $\times$ Prosocial Type & $\begin{array}{c}0.029 \\
(0.024) \\
{[0.077]}\end{array}$ & $\begin{array}{c}0.020 \\
(0.018) \\
{[0.074]}\end{array}$ \\
\hline Personal Treatment, Private \& Public $\times$ Prosocial Type & $\begin{array}{l}-0.015 \\
(0.014) \\
{[0.222]}\end{array}$ & $\begin{array}{l}-0.005 \\
(0.010) \\
{[0.358}\end{array}$ \\
\hline $\begin{array}{l}\text { Neutral Mean } \\
\text { \# Villages } \\
\text { \# Observations }\end{array}$ & $\begin{array}{c}0.030 \\
192 \\
9310\end{array}$ & $\begin{array}{c}0.017 \\
192 \\
9310\end{array}$ \\
\hline \multicolumn{3}{|l|}{$\underline{\text { Linear Restrictions }}$} \\
\hline Social Private $\times$ Prosocial Vs Personal Private $\times$ Prosocial & $\begin{array}{l}0.020 \\
(0.020) \\
{[0.208]}\end{array}$ & $\begin{array}{c}0.010 \\
(0.018) \\
{[0.284]}\end{array}$ \\
\hline Social Public $\times$ Prosocial Vs Personal Public $\times$ Prosocial & $\begin{array}{l}0.008 \\
(0.023) \\
{[0.370]}\end{array}$ & $\begin{array}{l}0.012 \\
(0.013) \\
{[0.255]}\end{array}$ \\
\hline Social Public \& Private $\times$ Prosocial Vs Personal Public \& Private $\times$ Prosocial & $\begin{array}{c}0.043 \\
(0.024) \\
{[0.041]}\end{array}$ & $\begin{array}{c}0.025 \\
(0.017) \\
{[0.075]}\end{array}$ \\
\hline
\end{tabular}

Notes: The table uses a dataset of randomly selected individuals. The dependent variable in column 1 and 2 is equal to 1 if the person from the experimental sample became a filer and was elected to the village council respectively. Each regression uses block fixed effects. Standard errors are clustered at the village level and reported in parentheses. Exact p-values are in square brackets. 


\section{L.2 Robustness Checks for Sub-group Analysis by Prosocial Type}

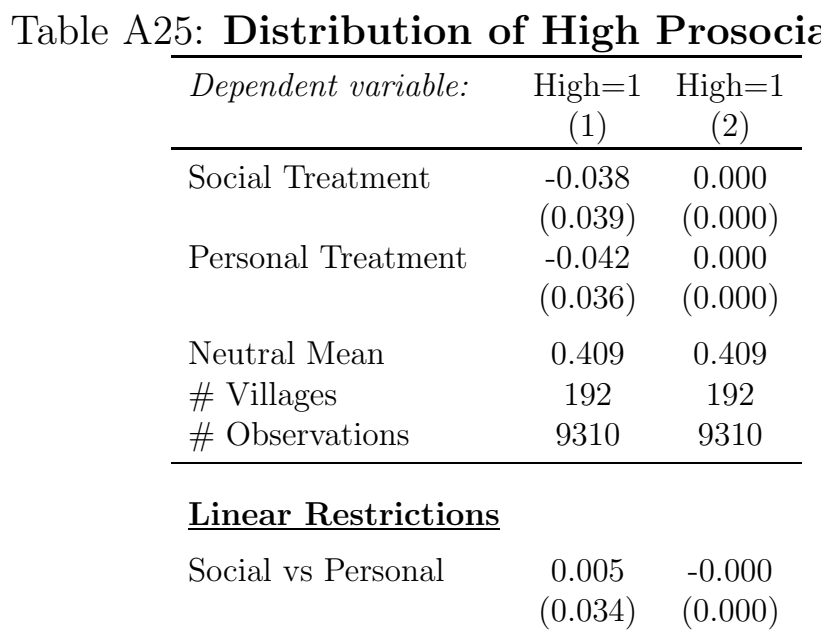

Notes: This table uses data of random individuals to test the relationship between treatments and distribution of prosocial "high" types in a village. The dependent variable takes a value 1 if the individual is "high" prosocial type and 0 otherwise. In column 1 the table reports the relationship without controlling for the proportion of high types and column 2 reports the relationship after controlling for the proportion of high types in a village. Each regression uses block fixed effects. Standard errors are clustered at the village level and reported in parentheses.

Table A26: Heterogeneous Response by Prosocial Type (with controls)

\begin{tabular}{|c|c|c|c|c|c|c|}
\hline & $\begin{array}{c}\text { Filer } \\
(1)\end{array}$ & $\begin{array}{l}\text { Elect } \\
(2) \\
\end{array}$ & $\begin{array}{c}\text { Filer } \\
(3) \\
\end{array}$ & $\begin{array}{c}\text { Elect } \\
(4)\end{array}$ & $\begin{array}{c}\text { Filer } \\
(5)\end{array}$ & $\begin{array}{c}\text { Elect } \\
(6) \\
\end{array}$ \\
\hline Social Treatment & $\begin{array}{c}0.008 \\
(0.007) \\
{[0.109]}\end{array}$ & $\begin{array}{c}0.003 \\
(0.005) \\
{[0.219]}\end{array}$ & $\begin{array}{c}0.008 \\
(0.007) \\
{[0.113]}\end{array}$ & $\begin{array}{c}0.003 \\
(0.005) \\
{[0.255]}\end{array}$ & $\begin{array}{c}0.008 \\
(0.007) \\
{[0.122]}\end{array}$ & $\begin{array}{c}0.002 \\
(0.005) \\
{[0.313]}\end{array}$ \\
\hline Personal Treatment & $\begin{array}{l}-0.001 \\
(0.005) \\
{[0.492]}\end{array}$ & $\begin{array}{l}-0.003 \\
(0.004) \\
{[0.267]}\end{array}$ & $\begin{array}{l}-0.001 \\
(0.005) \\
{[0.493]}\end{array}$ & $\begin{array}{l}-0.003 \\
(0.004) \\
{[0.256]}\end{array}$ & $\begin{array}{l}-0.001 \\
(0.005) \\
{[0.480]}\end{array}$ & $\begin{array}{l}-0.004 \\
(0.004) \\
{[0.214]}\end{array}$ \\
\hline High-Prosocial & $\begin{array}{c}0.016 \\
(0.010) \\
{[0.348]}\end{array}$ & $\begin{array}{c}0.006 \\
(0.008) \\
{[0.521]}\end{array}$ & $\begin{array}{c}0.015 \\
(0.010) \\
{[0.380]}\end{array}$ & $\begin{array}{c}0.006 \\
(0.008) \\
{[0.559]}\end{array}$ & $\begin{array}{c}0.016 \\
(0.009) \\
{[0.345]}\end{array}$ & $\begin{array}{c}0.006 \\
(0.007) \\
{[0.529]}\end{array}$ \\
\hline Social $\times$ High-Prosocial & $\begin{array}{c}0.010 \\
(0.015) \\
{[0.257]}\end{array}$ & $\begin{array}{c}0.009 \\
(0.011) \\
{[0.209]}\end{array}$ & $\begin{array}{c}0.009 \\
(0.015) \\
{[0.276]}\end{array}$ & $\begin{array}{c}0.009 \\
(0.011) \\
{[0.217]}\end{array}$ & $\begin{array}{c}0.008 \\
(0.015) \\
{[0.296]}\end{array}$ & $\begin{array}{c}0.008 \\
(0.011) \\
{[0.230]}\end{array}$ \\
\hline \multicolumn{7}{|l|}{ Linear Restrictions } \\
\hline Personal $\times$ High-Prosocial & $\begin{array}{l}-0.014 \\
(0.011) \\
{[0.128]}\end{array}$ & $\begin{array}{l}-0.006 \\
(0.008) \\
{[0.240]}\end{array}$ & $\begin{array}{l}-0.012 \\
(0.011) \\
{[0.159]}\end{array}$ & $\begin{array}{l}-0.004 \\
(0.008) \\
{[0.280]}\end{array}$ & $\begin{array}{l}-0.013 \\
(0.011) \\
{[0.143]}\end{array}$ & $\begin{array}{l}-0.005 \\
(0.008) \\
{[0.266]}\end{array}$ \\
\hline $\begin{array}{l}\text { Neutral Mean } \\
\text { \# Villages } \\
\text { \# Observations }\end{array}$ & $\begin{array}{c}0.030 \\
192 \\
9310\end{array}$ & $\begin{array}{l}0.017 \\
192 \\
9310\end{array}$ & $\begin{array}{c}0.030 \\
192 \\
9303\end{array}$ & $\begin{array}{c}0.017 \\
192 \\
9303\end{array}$ & $\begin{array}{c}0.030 \\
192 \\
9303\end{array}$ & $\begin{array}{c}0.017 \\
192 \\
9303\end{array}$ \\
\hline Social $\times$ High-Prosocial vs Personal $\times$ High-Prosocial & $\begin{array}{c}0.024 \\
(0.013) \\
{[0.046]}\end{array}$ & $\begin{array}{c}0.015 \\
(0.009) \\
{[0.078]}\end{array}$ & $\begin{array}{l}0.021 \\
(0.013) \\
{[0.067]}\end{array}$ & $\begin{array}{c}0.013 \\
(0.009) \\
{[0.102]}\end{array}$ & $\begin{array}{c}0.021 \\
(0.013) \\
{[0.065]}\end{array}$ & $\begin{array}{c}0.013 \\
(0.009) \\
{[0.102]}\end{array}$ \\
\hline Controlling For & \multicolumn{2}{|c|}{ Proportion of High Prosocial } & \multicolumn{2}{|c|}{ All Imbalanced Control } & \multicolumn{2}{|c|}{ All Controls } \\
\hline
\end{tabular}

Notes: This table reports heterogeneous effects by prosocial types while controlling for proportion of high prosocial types (columns $1 \& 2$ ) and all imbalanced covariates, such as, distance to district headquarters, distance to tehsil headquarters, perceived electability, perceived affordability, leadership experience and main castes (columns 3 \& 4). Columns 5 and 6 add all controls. Each regression uses block fixed effects. Standard errors are clustered at the village level and reported in parentheses. Exact p-values are in square brackets. 


\section{L.3 Effects on Coordination in Community}

Table A27: Effect of Treatment on Coordination over Candidacy

\begin{tabular}{lc}
\hline & Candidate and Community Nominated $=1$ \\
\hline Social Treatment & $(1)$ \\
& 0.009 \\
& $(0.005)$ \\
Personal Treatment & {$[0.085]$} \\
& -0.009 \\
Neutral Mean & $(0.004)$ \\
\# Observations & {$[0.085]$} \\
\hline
\end{tabular}

\section{Linear Restrictions}

Social vs Personal

0.018

$[0.007]$

Notes: This table uses responses a dataset of randomly selected individuals. The dependent variable is coded as one if the person is a candidate and reports that his clan or neighborhood nominated him, and zero if either of these conditions are not met. Each regression uses block fixed effects. Standard errors are clustered at the village level and reported in parentheses. Exact p-values are in square brackets. 


\section{Table A28: Effect of Treatment on Coordination over Candidacy: Private and}

Public Messages

\begin{tabular}{|c|c|}
\hline & $\begin{array}{l}\text { Candidate and Community Nominated }=1 \\
(1)\end{array}$ \\
\hline Social Treatment, Private & $\begin{array}{l}-0.010 \\
(0.008) \\
{[0.154]}\end{array}$ \\
\hline Social Treatment, Public & $\begin{array}{c}0.013 \\
(0.011) \\
{[0.083]}\end{array}$ \\
\hline Personal Treatment, Private & $\begin{array}{l}-0.006 \\
(0.007) \\
{[0.301]}\end{array}$ \\
\hline Personal Treatment, Public & $\begin{array}{l}-0.010 \\
(0.006) \\
{[0.158]}\end{array}$ \\
\hline Social Treatment, Private \& Public & $\begin{array}{c}0.023 \\
(0.012) \\
{[0.010]}\end{array}$ \\
\hline Personal Treatment, Private \& Public & $\begin{array}{l}-0.012 \\
(0.008) \\
{[0.108]}\end{array}$ \\
\hline Neutral Mean & 0.028 \\
\hline \# Villages & 192 \\
\hline \# Observations & 9310 \\
\hline \multicolumn{2}{|l|}{ Linear Restrictions } \\
\hline Social Private Vs Personal Private & $\begin{array}{c}-0.004 \\
(0.008) \\
{[0.378]}\end{array}$ \\
\hline Social Public Vs Personal Public & $\begin{array}{c}0.024 \\
(0.011) \\
{[0.029]}\end{array}$ \\
\hline Social Public \& Private Vs Personal Public \& Private & $\begin{array}{c}0.035 \\
(0.012) \\
{[0.002]}\end{array}$ \\
\hline
\end{tabular}

Notes: This table uses a dataset of randomly selected individuals. The dependent variable is coded as one if the person is a candidate and reports that his clan or neighborhood nominated him, and zero if either of these conditions are not met. Each regression uses block fixed effects. Standard errors are clustered at the village level and reported in parentheses. Exact p-values are in square brackets. 


\section{L.4 Further effects on Leadership and Project Proposals}

Table A29: Effects on Elected Pool from Experimental Sample: Private and Public

\begin{tabular}{lcc}
\hline & Leader or & Project \\
& Committee Member & Proposer \\
\hline Social Treatment, Private & $(1)$ & $(2)$ \\
& -0.002 & 0.007 \\
Social Treatment, Public & $(0.005)$ & $(0.007)$ \\
& {$[0.344]$} & {$[0.125]$} \\
& 0.000 & 0.013 \\
Personal Treatment, Private & $(0.004)$ & $(0.008)$ \\
& {$[0.457]$} & {$[0.025]$} \\
Personal Treatment, Public & -0.006 & -0.002 \\
& $(0.003)$ & $(0.004)$ \\
Social Treatment, Private \& Public & {$[0.071]$} & {$[0.391]$} \\
& -0.005 & -0.003 \\
Personal Treatment, Private \& Public & $(0.003)$ & $(0.003)$ \\
Linear Restrictions & {$[0.151]$} & {$[0.355]$} \\
Social Private Vs Personal Private & 0.006 & 0.009 \\
\# Villages & $(0.006)$ & $(0.006)$ \\
Social Public Vs Personal Public & {$[0.085]$} & {$[0.102]$} \\
& -0.006 & -0.002 \\
& $(0.003)$ & $(0.004)$ \\
& {$[0.066]$} & {$[0.410]$} \\
& 0.012 & 0.009 \\
& 192 & 192 \\
& 9310 & 9310 \\
\hline
\end{tabular}

Notes: The table uses a dataset of randomly selected individuals. The dependent variable in column 1 is equal to 1 if the person held the chair or vice chair of the village council, or was a member of a working committee on the council. The dependent variable in column 4 equals 1 if the person proposed a project that was selected in the final budget for the village council after the first year. Each regression uses block fixed effects. Standard errors are clustered at the village level and reported in parentheses. Exact p-values are in square brackets. 


\section{L.5 IV effects on Policy}

We run a village-level analysis where the policy outcomes are regressed on the total number of people elected from the experimental sample in that village. We also run analysis on four other variables of interest: the number of high prosocial types elected from the experimental sample, the number of people who reported running as a result of community coordination, the number elected to leadership positions from the experimental sample, and the number of project proposers elected to the village council from the experimental sample. These variables are constructed using the same definitions as in Section 5.2. In all cases, the number of people who are elected is instrumented by village level treatments from the experiment.

We present the analyses in Table A30 that uses the sample restricted to villages where a social or a personal message was given. We instrument for the number of people elected to the village council by an indicator variable for social villages (with personal villages as the omitted category). We can see that for the social versus personal villages sample, the election of different types of people from our sample to the village council closes some of the gap between policy outcomes and citizen preferences with the Anderson-Rubin confidence intervals not including zero (Andrews et al. 2019; Lal et al. 2021).

\section{Table A30: IV effects on Policy}

\begin{tabular}{|c|c|c|c|c|c|}
\hline \multirow[b]{3}{*}{ Number Elected } & \multicolumn{5}{|c|}{ Dep. Var: Euclidean distance between policy and citizen preferences } \\
\hline & $(1)$ & $(2)$ & $(3)$ & $(4)$ & $(5)$ \\
\hline & $\begin{array}{c}-16.636 \\
(10.636)\end{array}$ & & & & \\
\hline Number High Social Type Elected & & $\begin{array}{l}-24.966 \\
(18.329)\end{array}$ & & & \\
\hline Number Elected with Community Coordination & & & $\begin{array}{c}-16.282 \\
(10.272)\end{array}$ & & \\
\hline Number Elected to Leader Position & & & & $\begin{array}{c}-27.282 \\
(17.788)\end{array}$ & \\
\hline Number of Proj Proposers Elected & & & & & $\begin{array}{c}-17.008 \\
(10.280)\end{array}$ \\
\hline Anderson Rubin $90 \%$ CI & $(-52.6,-2.7)$ & $(-149.9,-3.8)$ & $(-47.9,-2.6)$ & $(-96.8,-4.4)$ & $(-49.2,-2.9)$ \\
\hline \# of Villages & 143 & 143 & 143 & 143 & 143 \\
\hline First stage F & 5.541 & 3.665 & 6.262 & 3.127 & 9.417 \\
\hline Instruments: & Social & Social & Social & Social & Social \\
\hline
\end{tabular}

Notes: The table uses a village level dataset. The dependent variable in all columns is the Euclidean distance between policy and citizen preferences. Columns 1-5 examine the social versus sample, instruments for the endogenous regressors shown in the columns with dummy variables for Social villages (with the omitted category being Personal villages). Each regression uses block fixed effects. Standard errors are in parentheses. 


\section{L.6 Decomposing Policy Effects}

Table A31: Decomposing Policy Effects Across Budget and Citizen Preferences

\begin{tabular}{|c|c|c|c|c|}
\hline & $\begin{array}{c}\text { Municipal } \\
(1) \\
\end{array}$ & $\begin{array}{c}\text { Infrastructure } \\
(2) \\
\end{array}$ & $\begin{array}{c}\text { Community } \\
(3) \\
\end{array}$ & $\begin{array}{c}\text { Not Primary } \\
\text { Responsibility } \\
(4)\end{array}$ \\
\hline \multicolumn{5}{|c|}{ Panel A: Budget Spending } \\
\hline Social Treatment & $\begin{array}{l}4.884 \\
(4.806) \\
{[0.124]}\end{array}$ & $\begin{array}{l}-4.397 \\
(4.816) \\
{[0.145]}\end{array}$ & $\begin{array}{l}0.193 \\
(1.138) \\
{[0.409]}\end{array}$ & $\begin{array}{l}-0.680 \\
(1.185) \\
{[0.352]}\end{array}$ \\
\hline Personal Treatment & $\begin{array}{l}-3.462 \\
(4.552) \\
{[0.200]}\end{array}$ & $\begin{array}{c}2.906 \\
(4.670) \\
{[0.243]}\end{array}$ & $\begin{array}{l}-0.987 \\
(0.984) \\
{[0.162]}\end{array}$ & $\begin{array}{l}1.542 \\
(1.785) \\
{[0.159]}\end{array}$ \\
\hline $\begin{array}{l}\text { Neutral Mean } \\
\text { \# Observations }\end{array}$ & $\begin{array}{c}29.590 \\
189\end{array}$ & $\begin{array}{c}66.069 \\
189\end{array}$ & $\begin{array}{c}2.476 \\
189\end{array}$ & $\begin{array}{c}1.865 \\
189\end{array}$ \\
\hline \multicolumn{5}{|l|}{$\underline{\text { Linear Restrictions }}$} \\
\hline Social vs Personal & $\begin{array}{l}8.345 \\
(3.872) \\
{[0.033]}\end{array}$ & $\begin{array}{l}-7.303 \\
(3.827) \\
{[0.050]} \\
\end{array}$ & $\begin{array}{l}1.180 \\
(0.912) \\
{[0.119]} \\
\end{array}$ & $\begin{array}{l}-2.222 \\
(1.568) \\
{[0.100]} \\
\end{array}$ \\
\hline \multicolumn{5}{|c|}{ Panel B: Citizen Preferences } \\
\hline Social Treatment & $\begin{array}{l}0.645 \\
(3.210) \\
{[0.409]}\end{array}$ & $\begin{array}{l}-2.387 \\
(2.719) \\
{[0.145]}\end{array}$ & $\begin{array}{c}0.980 \\
(1.300) \\
{[0.203]}\end{array}$ & $\begin{array}{c}0.762 \\
(1.918) \\
{[0.338]}\end{array}$ \\
\hline Personal Treatment & $\begin{array}{l}-0.185 \\
(3.151) \\
{[0.469]}\end{array}$ & $\begin{array}{l}-2.655 \\
(2.760) \\
{[0.135]}\end{array}$ & $\begin{array}{l}0.179 \\
(1.231) \\
{[0.434]}\end{array}$ & $\begin{array}{l}2.661 \\
(1.813) \\
{[0.084]}\end{array}$ \\
\hline $\begin{array}{l}\text { Neutral Mean } \\
\text { \# Observations }\end{array}$ & $\begin{array}{c}66.105 \\
192\end{array}$ & $\begin{array}{c}22.588 \\
192\end{array}$ & $\begin{array}{c}4.127 \\
192\end{array}$ & $\begin{array}{c}7.180 \\
192\end{array}$ \\
\hline \multicolumn{5}{|l|}{$\underline{\text { Linear Restrictions }}$} \\
\hline Social vs Personal & $\begin{array}{l}0.830 \\
(2.820) \\
{[0.397]}\end{array}$ & $\begin{array}{c}0.268 \\
(2.048) \\
{[0.466]}\end{array}$ & $\begin{array}{c}0.801 \\
(1.154) \\
{[0.259]}\end{array}$ & $\begin{array}{l}-1.899 \\
(1.891) \\
{[0.180]}\end{array}$ \\
\hline
\end{tabular}

Notes: This table uses a village level dataset that is constructed based on official budget data from the councils and the preferences of citizens regarding the budget. Dependent variables in Panel A are the proportion of official budget allocated to each category mentioned in the column headers. Dependent variables in Panel $\mathrm{B}$ are the preferences of citizens regarding the proportion of budget allocated to each category mentioned in the column header. Each regression uses block fixed effects. Robust standard errors are reported in parentheses and exact p-values are reported in square brackets. 


\section{L.7 Citizen's Behavior}

Table A32: Effect on the Number of Meetings

\begin{tabular}{lc}
\hline & $\begin{array}{c}\text { Meeting } \\
\text { Councilors } \\
(1)\end{array}$ \\
\hline Social Treatment & -6.868 \\
& $(4.196)$ \\
& {$[0.041]$} \\
Personal Treatment & -5.028 \\
& $(4.062)$ \\
Neutral Mean & {$[0.107]$} \\
\# Observations & 83.708 \\
\hline
\end{tabular}

\section{Linear Restrictions}

Social vs Personal $\quad-1.840$

[0.328]

Notes: This table uses data from citizens. The dependent variable is the total number of meetings all the citizens reported to have held with their council members in the month before the survey. Robust standard errors are reported in parentheses and exact p-values are reported in square brackets. All regressions include block fixed effects.

\section{L.8 Selection into Public Meeting}

Table A33 examines if social versus personal messaging in private is affecting selection into the public meeting. We find that both in the experimental sample and the rest of the village, there is little evidence that treatments affected the number of people who showed up to the public meeting when we compare social versus personal villages. One reason for this is that in the experimental sample, there is a small positive increase in the number of people who attend the public meeting both when social treatments are delivered in private or when personal treatments are delivered compared to the neutral condition. This is consistent with our framework, which shows that the private signal can increase beliefs around returns from office that could increase the proclivity of people to attend the public meeting under both status quo (personal) and social messages. 
Table A33: Effects on Selection into Public Meeting

\begin{tabular}{lcccc}
\hline & $\begin{array}{c}\text { Attended } \\
\text { Public Meet } \\
(1)\end{array}$ & $\begin{array}{c}\text { \# Attended } \\
\text { Public Meet } \\
(2)\end{array}$ & $\begin{array}{c}\text { \# Attended } \\
\text { Exp Sample } \\
(3)\end{array}$ & $\begin{array}{c}\text { \# Attended } \\
\text { rest of village } \\
(4)\end{array}$ \\
\hline Social Private Treatment & 0.029 & 0.988 & 1.581 & -0.592 \\
& $(0.023)$ & $(1.032)$ & $(1.256)$ & $(0.550)$ \\
Personal Private Treatment & {$[0.422]$} & {$[0.173]$} & {$[0.111]$} & {$[0.141]$} \\
& 0.024 & 1.887 & 2.354 & -0.467 \\
Neutral Mean & $(0.022)$ & $(1.043)$ & $(1.254)$ & $(0.556)$ \\
\# Villages & {$[0.000]$} & {$[0.040]$} & {$[0.032]$} & {$[0.212]$} \\
\# Observations & 0.802 & 43.021 & 38.771 & 4.250 \\
Linear Restrictions & 192 & 192 & 192 & 192 \\
Social Private vs Personal Private & 9310 & 192 & 192 & 192 \\
& & & & \\
& 0.004 & -0.898 & -0.773 & -0.125 \\
& {$[0.028)$} & $(1.278)$ & $(1.535)$ & $(0.657)$ \\
& {$[0.113]$} & {$[0.247]$} & {$[0.323]$} & {$[0.420]$}
\end{tabular}

Notes: This tables examines selection into the public meeting. The first columns uses data from the experimental sample of randomly sampled individuals. The dependent variable takes a value of 1 if the individual attended the public meeting held in the village and zero otherwise. Columns 2-4 report results on the size of the pool of people who attend the public meeting at the village level. Column 2 reports it for the entire village, column 3 reports it for those who were randomly sampled in the village, while column 4 reports for people who attended the public meeting from the rest of the village. Standard errors are clustered at the village level and reported in parentheses. All regressions include block fixed effects.

\section{Appendix References}

Andrews, Isaiah, James H Stock, and Liyang Sun, "Weak instruments in instrumental variables regression: Theory and practice," Annual Review of Economics, 2019, 11, 727753.

Asiedu, Edward, Dean Karlan, Monica P Lambon-Quayefio, and Christopher R Udry, "A Call for Structured Ethics Appendices in Social Science Papers," 2021.

Bari, Farzana, "Women's Political Participation: Issues and Challenges," Technical Report November, United Nations, Division for the Advancement of Women (DAW) 2005.

Bénabou, Roland and Jean Tirole, "Incentives and prosocial behavior," American economic review, 2006, 96 (5), 1652-1678.

Khan, Sarah, "Personal is Political: Prospects for Womens Substantive Representation in Pakistan," 2017.

Lal, Apoorva, Mackenzie William Lockhart, Yiqing Xu, and Ziwen Zu, "How much should we trust instrumental variable estimates in political science? Practical advice based on over 60 replicated studies," Working Paper, 2021.

Olken, Benjamin A., "Promises and Perils of Pre-Analysis Plans," Journal of Economic Perspectives, 2015, 29 (3), 61-80. 